\title{
National Planning for Construction and Building $\mathrm{R} \& \mathrm{D}$
}

Subcommittee on Construction and Building

Civilian Industrial Technology Committee

National Science and Technology Council

Richard N. Wright, Co-Chair

Arthur H. Rosenfeld, Co-Chair

Andrew J. Fowell, Secretariat

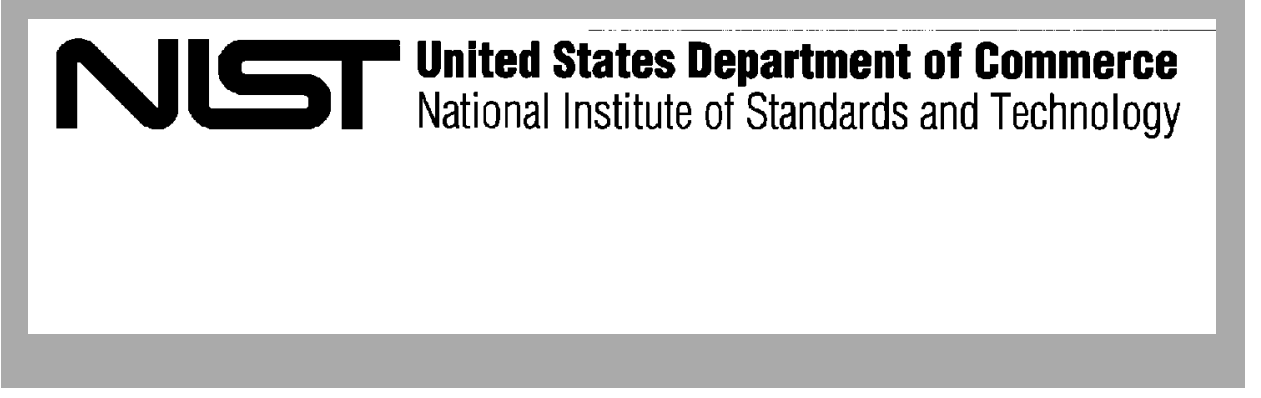




\section{National Planning for Construction and Building $\mathrm{R} \& \mathrm{D}$}

Subcommittee on Construction and Building Civilian Industrial Technology Committee National Science and Technology Council

Richard N. Wright, Co-Chair

Arthur H. Rosenfeld, Co-Chair

Andrew J. Fowell, Secretariat

November 1995
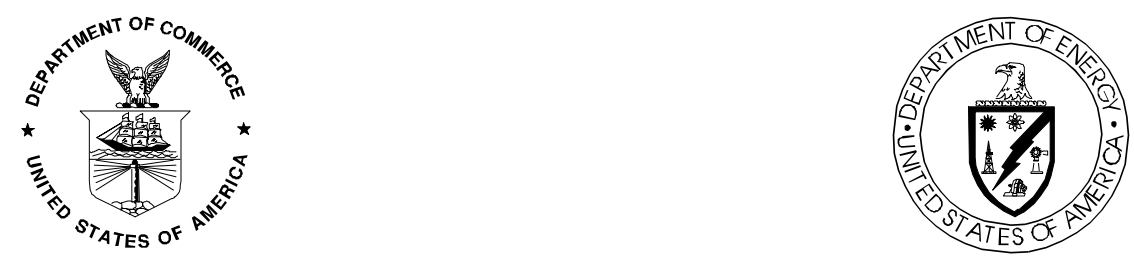

U.S. Department of Commerce

Ronald H. Brown, Secretary

Technology Administration

Mary L. Good, Under Secretary for Technology

National Institute of Standards and Technology

Arati A. Prabhakar, Director
U.S. Department of Energy

Hazel R. O'Leary, Secretary

Energy Efficiency and Renewable Energy Christine A. Ervine, Assistant Secretary 


\section{National Planning for Construction and Building R\&D}

\section{TABLE OF CONTENTS}

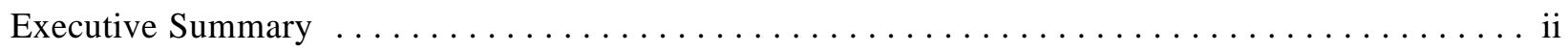

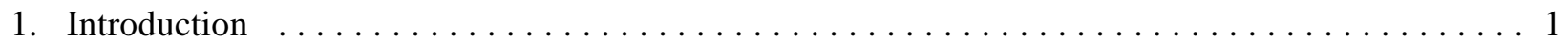

1.1 Background

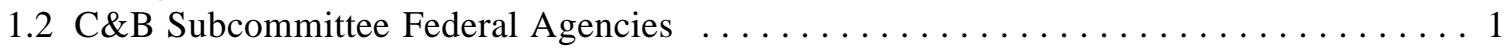

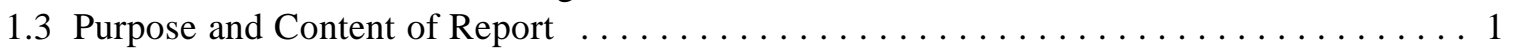

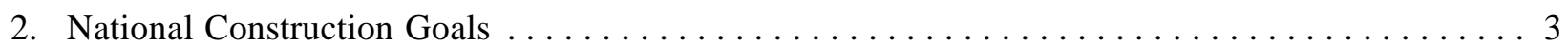

2.1 Vision . . . . . . . . . . . . .

2.2 Baselines and Performance Measures for the National Construction Goals . . . . . . . . 4

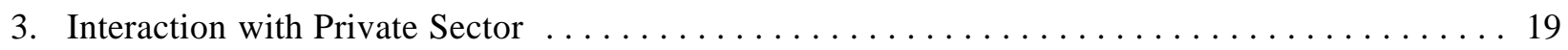

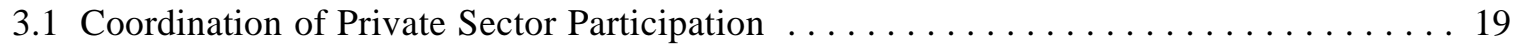

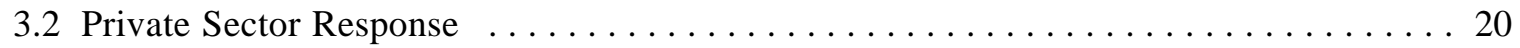

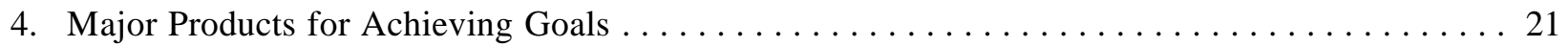

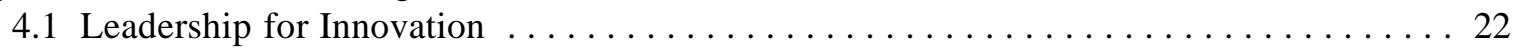

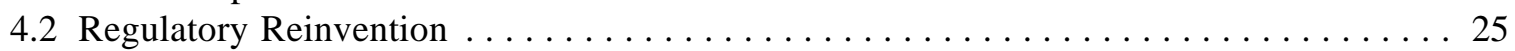

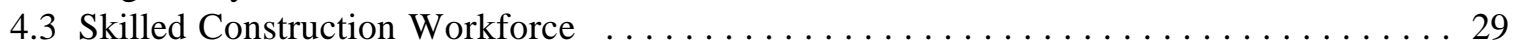

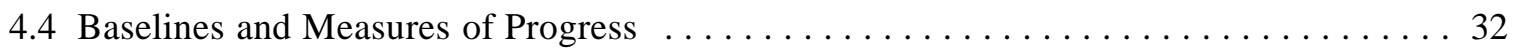

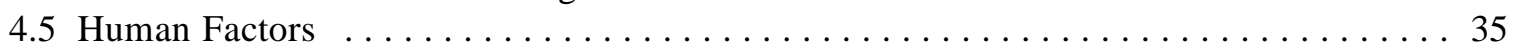

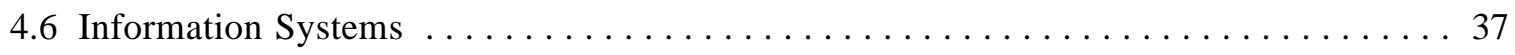

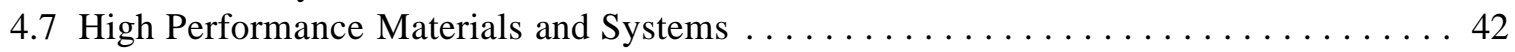

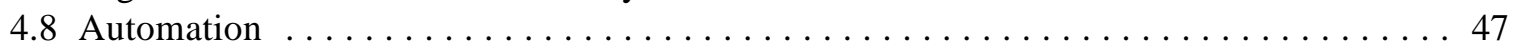

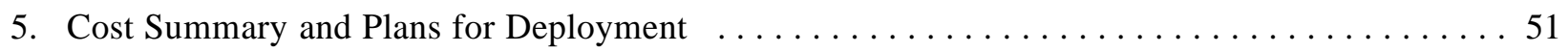

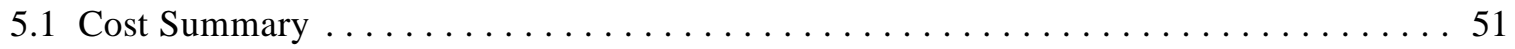

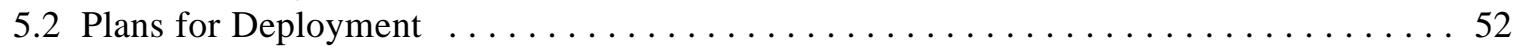

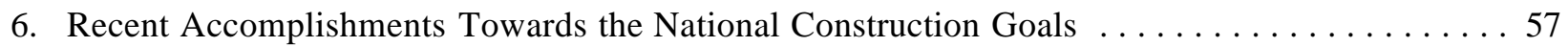

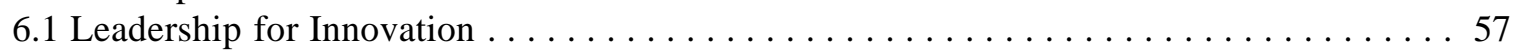

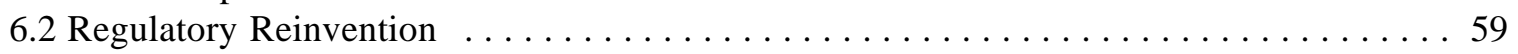

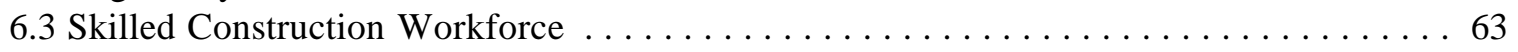

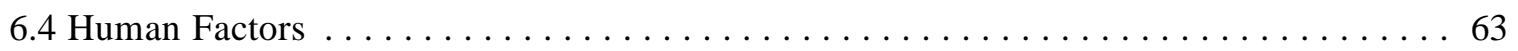

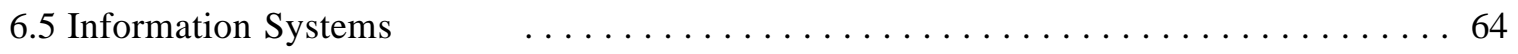

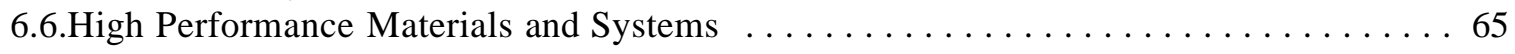

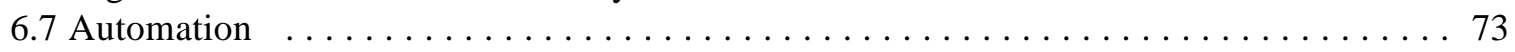

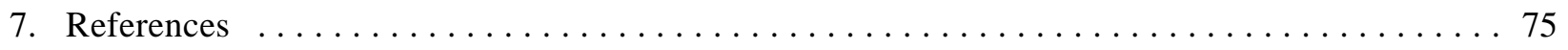

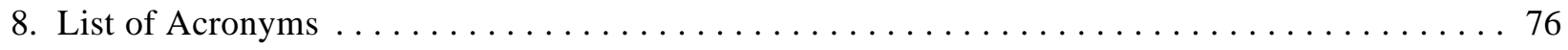

APPENDIX $\quad-$ Federal Agency Program Summaries $\ldots \ldots \ldots \ldots \ldots \ldots \ldots \ldots \ldots \ldots$ 


\section{EXECUTIVE SUMMARY}

This planning report is a resource document designed to provide the private sector with a straw man on a direction and strategy for construction and building research, development, and demonstration to achieve the National Construction Goals, and the products likely to be produced by that effort. The report also will provide federal agencies with information on each other's R\&D programs to facilitate coordination of effort. The Federal and private sector plans will be coordinated to form an industry-led National Plan to meet the National Construction Goals. This report provides background on each of the goals, the measures by which progress can be gauged, and research needed. The industry perspective on relative importance of the different goals by the various sectors of the construction industry is reported, and the initial strategy proposed by some of those sectors to provide a platform for the National Plan is outlined.

A key part of the national plan will be cooperation and coordination of programs between the Federal agencies and the private sector. The report describes progress towards the formation of a private sector focal point to provide leadership within the industry, and the formation of a strong link between the Federal and private sector R\&D efforts. An example of such a link is the formation of a CONstruction MATerials Council by industry representatives from 11 major construction materials areas (asphalt, concrete, steel, composites, roofing, coatings, timber, aluminum, masonry, stainless, and SMART materials) under a secretariat maintained by the Civil Engineering Research Foundation. Liaison members of the Council include representatives of the federal agencies which are materials of construction oriented such as the Corps of Engineers, the Federal Highway Administration (FHWA), the National Institute of Standards and Technology (NIST), and Naval Facilities Command. Each representative to the Council will act as the conduit to the association networks with which each is connected. This representation should greatly enhance the ability of the government to establish partnerships and leverage the government funds.

The vision for the National Construction Goals program is:

- $\quad$ High quality constructed facilities support the competitiveness of U.S. industry and everyone's quality of life.

- U.S. industry leads in quality and economy in the global market for construction products and services.

- The construction industry and constructed facilities are energy efficient, environmentally benign, safe and healthful, properly responsive to human needs, and sustainable in use of resources.

- Natural and manmade hazards do not cause disasters.

The National Construction Goals listed below, are based on research priorities expressed by the construction industry in numerous industry fora and have been strongly endorsed by the construction industry at two workshops held in 1994.

GOAL 1. 50\% reduction in delivery time

GOAL 2. $50 \%$ reduction in operation, maintenance and energy costs 
GOAL 3. $30 \%$ increase in productivity and comfort

GOAL 4. 50\% fewer occupant related illnesses and injuries

GOAL 5. 50\% less waste and pollution

GOAL 6. $50 \%$ more durability and flexibility

GOAL 7. $50 \%$ reduction in construction work illnesses and injuries

In an earlier report the following seven areas of technology were identified as those that will contribute most to achieving the goals:

1. Information and Decision Technologies

2. Automation in Design, Construction and Operation

3. High Performance Materials, Components, and Systems

4. Environmental Quality

5. Risk Reduction Technologies

6. Performance Standards System

7. Human Factors

At industry workshops held in April and December 1994 the construction industry identified the following six major non-technical barriers to the introduction of technical innovations:

1. Lack of Leadership

2. Regulatory Barriers

3. Liability

4. Adversarial Relations

5. Financial disincentives

6. Scarcity of skilled labor

The plan to achieve the National Construction Goals must deal with seven goals, five sectors of industry (residential, commercial, industrial, institutional, and public works), seven areas of technology, and six barriers. To avoid complexity in planning, it is suggested that it focus on eight major products each relating to all goals and all sectors. These products address the non-technical barriers to the introduction of innovative technology and the technologies themselves. For each product, the problems it addresses are explained, the product and its expected impact are described, public and private sector organizations that will develop it are identified, and a roadmap including milestones is outlined. Of the eight major products proposed, three address the removal of nontechnical barriers, and five address technology development and deployment including the assessment of baselines and measures of progress towards meeting the goals. The eight products are:

1. Leadership for Innovation

2. Regulatory Reinvention

3. Skilled Construction Workforce

4. Baselines and Measures of Progress

5. Human Factors

6. Information Systems

7. High Performance Materials and Systems

8. Automation 
Recent accomplishments by Federal agencies, which have already made substantial progress towards the National Construction Goals, are described. The report also describes individual Federal agency missions and programs, and provides the name of a contact within each agency who can provide additional information. 


\section{INTRODUCTION}

\section{$\underline{1.1 \text { BACKGROUND }}$}

The National Science and Technology Council (NSTC), a cabinet-level group charged with setting Federal technology policy, coordinates R\&D strategies across a broad cross-section of public and private interests. NSTC has established nine research and development committees, including the Committee on Civilian Industrial Technology (CCIT), to collaborate with the private sector in developing a comprehensive national technology policy. The purpose of CCIT is to enhance the international competitiveness of U.S. industry through Federal technology policies and programs. The Subcommittee on Construction and Building (C\&B) of CCIT coordinates and defines priorities for Federal research, development, and deployment related to the industries that produce, operate, and maintain constructed facilities, including buildings and infrastructure.

\subsection{C\&B SUBCOMMITTEE FEDERAL AGENCIES}

Agencies (listed below) participating in the Subcommittee include agencies with responsibilities as owners and operators, regulators, and researchers.

Department of Agriculture (Forest Service)

Department of Commerce, Co-chair (National Institute of Standards and Technology)

Department of Defense (Army Corps of Engineers)

Department of Energy, Co-chair

Department of Health and Human Services (National Institute for Occupational Safety and

Health)

Department of Housing and Urban Development

Department of Interior (U.S. Bureau of Mines and U.S. Geological Survey)

Department of Labor (Occupational Safety and Health Administration)

Department of Transportation (Federal Highway Administration)

Department of Veterans Affairs

Consumer Product Safety Commission

Environmental Protection Agency

Federal Emergency Management Agency

General Services Administration

National Aeronautics and Space Administration

National Science Foundation

\subsection{PURPOSE AND CONTENT OF REPORT}

This planning report is a resource document designed to provide the private sector with a strawman on a direction and strategy for construction and building research, development, and demonstration to achieve National Construction Goals and the products likely to be produced by that effort. The report will also provide Federal agencies with information on each other's R\&D programs to avoid duplication of effort. The Federal and private sector plans will be coordinated to form an industry-led national plan for Construction and Building to meet the National Construction Goals. Background is provided on each of the goals, the measures by which progress can be assessed, and the research needed. The industry perspective on relative importance of the different goals by the various sectors of the construction industry is reported, and the initial strategy proposed by some of those sectors to provide a platform for the national plan is outlined. A key part of the national plan will be cooperation 
and coordination of programs between the Federal agencies and the private sector. The report describes progress towards the formation of a private sector focal point to provide leadership within the industry, and the formation of a strong link between the Federal and private sector R\&D efforts.

The plan to achieve the National Construction Goals must deal with seven goals, five sectors of industry, seven areas of technology, and six barriers. To avoid extreme complexity in planning, it is suggested that the plan focus on eight major products each relating to all goals and all sections. These products address the non-technical barriers to the introduction of innovative technology, and the technologies themselves. For each product, the problems it addresses are explained, the product and its expected impact are described, public and private sector organizations that will develop it are identified, and a roadmap including milestones is outlined. Of the eight major products proposed, three address the removal of non-technical barriers, and five address technology development and

deployment including the assessment of baselines and measures of progress towards meeting the goals.

Recent accomplishments by Federal agencies, which have already made substantial progress towards the National Construction Goals, are described. The report also describes individual Federal agency missions and programs, and provides the name of a contact within each agency who can provide additional information. 


\section{NATIONAL CONSTRUCTION GOALS}

\section{$\underline{2.1 \text { VISION }}$}

The vision for the National Construction Goals program is:

- $\quad$ High quality constructed facilities support the competitiveness of U.S. industry and everyone's quality of life.

- U.S. industry leads in quality and economy in the global market for construction products and services.

- The construction industry and constructed facilities are energy efficient, environmentally benign, safe and healthful, properly responsive to human needs, and sustainable in use of resources.

- $\quad$ Natural and manmade hazards do not cause disasters.

The C\&B Subcommittee has studied research priorities expressed by the construction industry in numerous industry fora. Two priority thrusts; better constructed facilities, and health and safety of the construction workforce, were defined for focus of research, development and deployment (RD\&D) in the construction and building area. Within these thrusts the following seven goals were identified:

Better Constructed Facilities

GOAL 1. 50\% reduction in delivery time

GOAL 2. $50 \%$ reduction in operation, maintenance and energy costs

GOAL 3. $30 \%$ increase in productivity and comfort

GOAL 4. 50\% fewer occupant related illnesses and injuries

GOAL 5. 50\% less waste and pollution

GOAL 6. $50 \%$ more durability and flexibility

\section{Health and Safety of Construction Workforce}

GOAL 7. 50\% reduction in construction work illnesses and injuries

The baseline for each goal is industry performance in 1994. The objective is to have practices capable of meeting the goals available in 2003.

The C\&B program and goals were reviewed with a focus group of industry leaders convened on April 5, 1994, by the Civil Engineering Research Foundation, and priorities for the sections of construction were developed in an industry workshop in December 1994. Based on the endorsement of the goals by the industry leaders, they are now recognized as the National Construction Goals. 
This section presents a review of each of the National Construction Goals, quantifying their importance, the current situation, how performance improvement can be measured, what technology advances are likely to contribute to their achievement, and the research that is needed.

\section{GOAL $1: 50 \%$ Reduction in Delivery Time.}

\section{Background:}

Reduction in delivery time is ranked the highest priority of the National Construction Goals. It is considered a priority goal by all sectors of the construction and building industry, and of high priority by the residential, industrial, and institutional sectors.

Any delay during project design and construction is a waste of productivity and money. Reduction in the time from the decision to produce a new constructed facility to its readiness for service is vital to industrial competitiveness and project cost reduction. During the initial programming, design, procurement, construction and checkout/startup process, the need for the facility is not being met; needs evolve over time so a facility long in delivery may be obsolete or uncompetitive when it is finished; and the investments in producing the facility cannot be recouped until the facility is operational. The same need for reduction in delivery time exists for renovations and repairs of existing facilities. Owners, users, designers and constructors are among the groups calling for technologies and practices reducing delivery time.

Non-residential construction delivery times vary greatly depending on use, ownership, funding source, provider and location. The process is characterized by seemingly endless permitting, legal wrangling, reviews and inspections. Residential construction delivery times are much shorter and have less variability. Because cost is the most important factor in residential construction, and construction time has a direct relation to cost, overall delivery time is rated as a high priority by the residential sector.

Industrial sector requirements change rapidly because production processes and manufacturing technologies are changing almost continuously, and invariably require new facilities. The biggest factor inhibiting the reduction of delivery time in the industrial sector is the inability to standardize due to changing requirements.

The goal of reduced delivery time offers a challenge and large potential impact to the public works support infrastructure. Public works projects are increasingly subjected to regulatory, liability, budgetary, and procurement barriers, most of which have increased delivery times. Reversing this trend will require major breakthroughs in regulatory coordination, reductions in planning/design schedules, sharing in liability/risk, the use of performance standards, alternative procurement strategies, and incentives for innovation.

\section{Performance Measures:}

The measure of performance is not just construction time, but the total time from project conception to occupancy, or other beneficial use. National statistics are not collected on project delivery time although information on individual institutional and public works projects is available. The National Association of Home Builders has studied construction times, and data are contained in their research 
reports. The collection of data on project delivery time will require the examination of a representative selection of projects to develop some good estimates of baseline data.

\section{Baselines:}

For residential construction the steps in a project are: land acquisition, site planning, design, zoning clearance, construction of first model house, construction of first house for sale, closing on first house, completion of project (depends on local market)

The National Association of Home Builders determines that an achievable construction cycle time goal for on-site builders is 63 work days ( 88 calendar days) for a $185.8 \mathrm{~m}^{2}$ (sq. ft.) house from start of foundation excavation through to finishing work and settlement. This goal is derived from a pilot benchmarking study of best practice construction cycle times of innovative on site homebuilders and modular housing manufacturers. A realistic ideal goal for modular builders is 28 work days (42 calendar days) under the most favorable conditions.

A recently completed university building in Cincinnati was completed in 16 months using a design/build/leaseback approach. This compares with an estimated time of 60 months using the traditional approach including the legislative appropriation process.

In California when a total building system was used to construct over 5000 schools, typically construction time was reduced by $25-33 \%$. These improved delivery times were accompanied by improved performance coupled with a $20 \%$ reduction in cost. Establishing the baseline for delivery time for institutional buildings will require the examination of representative projects.

\section{$\underline{\text { Research Needed: }}$}

Technologies that are expected to make significant contributions in the near term towards this goal are:

Information systems: - appropriate databases available to and shared by all stakeholders, and electronic filing of building permit applications.

Engineering software: - user-friendly CAE (Computer Assisted Engineering) programs and 3D CADD systems.

Construction methods: - automated positioning and surveying, material management, and computer based construction simulation systems.

Construction equipment: - computer/satellite controlled earth moving equipment, continuous monitoring of tool wear.

Project delivery systems: - e.g., design/build.

Standardization of designs and codes: - code bodies working on single model codes for various buildings occupancies. Performance codes to augment specification codes for acceptance of innovation.

\section{GOAL 2: 50\% Reduction in Operation, Maintenance, and Energy Costs}




\section{Background:}

In the U.S. in 1995, the largest part of OM\&E (Operation, Maintenance, and Energy) in U.S. buildings was the energy bill, about $\$ 210$ billion ( $\$ 150$ billion for electricity, $\$ 60$ billion for "fuel" - e.g., gas, oil, ...). The Table below shows that for an office building this represents $27 \%$ of the total operation, maintenance and energy costs.

Table 1. 1995 Costs per gross square foot of office building for personnel, construction, and OM\&E (Operation, Maintenance, and Energy).

Source: BOMA (Building Owners and Managers Association, Experience Exchange Report, 1993, adjusted upwards 7\% for 2 years' inflation) for a large sample of office buildings in North America.

1. Personnel, including benefits $(\sim 45 \mathrm{k} / 150$ sq. ft) $\quad \$ 300.00$

2. Annualized cost of construction (11\%/year x \$150/sq. ft) $\quad \$ 16.00$

3. O,M,\&E for Technology Utilities (energy and water) $\$ 2.70$ Maintenance and Repairs $\$ 1.80$ Subtotal (technical) $\$ 4.50$

4. O,M,\&E, non-technical

Fixed Expense (taxes, insurance) $\quad \$ 2.40$

Cleaning $\$ 1.50$

Administration $\$ 1.00$

Roads, grounds, security $\$ \$ .60$

Subtotal (non-technical) $\$ 5.50$

3. + 4. Total O, M, \& E

Total OM\&E costs represent only $3 \%$ of the cost of running the business in the building because all of $\mathrm{OM} \& \mathrm{E}(\$ 10)$ is dwarfed by personnel costs. Thus from the point of view of the owner of the business and the operator of the building, if energy services and maintenance improve comfort and productivity, they may be supported and upgraded, but if upgrading and innovation are perceived to risk even brief malfunction and discomfort, they may probably be ignored.

Yet remarkable progress has been made. Since 1973, when the Arab oil embargo suddenly made the U.S. energy-conscious, the efficiency of energy services in buildings has been doubled, with a payback time of about 3 years.

Many services have quadrupled in efficiency; examples are lighting, windows, and refrigerators. But it took a panoply of strategies and policies ranging from labels on appliances, through standards for appliances, equipment, and whole buildings, to tax incentives and utility "demand-side management" programs. These programs have succeeded for one of two reasons: either 1) they work independently of the building owner and operator (as in the case of standards), or 2) they have made improved efficiency an offer that was too good to refuse.

\section{Performance Measures:}

In general, the data to measure progress towards reaching this goal is available. The measure of performance is dollars per $\mathrm{m}^{2}$ in the case of commercial buildings and dollars per household for 
residential costs. There are adequate records of energy consumption for assessing progress towards the goal because almost all energy is billed directly to the customer. Operation and maintenance costs are not as easy to assess because some services are purchased items while others are performed by residents or staff (in the case of commercial buildings). Also, when more reliable and durable equipment is installed subsequent repair costs cannot be assessed until the products reach the end of their life.

Baseline:

In order to achieve Goal 2, a significant number of showcase buildings (residential and commercial, new and retrofit) must be put in place by 2003, with energy bills and bills for repairs and maintenance which are half of 1994 averages. Then incentives must be introduced to cause the construction and building industry to copy these demonstrations, so that over the next 20 years, they penetrate the whole market.

There are also hundreds of studies of cost-effective improvements in building energy efficiency, most of which conclude that today 40-50\% savings can already be achieved. Most of these past studies have considered combinations of individual technologies -- the accepted methodology is to construct a "conservation supply curve" where, for each successive option, a "cost of conserved energy", (CCE), which is less than the price of purchased energy, can be calculated. The investment cuts off where CCE reaches the current price. Averaged over all the steps in such a curve, the typical simple payback time (SPT) is 3-4 years. But then most of these studies introduce a "safety factor" of about $15 \%$, simply because past experience is that real buildings usually save only about $85 \%$ of engineering estimates.

With modern information processing in the next 10-15 years, this $15 \%$ "loss" will probably be brought under control. This is because most commercial buildings already have Energy Management Control Systems computers which are just beginning to make it practical (and very cost-effective) to have buildings monitored in real time by professional building scientists or technicians. There can be the same trend in residences.

At Texas A\&M University, the Energy Systems Laboratory currently tracks 200 public buildings which have been retrofitted under the Texas LoanStar program. With good sensors and tools, and professional supervision, the laboratory achieved $100 \%$ of engineering estimates, and then found other problems, which were fixed, thus raising current savings to $124 \%$ of estimates. The simple payback time for the sensors and the service is about one year, so it can be assumed that this technique will spread.

Computers used for both design, commissioning, and operation can be counted on to get halfway to the goal of $50 \%$ savings, even with no change in design. More likely, new buildings will be designed (with computers) to reduce energy use by $50 \%$ (compared to 1995), and then automated monitoring and diagnostics will make it cost-effective to exceed these goals.

Even without breakthroughs, Maintenance and Repairs (M\&R) costs can drop for several reasons:

- $\quad$ Automated monitoring and "alarms" can ensure that equipment gets needed routine maintenance and prompt attention when a sensor detects that some part or lubricant needs replacing. Improved monitoring can lead to better record keeping, and thus strengthen the market for more durable equipment. 
- $\quad$ A significant part of M\&R is devoted to "HVAC" (Heating, Ventilation, and Air Conditioning). But the earlier half of our Goal 2 is halve HVAC costs, and thus halve the capacity and cost of the HVAC equipment. This will roughly halve the associated M\&R costs.

\section{$\underline{\text { Research Needed: }}$}

As was mentioned above, compared to energy efficiency, maintenance and repair seem relatively neglected and ripe for RD\&D, ratings, service-life labels, and automated maintenance and diagnostics.

Buildings energy efficiency has been so successful that it has grown both in RD\&D and in public programs. In 1994, Federal RD\&D into more energy efficient building technologies totaled about $\$ 300$ million, and utility Demand Side Management programs were over $\$ 2$ billion. Compared to these major efforts, RD\&D on reduced maintenance and repairs seems relatively neglected, even though, as was said above, O\&M in buildings probably costs $\$ 150$ billion, and could probably be decreased by programs analogous to those for energy efficiency.

\section{GOAL 3: 30\% Increase in Productivity and Comfort}

\section{Background:}

Maintenance of a competitive economy and high standards of living requires improvements in productivity and comfort. Occupant comfort depends largely on the nature of buildings, building furnishings, and indoor environments. The quality of indoor environments, where people spend $90 \%$ of their time, also has a large impact on occupant health and productivity. Because worker salaries usually exceed other building-related costs (e.g., energy costs, maintenance costs and annualized construction costs or rent) by approximately a factor of 12 (see Table 1), investments in buildings that result in even very small productivity gains will usually be very cost effective.

Thermal discomfort is a major source of complaints by building occupants, often requiring repeated expensive attempts at corrective action by building operators. In a large U.S. field study of commercial buildings, less than $25 \%$ of the subjects were moderately satisfied or very satisfied with the air temperature. Twenty-two percent of measured thermal comfort conditions during winter were outside of the boundaries of a recognized winter thermal comfort zone. Fifty percent of measured conditions during the summer were outside of the summer comfort zone. Furthermore, the variation in thermal preferences between individuals makes it impossible to obtain high levels of satisfaction with the thermal environment, without provision of greater individual control.

Other types of discomfort related to building environments are physical discomfort, discomfort with the lighting and acoustical environment, and irritation from indoor pollutants. Proper building design and operation can reduce the degree of discomfort.

By providing superior indoor environments to improve occupant health, absence from work, distractions while at work and health care costs can be decreased. Peoples' exposures to airborne infectious organisms, allergens, and chemical irritants can be decreased, reducing the incidence of certain infectious diseases, decreasing symptoms of allergies and asthma, and decreasing "sickbuilding" health symptoms including headache, fatigue, and irritation of eyes, nose, and throat.

There is evidence that better indoor air quality and lighting and better control of indoor temperatures can also directly improve the performance of physical and mental work. Even very small 
improvements in performance, a fraction of a percent, would be sufficient to justify investments to improve indoor environments.

Improvement of the quality of the indoor environment will increase the reliability of electronic equipment, on which our productivity increasingly depends. For example, approximately $20 \%$ of the circuit board failures in telephone switching offices have been attributed to indoor pollutants.

Deposition of microscopic particles on electronic circuits and the corrosive action of certain gaseous pollutants on conductors and electrical insulators are examples of known causes of failures that can be reduced.

From an overall business perspective, reductions in the cost of constructing, operating, reconfiguring, and refurbishing buildings will increase productivity, as long as the cost-saving measures do not adversely affect worker performance. Examples of methods of reducing operating costs include implementation of energy conservation measures and changes in the building or ventilation system design that facilitate (or reduce the need for) maintenance or building cleaning.

Many technologies and procedures for improving indoor environments already exist, but they are rarely used because the associated health, productivity, and comfort benefits have not been adequately quantified and demonstrated. Examples of these technologies include ventilation systems that provide occupants individual control of their thermal environment, more efficient air filters, and building materials with lower pollutant emissions. Procedures that can improve indoor environments and, thus, improve productivity and comfort, include more effective cleaning of buildings and improved maintenance of heating, ventilating and air conditioning systems.

\section{Performance Measures:}

Thermal comfort and its dependence on indoor environments is better understood than other types of comfort or productivity. Performance measures for thermal comfort include ratings by occupants using standardized questionnaires, and measured thermal conditions which may be related to ratings using thermal comfort models. Performance measures for acoustical comfort and lighting also include occupant ratings and measured conditions, although the methodologies are not as well developed.

Characterization of worker productivity is very difficult in many situations because productivity depends on both the quality and quantity of work. However, in some work situations such as manufacturing or claims processing, the work product is standardized and quantity of output per worker per unit time can be used as a performance measure for productivity.

For some companies, overall financial measures of output (e.g., sales or profit) per unit investment or financial input may be considered a measure of productivity. Alternately, the change in an overall financial measure (e.g., profit) associated with a specific investment can be employed to determine if the investment affects productivity. Changing national and world economic conditions complicate the use of these performance measures.

There are a large number of valuable indirect measures of aspects of productivity. Examples of these indirect measures include days of sick leave, time spent at work, prevalence and severity of various health symptoms (e.g., sick building symptoms, asthma, allergies) that distract workers or reduce time at work, injury rates, and the magnitude of costs to respond to complaints or relocate workers in buildings. Self assessments of productivity have also been used as performance measures but their validity is not known. Because building environments affect the reliability of certain types of 
equipment (e.g., electronic equipment) and may affect the yield of manufactured products, failure rates, system down times, and production yields are additional measures of productivity.

Because productivity is often difficult to define, worker performance on relevant standardized tests may be used as performance measures for productivity. Depending on the work situation, standardized tests may emphasize manual or cognitive activities. For example, one test of cognitive performance asks workers to identify errors when proofreading a document. Standardized tests already administered in schools might be used to relate learning performance to building characteristics.

\section{Baselines:}

Adequate baseline data are not available for assessments of future improvements in productivity and comfort; however some relevant data exist. Broad statistical data on disease incidence, injury rates, and time lost from work due to disease and injury are available. Small data bases on thermal comfort and prevalence of sick building symptoms are being generated. Data on student performance on standardized tests are available.

\section{Research Needed:}

Because productivity is influenced by many factors other than the building characteristics, focused studies that do not rely on baseline data are required to assess the degree to which changes in buildings improve productivity. In particular, performance measures can be used to characterize productivity and comfort before and after interventions are implemented. Potential interventions range from investments in better buildings at the construction stage to changing of thermal conditions, lighting, or ventilation rates in existing buildings. Such intervention studies must include suitable control populations.

At present, inadequate baseline data are available on virtually all of the performance measures for productivity and comfort. One approach to assess the degree to which productivity and comfort increase as a result of changes in buildings and indoor environments is to initiate a large program of data collection in representative samples of buildings. Collection of data using standardized methods over time, along with characterization of the relevant features of buildings and indoor environments, would be required. Intervention studies, described previously, are likely to be a more efficient method of relating productivity and comfort improvements to buildings and indoor environmental features.

To support intervention studies and the collection of standardized data over time, new measurement tools and data collection protocols are required. Measurement protocols for thermal comfort are reasonably well developed but tools and procedures are needed for measurement of most of the direct and indirect productivity performance measures. For example, further research is needed to develop and validate written and computer-based tests of worker cognitive performance.

The recommended program of research must be multi-disciplinary and supported through a collaboration of government agencies, with industry participation. Initially, attention should be devoted to the development of strong, peer-reviewed research designs. Then cross sectional and intervention studies should proceed in parallel with the development of improved measurement tools and protocols.

\section{GOAL 4. 50\% Fewer Occupant Related Illnesses and Injuries}




\section{Background:}

Buildings are intended to shelter and support human activities but the environment and performance of buildings can contribute to illnesses and injuries of building occupants. Examples of illnesses include infectious diseases such as Legionnaires disease transmitted from building systems, asthma caused or exacerbated by indoor allergens and irritants, and "sick building" symptoms from uncharacterized indoor air exposures. Injuries in buildings can result from slips and falls due to slippery surfaces, from violence in spaces without visibility, and from building damage or collapse during earthquakes, fire, or extreme winds. Improved building designs could reduce both illnesses and injuries and, by reducing workdays lost from these, could substantially increase worker productivity. The annual nationwide savings could reach billions of dollars.

Health effects associated with the indoor environmental quality (IEQ) of buildings can be categorized into building-related illness and sick building syndrome. Building-related illnesses are medical conditions of known etiology such as Legionnaire's disease, humidifier fever, respiratory allergies or asthma, carbon monoxide poisoning, and pesticide poisoning. These conditions can often be traced to a specific contaminant source in a building, and can be eliminated by removing the source. Appropriate building design, operation and maintenance procedures can prevent such illness in the first place. Transmission of infectious diseases among occupants, a major source of lost workdays among office workers, can also be reduced by improved design and operation of ventilation systems. Sick building syndrome, characterized by non-specific symptoms and less well-defined health problems among building occupants while in the building, can generally not be traced to specific indoor exposures. Current evidence suggests that improved building design, operation, and maintenance will reduce a variety of still unidentified indoor contaminants, and thereby prevent or reduce symptoms among building occupants.

Many of the injuries sustained in buildings can also be avoided by modifying the design of buildings. For example, injuries can be prevented by improving the structural integrity of buildings so that they can withstand the stress of earthquakes and strong winds and by using floor surfaces which minimize the risk of slips and falls. As well, crime prevention through environmental design techniques can be utilized to address issues of visibility, ease of access and egress, and separation of workers (legitimate building occupants) from potential perpetrators of crime. Building design and maintenance are also crucial with regard to emergency access and egress to/from buildings during times of crisis such as fires.

Fire and burn injuries cause significant amounts of morbidity and mortality in the United States. Fires rank fourth among causes of fatality due to unintentional injury after motor vehicle collisions, poisonings, and falls [1]. During 1991, residential fires were the second leading cause of injury deaths (after motor vehicle-related injuries) among children between one and nine years of age [1].

\section{Performance Measures:}

No national data are available on occupant related illnesses and injuries that can be used as performance baselines, performance measures, or to set benchmarks. Further research is needed to determine which occupant-related illnesses and injuries are associated with the greatest cost, to assess risk factors for occupant-related illnesses and injuries, and to determine the best interventions to reduce these illnesses and injuries. Possible performance measures include the prevalence of health effects such as building-related illnesses and symptoms of sick building syndrome. Baseline data could be obtained and trends assessed by collecting information about building-related illnesses and sick building syndrome manifestations in existing national surveys or by conducting special surveys of office 
workers. The data collected would describe and quantify the nature and scope of the problem, and could also identify high and low symptom buildings for focused etiologic research. Interagency demonstration projects could also be designed to evaluate the effect of current good practice guidelines on occupant health.

Also, the environmental exposures leading to building-related illness and sick building syndrome are not well-characterized or clearly measurable, and further research is needed to identify the relevant exposures. Until specific causal exposures are identified, prevention of building-related illness and symptoms can proceed by reducing the likelihood of problem indoor exposures through good building design, operation, and maintenance practices.

Although existing data do not explicitly categorize events by building use/misuse/malfunction, we know there are occasions where changes to building design, operation and maintenance could have prevented injuries and fatalities. A recent and tragic example in the workplace is the fire that swept through a Hamlet, North Carolina chicken processing plant. Appropriate unlocked emergency exit doors would have prevented many, if not all, of the 25 worker deaths. Similar situations arise almost daily on a smaller scale when families are trapped in homes by fires or other disasters. In addition, homicide has become the second leading cause of workplace injury and death, and more than half of these cases occur in retail trade and services sectors where crime prevention through environmental design (i.e., building design and maintenance) can play a major role in reducing the risk of workplace violence.

The National Center for Health Statistics maintains death certificate data from U.S. vital statistics mortality tapes. Fatalities are recorded as deaths per 100,000 people. The U.S. Fire Administration maintains the National Fire Incidence Reporting System (NFIRS). The incidence of fatalities are recorded with association with cause.

\section{Baselines:}

No national data are available on occupant-related illnesses and injuries that can be used as baselines. The baseline for residential fire deaths is 1.5 per 100,000 people in 1991. Based on death certificate data, residential fires accounted for 3,683 deaths in 1991. The rate of fire-related deaths was highest for the young and the elderly. Based on upon 1990 data for the winter months from NFIRS, the causes of fires were highest (266 deaths) for problems with the electrical distribution, including wiring, transformers, meter boxes, power switching gear, outlets, cords, plugs, and lighting fixtures. Another leading cause of residential fires (58 deaths) is fireplaces and chimneys for these months.

\section{Research Needed:}

- develop performance fire standards and the technical basis for engineered fire safety

- develop an understanding of the molecular factors affecting materials flammability

- develop methods of predicting the effects of natural hazards such as wind and earthquakes on constructed facilities

- develop improved understanding of the relationships between building design and accidents such as slips and falls

- develop improved measurements for both environmental exposures and health outcomes in indoor environments 
- $\quad$ assess the baseline prevalence of health effects related to problems with indoor environmental quality, and monitor trends. This could be done by collecting data on building-related illnesses and symptoms of sick building syndrome in existing national surveys or by conducting surveys of office workers. The information collected could also be used to identify high and low symptom buildings for focused etiologic research.

- design interagency demonstration projects to evaluate the effect of current good practice guidelines on occupant health.

- conduct methodologically strong studies of the impact of various interventions on building-related illnesses and symptoms of sick building syndrome.

- conduct special studies of crime in special environments (e.g., convenience stores, schools, restaurants/bars) to assess the potential for and efficacy of crime prevention through environmental design.

\section{GOAL 5. 50\% less Waste and Pollution}

\section{Background:}

Because buildings shelter and support most human activities, improvement of the performance of constructed facilities provides major opportunities to reduce waste and pollution at every step of the delivery process, from raw material extraction to final demolition and recycling of the shelter and its contents. Examples are reduced energy use and greenhouse gas emissions and reduced water consumption and waste water production. Waste and pollution also can be reduced in the construction process: construction wastes are estimated at 20-30\% of the volume of landfills.

While the demand for residential housing starts seems to have slowed, the actual demand for building materials has increased mainly due to the increasing size of the new units. Therefore, pressure on material extraction for housing and construction materials remains high. Extra efforts must be put in environmentally sensitive ways to manage natural resources and produce materials and products to minimize waste and pollution.

Waste and pollution can be generated during the construction phase. Efficient designs and construction methods can reduce the amount of materials used and cut down wastes generated on site. Demolition wastes also contribute to this amount. Recycling and reuse of construction wastes is fertile ground for making advances toward the goal. Furthermore, recycling should extend to the concept of recycling of buildings, for example, renovating or rehabilitating buildings for the same use, or using buildings for other uses, when they no longer are suitable for the original intended use.

It is estimated that half of the world's energy is spent in construction and operations of buildings. Because our state of the art in energy production is based mostly on combustion of fossil fuel, energy consumption is directly tied to emission of carbon dioxide which is a greenhouse gas. Reduction of energy consumption will delay the greenhouse threat. Presently, there are excellent energy analysis tools but a lack of computer tools and data bases to minimize material waste.

Current tax laws and other policies pose significant barriers to reduction of waste and pollution with respect to building and construction. They encourage consumption, buying larger houses, depreciation 
and disposal of buildings. Current policy of lowest bid/low upfront costs is incompatible with the concept of life cycle costing.

Finally, other aspects of building operations such as air and water quality issues must be considered in the design and siting phases as well as selection of plumbing and appliances to ensure minimum impact on the environment.

\section{Performance Measures:}

In order to measure progress, first we have to know where we are. Therefore, one of the first tasks is to have a good understanding of the state of the art. Data and methods are needed in the life cycle assessment of flow of materials at different stages: raw materials, sequestered materials, materials going to landfills, and materials recovered from landfills for reuse or recycling. Life cycle assessment techniques are needed in the process of selecting materials from sustainable sources, as well as to measure environmental impact of building and construction activities.

In addition to materials used in construction, other aspects of wastes and pollution deal with the energy efficiency of the buildings, effluents if any from the use of the buildings, and how they are handled, and a whole hosts of others. These factors can best be addressed by standards such as those being developed by the American Society for Standards and Materials (ASTM) Committee E-5 on Environmental Assessment and specifically the subcommittee on Green Buildings.

Some specific performance measures should focus on volume of materials that end up as wastes, and energy consumption. (American Society of Heating Refrigerating and Air Conditioning Engineers publishes Series 90 Building Energy Performance Standards, but not all states adopt them and fewer states enforce them.)

\section{Baselines:}

Adequate baseline data are not available for assessments of future reductions in waste and pollution; however, some relevant data exist. Standards are developed for life cycle assessment for materials and products to be used in housing and constructions.

Standards are developed to evaluate green building design and operations.

Technologies are developed to recycle and reuse construction and demolition wastes, and renovation, rehabilitation of existing buildings.

Improved tools and standards will improve accuracy, measurements, and therefore quality of construction.

Implementing Total Quality methods and practices in the building industry, improving communication between suppliers, constructing companies, and other players will eliminate wastes in the process.

\section{Research Needed:}

- Life cycle assessment of resources, building materials, and environmental impacts.

- Technologies to collect, reuse, or recycle construction materials. 
- Technologies to increase efficiency of construction in choosing materials, effective designs, and energy consumption and to reduce losses from fire, wind, earthquakes, etc.

- $\quad$ Scientific research needed to provide bases for environmental assessment standards.

- Development of analytical models to assess energy efficiency and options for decisions on renovation, rehabilitation, or new buildings.

\section{GOAL 6. 50\% More Durability and Flexibility}

\section{Background:}

All sectors of the industry give importance to life cycle performance in durability and flexibility. The National Construction Goals Perspective shows that residential, commercial and public works ranked it as high priority and priority. However, major investments such as interstitial floors show its importance for institutional buildings (which often have very long service lives). Durability and flexibility also are important qualities for industrial facilities.

Durability will be affected by:

- Design including siting, configuration and materials selection to provide a facility that will endure in its natural and manmade environments.

- Manufacture of materials and components to treat materials properly and meet plans and specifications.

- Construction and placement of materials and components to treat them properly (avoid damage) and conform with plans and specifications.

- Operation and maintenance to prevent damages.

- $\quad$ Repair and renovation to avoid increasing problems (e.g., leaky roof)

Flexibility will be affected principally by design to limit barriers to alternative uses. For instance, higher floor capacities, wider column spacings and higher ceiling heights may avoid structural interferences with alternative uses. It is very difficult to make a rational investment in flexibility when the nature of alternative use is unknown. An alternative is to allow facile removal of building systems, e.g., partitions, so that alternative use can be accommodated. Additionally, building interiors, furnishings, and ventilation systems can be made more modular and flexible, to decrease the costs associated with future changes in building use. For example, some new task-ventilation systems draw supply air from a plenum beneath the floor. Air supply diffusers for these systems can be quickly relocated if interior loads or office locations change. Also, design features that facilitate the installation and re-configuration of communications wiring can decrease future costs.

The most valuable technical advance for durability is ability to predict service life for a specified material, component or system in a specified configuration and environment. The most valuable technical advance for flexibility may be performance criteria for the variety of uses of constructed facilities. With these performance criteria, the effort and cost to adapt a facility can be determined as a measure of flexibility. 


\section{Performance Measures:}

The performance measure for durability is present value or annualized life cycle cost considering the initial, operating and maintenance costs over the expected service life, probabilities of failures and consequences of failures. The performance measure for flexibility is the present value of the costs of renovations or replacements to accommodate a suite of potential alternative uses, and the present value of future alternative uses.

\section{Baselines:}

No national data are available on durability and flexibility that can be used as baselines.

\section{Research Needed:}

Data on, or models for, expected service life are quite lacking. Data are needed on operating, maintenance and renovation or repair costs, too. An early milestone for pursuit of this goal is to collect and critique data on modeling durability and flexibility.

\section{GOAL 7. 50\% Reduction in Construction Work Illnesses and Injuries}

\section{Background:}

The construction industry is one of the most hazardous industries in the Nation. More fatalities occur in the construction industry than in any other industry. Construction workers also experience a higher incidence rate of nonfatal injuries and illnesses than workers in other industries.

The cost of these injuries and illnesses is a major barrier to the international competitiveness of the construction industry. Workers' compensation insurance depends on the type of job and the safety record of respective companies. In 1992 the average workmen's compensation insurance was $2.58 \%$ of payroll [2]. In contrast, workers' compensation insurance premiums in construction workplaces average about $30 \%$ of payroll and range upwards to over $100 \%$ of payroll [3]. These injuries and illnesses can also contribute to project delays and lost productivity. Reducing workplace injuries and illnesses among construction workers would allow the construction industry to be more competitive by reducing these costs.

This goal is achievable as demonstrated by the construction industry in other countries and by some contractors in the United States who already operate with an injury and illness rate below this level. For example, there were only 3.3 deaths per 100,000 construction workers in the Netherlands in 1992 compared to 14 deaths per 100,000 construction workers in the United States. The lost-time injury rate of the National Constructors Association, which consists of several large construction contractors in the U.S., was less than 1 per 100 full-time workers in 1993 compared to the national average in construction of 5.1 per 100. The average lost-time injury rate from 1988 to 1994 for Army Corps of Engineers construction projects was also less than 1 per 100 full-time workers.

\section{Performance Measures:}

The Bureau of Labor Statistics maintains the Census Fatal Occupational Injuries and a Survey of Occupational Injuries and Illnesses .

Fatalities are recorded as deaths per 100,000 workers. 
Work-related injuries and illnesses resulting in days away from work are recorded as days away from work per 200,000 hours or per 100 workers.

Skin disorders and diseases are listed as incidences per 20,000,000 hours worked or per 10,000 workers.

Hearing loss is measured as a significant threshold shift $(15 \mathrm{~dB})$ on audiometric testing.

Deaths from silicosis and asbestosis are recorded by the National Center for Health Statistics as occurrences per 10,000 workers whose usual employment was in construction.

\section{Baselines:}

The fatality rate from injuries in the construction industry is nearly three times greater than the average occupational fatality rate of all workers (14 vs. 5 per 100,000 full-time workers in 1993) [4]. NIOSH data indicates that during 1990 and 1991, structural metal workers, operating engineers, construction laborers, and roofers were among the 20 occupations with the highest annual fatality rates $(67,40,32.9$, and 20.9 per 100,000 respectively). Based on data from BLS in 1993, structural metal workers, electrical power installers and repairers, and construction laborers are among the occupations at highest risk of fatal injury.

Days away from work as a result of work-related injuries and illnesses for the construction industry are 4.9 per 200,000 hours worked in 1993[5]. Of the major industrial divisions, the construction industry has the highest rate of occupational injuries and illnesses resulting in days away from work. The construction industries with the highest rate of occupational injuries and illnesses resulting in days away from work are roofing, siding and sheet metal work; masonry, stonework, and plastering; carpentry and floor work; concrete work; and water well drilling (8.0, 6.1, 5.9, 5.9, and 5.9 per 200,000 hours worked). The leading types of injuries resulting in days away from work are sprains or strains (38\%), fractures $(10 \%)$, and cuts and lacerations $(9 \%)$. The most common parts of the body affected are the back $(25.3 \%)$, finger $(8.3 \%)$, knee $(7.5 \%)$, and eye $(6.4 \%)$. Common events leading to nonfatal injuries and illnesses involving days away from work are contact with objects and equipment (34\%), overexertion $(23 \%)$, and falls (19\%).

The baseline for occupational skin disorders and diseases is 6 per 20,000,000 hours worked in 1992. A variety of exposures including exposures to solvents, cement, and fiberglass insulation can lead to occupational skin disorders in construction workers. The actual number of cases of occupational skin disorders may be 10-50 times higher than reported by BLS. This potential under-estimation can be illustrated using data from the National Health Interview Survey 1988 Occupational Health Supplement in which $2.6 \%$ of workers in construction trades and other construction occupations reported dermatitis due to contact with substances at work. The construction industries with the highest rates of skin diseases or disorders according to BLS data are painting and paper hanging; heavy construction except highway; masonry, stonework, and plastering; and concrete work (13.8, 11.4, 8.4, and 7.5 per 10,000 full-time workers respectively).

Data on hearing loss are not available. NIOSH, based on the National Occupational Exposure Survey conducted from 1981 to 1983 , estimated that approximately 420,000 construction workers were exposed to hazardous levels of continuous noise (exposure to average daily noise levels in excess of 85 dBA). Most of these workers are not included in hearing conservation programs and can be expected to develop varying amounts of occupational hearing loss. There are no national data to track trends in the number of construction workers exposed to hazardous levels of noise or to track the number of 
construction workers who develop hearing loss as indicated by a significant threshold shift on audiometric testing. Methods for tracking trends in noise exposure and hearing loss among construction workers is needed.

The annual death rates from silicosis and asbestosis for workers who were in the construction were 2.1 per 10,000 and 22.1 respectively in 1992.

Silicosis is a preventable occupational lung disease that is caused by the inhalation and pulmonary deposition of respirable crystalline silica dust. Construction workers can be exposed to crystalline silica by engaging in construction-related activities, including, but not limited to: abrasive blasting using silica sand as the abrasive; abrasive blasting of concrete regardless of the type of abrasive used; sawing, hammering, drilling, grinding, and chipping of concrete; demolition of concrete and masonry; dry sweeping or pressurized air blowing of concrete, rock, and sand dust; ripping, chipping, hammering, and drilling and blasting of silica containing rock. NIOSH, based on the National Occupational Exposure Survey conducted from 1981 to 1983, has estimated that approximately 700,000 construction workers are potentially exposed to silica dust. NIOSH has found that some construction workers may be exposed to short-term respirable silica levels in excess of 200 times the NIOSH Recommended Exposure Level (REL).

There are no national data to track trends in the number of construction workers who are exposed to hazardous levels of respirable silica or asbestos fibers. In addition, the full benefit of current efforts to reduce hazardous silica or asbestos exposures in the construction industry may not be realized for many years.

Research Needed:

- Hearing loss data

- Data on exposure to hazardous levels of respirable silica and asbestos fibers

\section{INTERACTION WITH PRIVATE SECTOR}

\section{$\underline{3.1 \text { COORDINATION OF PRIVATE SECTOR PARTICIPATION }}$}

From its inception, the National Construction Goals program has involved close collaborations between the private sector and Federal agencies. Such collaboration is vital to the purpose and success of the program.

The Federal activities are conducted under the auspices of the Subcommittee on Construction and Building of the Committee on Civilian Industrial Technology of the National Science and Technology Council. The purpose of the Committee on Civilian Industrial Technology is to enhance the competitiveness of U.S. industry through federal technology policies and programs. The initial program for the Subcommittee on Construction and Building (C\&B), its basis in the Administration's technology policy goals and the $\mathrm{C} \& \mathrm{~B}$ goals, which have become the National Construction Goals, are described in Reference [6].

Shortly following the formation of $\mathrm{C} \& \mathrm{~B}$, a focus group of industry leaders was convened on April 5, 1994, by the Civil Engineering Research Foundation (CERF) to discuss with C\&B its program and goals. The response of the focus group is described in the construction industry whitepaper "Innovation 
in the U.S. Construction Industry: An Essential Component for America's Economic Prosperity and Well-Being," Reference [7] which also is incorporated in [6] and [9]. The whitepaper is an industry perspective of methods and means that, if jointly supported and implemented by the public and private sector, promise to transform the construction sector into the high technology/high skill sector America requires. Construction industry leaders strongly endorse the ambitious goals recently established by the NSTC Subcommittee on Construction and Building. Industry leaders urge expanded dialogue and, most important, the immediate initiation of industry-Federal government cooperative efforts to refine and implement actions.

In response the strong private sector endorsement, the President's Office of Management and Budget and Office of Science and Technology Policy [8] gave priority to strengthened construction research and development for the preparation of the fiscal year 1996 budget request: "Activities that support the residential/commercial building construction industry and its suppliers in the development of advanced technologies aimed at increasing the productivity of construction, improving product quality (including energy efficiency and improved indoor air quality), use of renewable resources, and increased worker health and safety." For guidance to the Federal agencies and private sector collaborators in preparing program plans C\&B developed Reference [9], "Rationale and Preliminary Plan for Federal Research for Construction and Building."

In order to gain industry perspective on the approach to collaborative work to achieve the goals, $\mathrm{C} \& \mathrm{~B}$ sponsored a White House Construction Industry Workshop on National Construction Goals, December 14-16, 1994. The industry steering committee that planned the workshop recommended that it be structured according to the diverse sectors that comprise the industries of construction: residential, commercial, institutional, industrial and public works. There are distinct differences in the owners, finance, labor, design and construction companies comprising these sectors; the paths to accomplishment of the goals may differ. Whitepapers relating the goals to sectors were prepared by leaders of the sectors [10]. As described in the workshop report [11], the goals were affirmed, priorities were identified for each sector, and it was recommended that sectoral implementation processed be developed.

Following the workshop, the steering committee provided further guidance on the strategy for achieving the goals [12]. It is recommended that sectoral councils be established to formulate and coordinate implementation plans and roadmaps. Each sectoral council should obtain representation of the owners, industries, labor, etc., participating in the sector so that the plan is inspiring and practical and receives the active support of sector participants.

\subsection{PRIVATE SECTOR RESPONSE}

The private sector has responded enthusiastically to the invitation to pursue the National Construction Goals with collaboration from $\mathrm{C} \& \mathrm{~B}$. The following organizations have agreed to convene sector councils:

$\underline{\text { Sector }}$

Organization

Residential

National Association of Home Builders Research Center

Industrial

Construction Industry Institute

Public Works

American Public Works Association

November 24, 1995 constr|plan95.n14 
A convening organization is being sought for the commercial/institutional sector. The Civil Engineering Research Foundation has been engaged to assist C\&B in coordination of the activities of the councils and the Federal agencies. This strawman planning document has been prepared as a resource for the private sector councils and the Federal agencies to use in developing the definitive plans for private and public activities for each sector.

Cooperative private/public sector activities contributing to the goals will be accomplished by agreements between appropriate private sector entities and one or more Federal agencies (rather than by agreements with $\mathrm{C} \& \mathrm{~B}$ ). To inform potential private sector collaborators of the programmatic interests of the Federal agencies and the mechanisms of each for collaboration, a Collaborations Conference is scheduled for January 17-18, 1996. Following an overview of the National Construction Goals Program, each Federal agency will, in poster session format, describe its program, capabilities and collaborative mechanisms to interested private sector participants. To make feasible the scale of the activity, conference participation will be by invitation. A conference report will share the information developed with all interested persons.

\section{MAJOR PRODUCTS FOR ACHIEVING GOALS}

In an earlier report the following seven areas of technology were identified as those that will contribute most to achieving the goals:

1. Information and Decision Technologies

2. Automation in Design, Construction and Operation

3. High Performance Materials, Components, and Systems

4. Environmental Quality

5. Risk Reduction Technologies

6. Performance Standards System

7. Human Factors

At industry workshops held in April and December 1994 the construction industry identified the following major non-technical barriers to the introduction of technical innovations:

1. Lack of Leadership

2. Regulatory Barriers

3. Liability

4. Adversarial Relations

5. Financial Disincentives

6. Scarcity of Skilled Labor

The plan to achieve the National Construction Goals must deal with seven goals, five sectors of industry (residential, commercial, industrial, institutional, and public works), seven areas of technology, and six barriers. To avoid extreme complexity in planning, it is suggested that the plan focus on eight major products each relating to all goals and all sectors. These products address the non-technical barriers to the introduction of innovative technology, and the technologies themselves. For each product, the problems it addresses are explained, the product and its expected impact are described, public and private sector organizations that will develop it are identified, and a roadmap including milestones is outlined. Of the eight major products proposed, three address the removal of nontechnical barriers, and five address technology development and deployment including the assessment of baselines and measures of progress towards meeting the goals. The products are: 
1. Leadership for Innovation

2. Regulatory Reinvention

3. Skilled Construction Workforce

4. Baselines and Measures of Progress

5. Human Factors

6. Information Systems

7. High Performance Materials and Systems

8. Automation

Although each of the products relate to all the goals, some will have a greater impact on specific goals. The following table shows which goals will be impacted most by each of the products.

\begin{tabular}{|c|c|c|c|c|c|c|c|}
\hline Product & $\begin{array}{l}\text { Goal 1, } \\
\text { Delivery } \\
\text { time }\end{array}$ & $\begin{array}{l}\text { Goal 2, } \\
\text { Operation } \\
\text { maintenence } \\
\text { and energy }\end{array}$ & $\begin{array}{l}\text { Goal 3, } \\
\text { Productivity } \\
\text { and comfort }\end{array}$ & $\begin{array}{l}\text { Goal 4, } \\
\text { Occupant } \\
\text { illness and } \\
\text { injury }\end{array}$ & $\begin{array}{l}\text { Goal } 5, \\
\text { Waste and } \\
\text { pollution }\end{array}$ & $\begin{array}{l}\text { Goal 6, } \\
\text { Durability } \\
\text { and } \\
\text { flexibility }\end{array}$ & $\begin{array}{l}\text { Goal } 7, \\
\text { Constructio } \\
\text { n work } \\
\text { illness and } \\
\text { injury }\end{array}$ \\
\hline $\begin{array}{l}\text { Leadership } \\
\text { for } \\
\text { innovation }\end{array}$ & $X$ & $X$ & $X$ & $X$ & $X$ & $\mathrm{X}$ & $X$ \\
\hline $\begin{array}{l}\text { Regulatory } \\
\text { reinvention }\end{array}$ & $X$ & & & $X$ & $X$ & & $X$ \\
\hline $\begin{array}{l}\text { Skilled } \\
\text { workforce }\end{array}$ & $X$ & $\mathrm{X}$ & & & $\mathrm{X}$ & $\mathrm{X}$ & $X$ \\
\hline $\begin{array}{l}\text { Baselines \& } \\
\text { measures }\end{array}$ & $X$ & $X$ & $X$ & $X$ & $X$ & $\mathrm{X}$ & $\mathrm{X}$ \\
\hline $\begin{array}{l}\text { Human } \\
\text { factors }\end{array}$ & $X$ & $X$ & $X$ & $X$ & $X$ & & $X$ \\
\hline $\begin{array}{l}\text { Information } \\
\text { systems }\end{array}$ & $X$ & $\mathrm{X}$ & $\mathrm{X}$ & $X$ & $\mathrm{X}$ & $\mathrm{X}$ & $X$ \\
\hline $\begin{array}{l}\text { High perf. } \\
\text { matls. and } \\
\text { systems }\end{array}$ & $X$ & $\mathrm{X}$ & $\mathrm{X}$ & $\mathrm{X}$ & $\mathrm{X}$ & $\mathrm{X}$ & $X$ \\
\hline Automation & $X$ & $X$ & $\mathrm{X}$ & $X$ & $X$ & $X$ & $X$ \\
\hline
\end{tabular}

The three products proposed to reduce the barriers to innovation are leadership for innovation, regulatory reinvention, and the training of a skilled workforce. The leadership product is the formation of a private sector council which will not only coordinate the private sector $R \& D$ effort, but address most of the other non-technical barriers including liability, adversarial relations, financial disincentives, parochialism, fragmentation of the industry, and inadequate owner involvement.

To achieve the National Construction Goals not only must non-technical barriers be overcome but also the current baseline must be determined, and major technological products are needed in four areas, human factors, information systems, high performance materials and systems, and construction automation. 
The following section outlines a roadmap for completing each of the proposed products. The expected impact of these products is also identified.

\subsection{LEADERSHIP FOR INNOVATION}

\section{Objective:}

Forge partnerships of the private sector and government to develop and achieve the national construction goals for the built environment.

\section{Problem:}

A number of studies have cited lack of leadership as a barrier to the competitiveness of the U.S. construction industry. The construction industry is desegregated with architectural design, engineering design, construction, materials supply, mechanical systems installation, building operation and management, all being independent operations often in conflict with each other. Furthermore, the five sectors of the industry, residential, commercial, industrial, institutional, and public works have different customers, sales and contracting procedures, methods of financing and regulatory environments.

Major barriers to potentially beneficial and competitive innovations in construction products and services are:

- $\quad$ liability and susceptibility to litigation for owners of constructed facilities, producers of products and services, designers and contractors.

- adversarial relations often existing between participants in construction projects.

- $\quad$ financial disincentives to innovations including the initial costs of applying innovative technologies and the potential for liability and litigation when problems inevitably arise as innovations are applied.

- $\quad$ over emphasis on first cost at the expense of life cycle cost.

\section{Products:}

Private Sector Council: private sector leaders, including industry, labor, users of constructed facilities, academia, codes and standards, and Federal, state, and local government officials, will organize a council to develop and implement coordinated private and public sector programs to refine and achieve national construction goals.

National and state tort reform legislation will fairly bound liabilities and susceptibility to litigation for owners of constructed facilities, producers of products and services, designers and contractors.

Model agreements, such as project-wide insurance, and model legislation will support teamwork in reaching project objectives, in place of adversarial actions when problems arise.

Federal R\&D will focus on critically needed fundamental, enabling and generic technologies including appropriate private sector cost sharing. 
Low risk test beds for innovations: self-insured Federal, state and local government construction projects will reduce risks to innovators. Agreements between Federal programmatic and research agencies and private sector proponents of construction innovations will share costs of development, demonstration, evaluation and showcasing of innovations with intellectual property rights for participating industry.

Impact:

The formation of the Council and the development of and prosecution of coordinated private/public sector plans will provide the necessary leadership to reach all National Construction Goals. Private sector R\&D for improved products and services will be stimulated by Federal R\&D focused on critical fundamental, enabling and generic technologies, and by the removal of nontechnical barriers to innovation. The ultimate impacts will be improved international competitiveness of the construction industry and improved quality of constructed facilities. These improved facilities will strengthen the competitive position of all U.S. industries, increase good jobs, and support everyone's quality of life.

\section{Participating Organizations:}

The Council will be made up of construction community leaders, including, architects, engineers, constructors, suppliers, labor, finance, insurance, standards and codes, education, research, state and local officials and owners and operators of constructed facilities. The Construction and Building Subcommittee will work directly with the Council, but the Council will not be an advisory committee to Federal agencies.

Collaborative activities will be conducted between appropriate private sector and governmental organizations to produce needed products. Most will be focused on National Construction Goals, but some, such as tort reform, will involve only an advisory role for the construction community.

\section{Delivery Mechanisms:}

The Council provides a mechanism for delivery of recommendations for programs and practices to private sector associations, individual enterprises and governmental agencies. Implementation of recommendations will occur primarily through the programs and projects of existing associations, enterprises and agencies.

\section{Roadmap:}

\begin{tabular}{||l|c|c|c|l||}
\hline \multicolumn{1}{|c|}{ MILESTONES } & $\begin{array}{c}\text { START } \\
\text { FY }\end{array}$ & $\begin{array}{c}\text { END } \\
\text { FY }\end{array}$ & $\begin{array}{c}\text { COST } \\
\$ \mathrm{M}\end{array}$ & \multicolumn{1}{|c|}{ PARTICIPANTS } \\
\hline \hline 1. Council Recommendations & 1996 & 2003 & 8 & All concerned \\
\hline 2. Tort Reform & 1995 & 2000 & 1 & All, legislatures \\
\hline 3. Partnering Agreements & 1996 & 2000 & 1 & All concerned \\
\hline 4. Demonstrations & 1995 & 2003 & -- & $\begin{array}{l}\text { Innovators, owners, project teams, } \\
\text { researchers }\end{array}$ \\
\hline 5. Collaborative Mechanisms & 1996 & 2000 & 2 & Industry, R\&D agencies \\
\hline
\end{tabular}




\section{Milestone Description:}

1. Council Recommendations

The Council, involving leaders representing all concerned associations of the construction community, will be established to refine and guide prosecution of the National Construction Goals. The costs of the Council will be supported by private sector contributions, direct and in kind, and by Federal cost sharing in Council projects. Council recommendations will range from early recommendations for cooperative activities to ultimate recommendations for implementation of improved technologies and of barrier removal practices.

\section{Tort Reform}

Recommend national and state legislation fairly bounding liabilities and susceptibility to litigation for owners of constructed facilities, producers of products and services, designers and contractors.

\section{Partnering Agreements}

Produce model agreements and model legislation supporting teamwork in reaching project objectives when problems arise.

4. Demonstrations

Implement existing authorities for collaborations in demonstration of advanced technologies and practices, such as Executive Order 12902, Energy Efficiency and Water Conservation at Federal Facilities, of March 8, 1994, and develop guidelines and recommendations to facilitate trial use of advanced technologies and practices. Funds for the incremental costs of demonstrations (beyond the facility cost were there no demonstration) are not estimated here, but will be included in the cost estimates for the products to be demonstrated.

\section{Collaborative Mechanisms}

Implement throughout the construction community existing mechanisms, such as the Corps of Engineers' Construction Productivity Advanced Research Program (CPAR), NIST's Advanced Technology Program (ATP) and Manufacturing Extension Partnership (MEP), the Department of Energy's Federal Energy Management Program (FEMP), and Cooperative Research and Development Agreements (CRDA)s, for collaborations in research, development and demonstration of advanced technologies and practices, and improve mechanisms based on experiences in implementation.

\subsection{REGULATORY REINVENTION}

\section{Objective:}

Achieve the regulatory objectives of public health, safety and welfare, and reduce the economic burdens of regulatory delays and compliance by developing and implementing performance standards and conformance assessment practices which open the marketplace for beneficial innovations. 
Problem:

Regulations affecting U.S. construction are promulgated and enforced by a bewildering variety of local, state and federal regulatory authorities. Most regulatory barriers to innovation and to reducing construction costs are state and local. Regulations affect land use, siting, design, materials, construction, operations, maintenance - every facet of the whole life cycle of the constructed facility. Generally, regulations have grown incrementally and often reflect prescriptive, arbitrary provisions for precluding recurrence of past problems. The result of multiple, prescriptive regulations is that provisions and regulatory authorities often are in conflict making it difficult to do anything, let alone to introduce a beneficial, innovative product or service. Also, some private sector organizations have supported prescriptive regulations as a means to deny potential competitors entry to the marketplace.

Over constraining, time-consuming regulatory requirements inhibit use of beneficial, innovative products and services, increase costs of constructed facilities, and delay project delivery. Thus, the well-intentioned regulatory system for construction and constructed facilities has become a barrier to quality and economy in constructed facilities, to the productivity of all U.S. industries and everyone's quality of life, and to the international competitiveness of the U.S. industries of construction.

Moreover, the General Agreements on Tariffs and Trade require the U.S. and other nations to remove non-tariff barriers to trade. The complexities of the state and local building regulations have been identified as trade barriers by international trading partners. The U.S. needs to reinvent its building regulatory system to promote innovative, world-class U.S. industries of construction before it is forced by treaty to open its construction marketplace to highly competitive foreign firms.

\section{Products:}

To encourage state and local regulation reform, model statutes and model administrative practices should be developed for use by local governments, technical assistance and demonstrations should be provided to state and local governments for voluntary actions on eliminating regulatory barriers. The process will be supported by the National Information Infrastructure to provide common formats for submittals, and real time interactions between project proponents, regulatory authorities and concerned third parties.

A construction reinvention award program is planned that will provide ombudsmen to assist in the Federal regulatory process, provide liaison with State and local agencies, and obtain technical help from Federal R\&D agencies. The ombudsman will assist project staff in addressing regulatory requirements, and obtaining technical assistance.

Performance standards for construction products (from land use to fasteners) and services that describe the qualities needed by users and the public without specifying a particular solution. The standards include quantitative criteria for performance and methods for evaluating performance with respect to the criteria. Performance standards are complementary to the prescriptive and procedural standards which have been shown to supply the desired performance and are used with conventional products and services. Industry and government will collaborate through the existing, non-governmental, voluntary, national standards system to develop the needed family of standards and to promote their adoption as international standards. Regulatory authorities will adopt the performance standards (and the consistent prescriptive and procedural standards) as the basis for regulations to achieve uniformity in U.S. standards without preemption of the authorities of local and state governments.

Regulatory authorities must require an expert and authoritative evaluation of innovative and conventional products and services for conformance with standards. However, one expert and 
authoritative evaluation should be recognized nationally and internationally by regulatory authorities, rather than requiring an innovator or supplier to endure the costs and delays of multiple evaluations for multiple authorities. An enhanced National Evaluation Service will be formed using the best expertise from the building industry research, regulatory and owner community targeted to the specific technology being evaluated. The service will evaluate technology beyond regulatory requirements, and include overall system performance and suitability for use. Procedures will be established for national and international accreditation of non-governmental evaluation organizations, following models well established in the European Union and Japan, so that the evaluations of a specific organization can be accepted within its domain of competence. This mechanism will include, when appropriate, self certification by the manufacturer.

Federal barriers are either environmental (EPA) or relate to construction worker health and safety (OSHA). EPA will expand a pilot project recently announced that involves granting of regulatory flexibility in exchange for an enforceable commitment by a regulated entity to achieve better environmental results than would have been achieved through full compliance with regulations. OSHA is planning an effort to develop a single point of contact for all OSHA regulations relating to a single industry.

Impact:

The first order impact of regulatory reinvention will be the reduction of regulatory burdens on the costs and delivery time of constructed facilities. However, larger, life cycle benefits will arise from opening the construction marketplace to innovative products and services that will contribute to achievement of all of the National Construction Goals, and to the international competitiveness of all U.S. industries, improved jobs and quality of life.

\section{Participating Organizations:}

The Regulatory Reinvention effort will involve all of the industries of construction and the local, state and Federal agencies concerned with construction.

Owners, developers, designers, builders, labor, manufacturers, researchers and regulators will participate in development of voluntary, national, consensus performance standards for products and services. Experts from industry, academia and government will participate in the evaluation, conformance assessment and accreditation organizations that assess the conformance of innovative and conventional products with standards.

The National Homeownership Strategy involving the Department of Housing and Urban Development and scores of private sector partners is addressing the aspects of Regulatory Reinvention pertinent to lifting America's homeownership rate to an all-time high. This Regulatory Reinvention effort is an integral part of the National Homeownership Strategy and extends the effort for Regulatory Reinvention to all sectors of the industries of construction.

\section{Delivery Mechanisms:}

The fundamental delivery mechanism is: the existing regulatory authorities of local, state and Federal agencies; the existing voluntary national standards developing organizations, and existing and new organizations for evaluation and acceptance of innovative and conventional products and services. Thus, regulatory reinvention does not require building elaborate new delivery mechanisms, but 
improved technologies and practices (particularly the National Information Infrastructure) for the existing system.

Roadmap:

\begin{tabular}{||l|c|c|c|l||}
\hline \multicolumn{1}{|c|}{ MILESTONES } & $\begin{array}{c}\text { START } \\
\text { FY }\end{array}$ & $\begin{array}{c}\text { END } \\
\text { FY }\end{array}$ & $\begin{array}{c}\text { COST } \\
\$ \mathrm{M}\end{array}$ & \multicolumn{1}{|c||}{ PARTICIPANTS } \\
\hline \hline $\begin{array}{l}\text { 1. Information System for Project } \\
\text { Approvals }\end{array}$ & 1996 & 2000 & 2 & Research, Practice, Regulatory \\
\hline $\begin{array}{l}\text { 2. National Homeownership Strategy } \\
\text { Actions }\end{array}$ & 1996 & 2000 & 10 & Partners \\
\hline 3. Extend Actions to Other Sectors & 1997 & 2003 & 10 & Interested partners and others \\
\hline 4. National Evaluation Service & 1996 & 2003 & 10 & $\begin{array}{l}\text { Research, Regulators, Product } \\
\text { Manufacturers }\end{array}$ \\
\hline 5. Achieve Greater Flexibility in Regulation & 1996 & 1999 & 5 & EPA, OSHA \\
\hline
\end{tabular}

\section{Milestone Description:}

1. Information System for Project Approvals

A uniform format for project description would be developed by EPA, NIOSH, NIST, State and local regulators, and private sector representatives, to meet the needs of State and local regulatory jurisdictions and allow electronic submittal using the National Information Infrastructure. The format would be drafted, subjected to trial use and revised to meet needs of proponents and regulators. The system would be open and well characterized to allow industry to develop and market tools to assist regulators, owners, designers, builders, manufacturers, etc. to evaluate conformance with regulatory requirements.

2. National Homeownership Strategy Actions

The National Homeownership Strategy [11] describes a number of actions. The following, taken from the strategy, focused on regulatory reinvention:

1. Assessing regulatory impacts on affordable homeownership

2. Modernizing planning, zoning and subdivision laws

3. Education and technical assistance for regulatory reform

6. Models of regulatory flexibility and development controls

7. Expanded research on regulatory reform

8. Building code reform

10. Fast track administrative review for starter homes

13. Flexible regulations to accommodate home rehabilitation

20. Enhanced homebuilding product evaluation

21. HUD technical evaluations of homebuilding products

23. Regulatory review of manufactured homes

27. Zoning and land development reform for manufactured homes 
The relevant resources of the $\mathrm{C} \& \mathrm{~B}$ agencies will be joined with the partners in the National Homeownership Strategy to carry out these actions for regulatory reinvention for housing.

3. Extend Actions to Other Sectors

A number of the Homeownership Strategy actions are relevant to other sectors. Appropriate private sector participation will be developed to achieve this extension of the products.

Planning of the private sector councils for the National Construction Goals will address definition and implementation of additional actions needed for regulatory reinvention for the various sectors. Examples include construction workforce safety regulations and environmental regulations affecting commercial, institutional, industrial and public works facilities.

4. National Evaluation Service

A national system for the evaluation of innovative (non-standard) construction products and systems will be developed. When operational, the service will issue unbiased technical appraisals for non-standard innovative building products, components and systems. The appraisals will be used by designers, specifiers, regulators and owners. The service will require cooperation and support of the industry, and evaluation will be based on performance criteria developed in cooperation with industry.

5. Achieve Greater Flexibility in Regulation

A series of construction projects will be used to demonstrate that regulatory goals can best be achieved by providing regulatory and policy flexibility while maintaining accountability and lowering costs. Better decisions will result from a collaborative process with people working together and focussing on the constructed facility where protection is sought. EPA has already announced plans to select regulatory reinvention (XL) pilot projects. OSHA has initiated a new construction enforcement policy that follows the strategy of targeting the worst actors and the worst offenses. If contractors have effective safety and health programs and an on-site person responsible for safety, inspectors will focus on only the four major killers; falls, electrocution, being caught in trenches, and being struck by machines or materials. OSHA will seek to use partnerships to promote training and education, voluntary compliance programs, cooperative research and other outreach activities. OSHA will also simplify record keeping requirements.

\subsection{SKILLED CONSTRUCTION WORKFORCE}

\section{Objective:}

To assure that construction workers are skilled in the latest methods and equipment used in their trade or profession for productivity, recognition and control of risks to health and safety, and environmental protection.

Problem:

Both demands for reinvention of enterprises and the rapid evolution of technologies require continuous learning by the workforce (labor, professions and management) of the whole construction process (design, construction, operation, maintenance, renovation and demolition). 
The construction trades have a history of training based on apprentice programs. These programs have a combination of class room instruction and on the job training. Historically, these apprenticeship programs have been labor-management based. With union membership low in construction, workers have increasingly gained their training on the job as helpers, from employer-based programs and vocational schools. However, apprentice programs have been recognized as developing the best skilled workers, and countries such as Germany have fostered this approach and increased their competitiveness. With the rapidly evolving new materials and methods used in construction, continuous training is needed.

Construction professionals, such as architects and engineers, traditionally have earned a professional degree from an accredited institution of higher learning, served an apprenticeship with licensed senior professionals and been licensed by examination by a state. Institutions of higher learning are challenged to maintain the relevance of professional education to rapidly changing professional responsibilities and rapidly evolving technologies. Continuing education to remain abreast of advancing knowledge is a strong need and professional responsibility.

Managers in the industries of construction traditionally have emerged from the trades and professions. However, the challenges of management for productivity, teamwork, health, safety and environmental quality deserve both formal and continuing education.

Currently some companies using "best practices" have one-sixth of the average worker compensation costs in construction. Education and training regarding known safe work practices can improve workforce safety in the U.S. immediately. Consideration of training needs in the development and implementation of new technologies will improve safety and improve productivity in the future.

New delivery mechanisms need to be developed and evaluated to meet the challenges of training a workforce that is highly mobile and involves working in ever changing workgroups and work environments.

\section{Products:}

For each of the technologies and practices developed in the National Construction Goals Program equally progressive training materials, curricula, and methods of implementation must be developed and evaluated for labor, professionals and management. These materials and programs must be developed in consultation with those who will be the recipients of the educational programs to insure that the materials and methods reflect incentives and barriers to learning often best recognized by those working closest to the actual construction project. These curricula should be developed to meet both formal and/or basic education and continuing education needs.

\section{Impact:}

The skilled and healthy workforce is essential to achievement of all seven National Construction Goals. However, the major impact will be on goals 1(delivery time), 2 (operation, maintenance, and energy costs), 5 (waste and pollution), and 7 (construction worker health and safety).

\section{Participating Organizations:}

For each segment of the construction workforce there exists organizations concerned with initial and continuing education such as the AFL/CIO Building and Construction Trades Council, the Center for Construction Education and Research, the Associated Schools of Architecture, and the American 
Society for Engineering Education. The Department of Labor supports education for craftsmen, the National Institute of Environmental Health Science training for hazardous wastes cleanup, NIOSH lead abatement training, NSF supports research and improvements for science and engineering education, and NIST's MEP addresses technology transfer to small and medium sized enterprises. These organizations will participate in planning and developing curricula, materials and initial and continuing educational programs.

Delivery Mechanisms:

Curricula and training materials will be delivered through existing institutions serving the construction workforce, including employer, professional and labor organizations. New methods of educating the workforce will draw on the past successes of apprentice programs.

Roadmap:

\begin{tabular}{||l|c|c|c|l||}
\hline \multicolumn{1}{|c|}{ MILESTONE } & $\begin{array}{c}\text { START } \\
\text { FY }\end{array}$ & $\begin{array}{c}\text { END } \\
\text { FY }\end{array}$ & $\begin{array}{c}\text { COST } \\
\$ \mathrm{M}\end{array}$ & \multicolumn{1}{|c||}{ PARTICIPANTS } \\
\hline \hline $\begin{array}{l}\text { 1. Plan, develop and implement apprentice } \\
\text { and continuing education for trades }\end{array}$ & 1996 & 2003 & 100 & Labor, DOL, employers, etc. \\
\hline $\begin{array}{l}\text { 2. Plan, develop and implement formal and } \\
\text { continuing education for professionals }\end{array}$ & 1996 & 2003 & 100 & $\begin{array}{l}\text { Universities, NSF, Professionals, } \\
\text { Employers }\end{array}$ \\
\hline $\begin{array}{l}\text { 3. Plan, develop and implement initial and } \\
\text { continuing education for managers }\end{array}$ & 1996 & 2003 & 100 & Employers, universities, NSF \\
\hline
\end{tabular}

\section{Milestone Description:}

1. Education for Trades

Labor, management and educational organizations will, on a continuing basis, define educational needs, develop educational materials and curricula and organize apprentice and continuing education programs. Advanced information technologies will be exploited.

2. Education for Professionals

Professional, industrial and educational organizations will, on a continuing basis, define educational needs, develop educational materials and curricula, and organize formal and continuing education programs. Advanced information technologies will be exploited.

3. Education for Managers

Industry and educational organizations will, on a continuing basis, define educational needs, develop educational materials and curricula, and organize formal and continuing education programs. Advanced information technologies will be exploited. 


\subsection{BASELINES AND MEASURES OF PROGRESS}

\section{Objective:}

Develop baseline measures of current practice and measures of progress with respect to each of the seven National Construction Goals.

\section{Problem:}

Data describing current practices of the U.S. construction industry are needed to establish a baseline against which to measure progress of the industry towards achieving the seven National Construction Goals. Although information having relevance to the seven goals is available, for the most part, this information has such a narrow focus that a consistent set of baseline measures can not be produced without first conducting a significant research effort. Specifically, information from a wide variety of data sets needs to be collected, reviewed, analyzed, and critiqued to ensure that the baselines and measures of progress which result are adequate (i.e., they not only capture the complexities of the U.S. construction industry but also represent a consensus among experts in the field) and suitable for dissemination to the public.

\section{Products:}

- Develop measures which characterize current industry performance with respect to each of the seven goals. The averages of current practice (i.e., industry performance in 1994) will become the baselines for measuring progress towards achieving each of the goals.

- Develop methods for measuring progress. These "results" measures are envisioned as a composite of performance measures offering a means not only for monitoring actual performance but also for marshaling support for improving results.

- $\quad$ Provide on an annual basis information on actual progress towards achieving each of the seven goals. This information will be made available to interested parties both through publications and electronically via the World Wide Web.

\section{Impact:}

It is essential to have baseline data and associated measures of progress to determine the success of actions taken to improve the competitiveness of the U.S. construction industry in the domestic and international markets. In addition, baselines and measures of progress will make it possible to demonstrate the benefits of advanced technologies and practices, and to guide decision makers in prioritizing potential programs.

\section{Participating Organizations:}

Collaborative activities will be conducted between appropriate private sector and governmental organizations and academic institutions to produce the needed products. Specifically, NIST (BFRL) will collaborate with appropriate private-sector organizations (e.g., the four sector council member organizations), government agencies (e.g., the C\&B Subcommittee member organizations) and academic institutions to collect, review, analyze, and critique data for use in developing and disseminating baselines and measures of progress for each of the seven goals. 


\section{Delivery Mechanisms:}

The data will be delivered initially in the form of tables and reports. Potential outlets for the baselines and measures of progress include the C\&B Subcommittee member organizations and the four sector council member organizations. In order to reach an even larger audience, data will be incorporated into a computerized delivery system and made available on the World Wide Web.

Roadmap:

\begin{tabular}{||l|c|c|c|l||}
\hline \multicolumn{1}{|c|}{ MILESTONE } & $\begin{array}{c}\text { START } \\
\text { FY }\end{array}$ & $\begin{array}{c}\text { END } \\
\text { FY }\end{array}$ & $\begin{array}{c}\text { COS } \\
\text { TM }\end{array}$ & ORGANIZATIONS \\
\hline \hline 1. Conduct preliminary search for possible data sources. & 96 & 96 & 0.3 & NIST, Census, OSHA \\
\hline $\begin{array}{l}\text { 2. Match goals with best available data to support } \\
\text { establishment of current performance baselines for each of } \\
\text { the seven goals. }\end{array}$ & 96 & 97 & 0.6 & All concerned \\
\hline $\begin{array}{l}\text { 3. Develop conceptual approaches for baseline } \\
\text { development. }\end{array}$ & 96 & 97 & 0.6 & All concerned \\
\hline $\begin{array}{l}\text { 4. Collect data in support of the approaches and store data } \\
\text { in a computer database. }\end{array}$ & 96 & 97 & 0.7 & All concerned \\
\hline $\begin{array}{l}\text { 5. Develop methods for measuring progress towards } \\
\text { goals. }\end{array}$ & 96 & 98 & 1.0 & All concerned \\
\hline $\begin{array}{l}\text { 6. Develop user-friendly decision support software to } \\
\text { access baseline data and measures of progress towards } \\
\text { goals. }\end{array}$ & 97 & 98 & 1.0 & NIST lead \\
\hline $\begin{array}{l}\text { 7. Measure and report progress annually with respect to } \\
\text { the seven goals. Make available on the World Wide Web. }\end{array}$ & 98 & 02 & 1.2 & NIST lead \\
\hline
\end{tabular}

\section{Milestone Description:}

1. Review of Data Sources

Criteria for selecting data sources have been established and are based on the following key concepts; namely, data should be: (1) published by a reliable, nationally-recognized organization and available to the public; (2) updated on a regular basis; and (3) able to be normalized to account for changes in the building stock and the level of construction activity.

2. Match Goals to Data

This activity will match goals to data which satisfy the three criteria referenced above; it will be conducted in three parts. One part will emphasize matching goals (e.g., Construction Worker Fatalities, Injuries and Illnesses) to readily available data (e.g., U.S. Statistical Abstract, Census, OSHA). Another part will, emphasize data collection for "High Priority" goals (e.g., Reduction in Delivery Time) identified in the C\&B Subcommittee report Construction and 
Building: Federal Research and Development in Support of the U.S. Construction Industry. The third part will emphasize data collection for "Human Factors" goals (e.g., Productivity and Comfort).

3. Develop Conceptual Approaches

Analytical studies of the data from all three parts will first be conducted. "Sets" of proposed data and derived measures (e.g., baselines and measures of progress) will then be produced. Next, a "Focus Group" of industry experts will be formed to discuss the proposed data and derived measures. Finally, the C\&B Subcommittee will be briefed and feedback solicited.

4. Collect and Store Data

Based on the focus group discussions and feedback from the C\&B Subcommittee, the data sets and derived measures will be finalized for each of the seven goals. To promote further analysis and the production of down-stream products, these data will be stored electronically. Baseline measures for each of the seven goals will then be produced.

5. Develop Methods for Measuring Progress

The methods for measuring progress will use the baselines as their reference point. These methods will make use of both key outputs (i.e., summary measures) and interlinking metrics (i.e., a composite of performance measures including constituent parts and functional relationships). Special emphasis will be placed on analyzing how changes in individual metrics affect the level and rate of change of key outputs.

6. Develop Decision Support Software

Decision support software will be developed to facilitate access to information on baselines and measures of progress resident on the World Wide Web. Such software will also enable users to download information, including selected data sets, for their own review and analysis.

7. Measure and Report Progress

On an annual basis, information on actual progress towards achieving each of the seven goals will be made available via publications and the World Wide Web. Such information will include, for each of the seven goals, the baseline, the current year's progress, and measures of progress for previous years.

\subsection{HUMAN FACTORS}

\section{Objective:}

Develop and implement knowledge making the built environment functional, healthy and safe for the people who construct or use it.

\section{Problem:}

Support of human needs is the purpose of most constructed facilities, but little attention and few resources have been put into understanding how the built environment affects people. It is recognized 
that the environment influences productivity, comfort, health and safety, but knowledge is lacking to guide choices in design, construction, operation and maintenance that will cost effectively provide a productive, comfortable, healthy and safe environment for the intended use. Recognizing the complexity of the problem, diverse people in a multifaceted human and physical environment, we must seek knowledge at a variety of scales, such as ergonomics affecting individual's use of stairs and how the relationships of spaces affect the functions of hospitals.

Health and physiological research is needed on environmental effects on exposure and resistance to illnesses and accidents as well as the capabilities conducive to productivity. Psychological and sociological research is needed on how the environment, physical and human, affects occupants' attitudes and capabilities. This knowledge must be applied by architects, decorators, engineers, builders, owners and occupants. They need to be involved in the research to assure its relevance and to help put the results in useful form. Since quality is achieved through design, implementation, evaluation and change to fulfill needs of customers, evaluation techniques must be developed and incorporated into the methods used by designers, constructors, and operators. Post occupancy evaluation should become a recognized technique for responding to customers' needs rather than a threat to owners, designers or builders.

\section{Products:}

Predictive, verified models and data describing how environmental factors, cognitive processes, physiology, ergonomics, human interactions with equipment and environment, and inter-personal and inter-group relations affect the functional performance, health and safety of persons using constructed facilities and people working in construction.

Guidelines, standards and practices for planning, design, construction, commissioning, operations and maintenance which incorporate human factors knowledge to provide functional, healthy and safe constructed facilities and construction practices.

An informed and upgraded total design, construction and operation process, based on a team approach, and including planning, programming, site selection, siting, design, construction, equipping and furnishing, commissioning, training, initial use and changes in use, renovation and demolition. Critical to the process is feedback evaluation of the process and its results in order to gather data for use in subsequent projects.

Objectives should include: programmatic components; functionality; flexibility; fire and safety; security; indoor environmental quality - lighting, ventilation, temperature, sound characteristics, visual stimulation, color, finishes, graphics, plant materials and other aesthetic elements; ergonomics exterior and interior design, furniture and equipment; and materials.

\section{Impact:}

Human factors knowledge and practice significantly impact each of the National Construction Goals:

- Better teamwork and inter-personal relations in the project team will speed project delivery.

- $\quad$ Life cycle expenditures for operations, maintenance and energy will be focused on providing the environment needed to achieve the purpose of the facility. 
- The built environment will be designed and operated to achieve productivity and comfort of its users.

- The built environment will promote the health and safety of occupants.

- Waste will be avoided by focusing resources on occupants' needs.

- $\quad$ Durability will be promoted by initially providing a facility supporting occupants needs and flexibility will be promoted by knowledge supporting optimal response to changed needs.

- $\quad$ Construction workforce health and safety will be promoted by practices and equipment designed for healthy, safe use.

\section{Participating Organizations:}

Participants will include: institutions for human factors research, such as the National Institutes of Health, the National Institute for Occupational Safety and Health, and universities; organizations of the professionals who will be major appliers of the knowledge, such as the American Institute of Architects and the American Society of Heating, Refrigerating and Air-Conditioning Engineers; trade associations, such as the Association of General Contractors and the National Association of Home Builders; labor organizations, such as the Center for Protection of Workers' Rights; standards organizations that will incorporate human factors knowledge in standards for construction products and services; and local, state and Federal regulatory organizations responsible for health and safety.

The Construction Industry Perspective on National Construction Goals recommends that the initial focus of the effort be on research providing a sound technical basis for setting and realizing objectives. This research can be organized by the Federal agencies with corresponding research responsibilities, such as the National Institutes of Health, the National Institute for Occupational Safety and Health, and the Environmental Protection Agency, and guided by the councils representing the sectors of the industries of construction.

\section{Delivery Mechanisms:}

Incorporation of human factors knowledge in guidelines, standards and practices for planning, siting, design, design, construction, operation and maintenance will be addressed by the organizations producing these documents with strong participation by the researchers and end users of the documents.

\section{Roadmap:}

\begin{tabular}{||l|c|c|c|l||}
\hline \multicolumn{1}{|c|}{ MILESTONE } & $\begin{array}{c}\text { START } \\
\text { FY }\end{array}$ & $\begin{array}{c}\text { END } \\
\text { FY }\end{array}$ & $\begin{array}{c}\text { COST } \\
\$ M\end{array}$ & PARTICIPANTS \\
\hline \hline 1. Program Planning & 1996 & 1997 & 1 & All concerned \\
\hline 2. Research & 1997 & 2003 & 100 & Research Organizations \\
\hline $\begin{array}{l}\text { 3. Practices, drafted, tested and } \\
\text { completed }\end{array}$ & 1998 & 2003 & 100 & All concerned \\
\hline
\end{tabular}




\section{Milestone Description:}

1. Program Planning

The focused, coordinated, well-funded program needed can not evolve from the current fragmented and poorly funded activities. A major program planning effort is needed. It must be conducted and led by an organization capable of convening leaders of the needed research, professional, labor and trade organizations to produce a credible plan deserving of major private and public sector investments.

2. Research

The fundamental and applied human factors research needed can be only roughly estimated at this stage. An effort of the order of $\$ 100$ million over 5 years is estimated, but ongoing work should continue in fiscal years 1996-97.

3. Development of Practices

Ongoing efforts to incorporate human factors knowledge in practices of design, construction and use should continue. The planning effort is anticipated to identify much knowledge ready for use, but unexploited that will allow the effort for development of practices to begin concurrently with the strengthened program of research. Development of practices involves drafting, trial use, evaluation, promulgation of definitive practices and training. Only an order of magnitude estimate of cost is possible prior to completion of milestone 1.

\subsection{INFORMATION SYSTEMS}

\section{Objective:}

To provide designers, builders, owners, and facility managers with the information, and analytical and computational tools they need to make cost effective building and construction choices over the life cycle of the building.

\section{Problem:}

Information is the linchpin that holds our business and all its elements together; it is the glue that provides cohesion and the opportunity to continuously improve. Access to the world's generic knowledge (such as fire properties of materials) relevant to the life cycle of constructed facilities is not readily available to all who could make good use of it. All participants in the life cycle of a specific project need easily accessible project information concerning the design, construction, maintenance, modification of the facility over its life. This information is seldom complete and accessible from a single source, and is traditionally stored in different forms (drawings, written documents, manuals, personal recollections, records of calculations, equipment inventories, $\mathrm{O} \& \mathrm{M}$ documents. etc). Current methods used for storage and retrieval of generic and project specific design, construction, and maintenance do not encourage the maintenance of up-to-date records or the efficient use of the information.

Standardization to ensure open systems with maximum feasible connectivity is vital to allow efficient exchange of information among the diverse participants in a typical project. The following guiding principles apply: 
1. A National Construction Dictionary/Thesaurus of words and terms universally accepted and used by all elements of $\mathrm{A} / \mathrm{E} \& \mathrm{C}$ is a basic requirement.

2. Object oriented design is the future where all products, systems, and mission elements are represented by unique standard objects that contain as part of their definition, all needed attributes such as engineering characteristics, geometry, and cost.

3. All computer programs are hardware and operating system independent.

4. All hardware shall be programming language, operating system and communications language independent.

5. Government shall utilize national industrial/business standards to the maximum extent cost effective.

6. Commercial off the shelf software shall be utilized to the maximum extent feasible.

7. All elements of the Information Systems road map shall be fully integrated.

\section{Products:}

Economic methods and aids for decision making: A set of standard economic methods similar to ASTM's Compilation of Building Economic Standards and decision support software, to help users implement the standard economic methods, will be produced. Two standard methods, value analysis standard and multiple-criteria decision analysis standard are planned. Support software is also planned.

Information classification systems: Coordinate current classifications, like the CSI 16 division system, the budding Object Oriented system and other similar systems, into one system that utilizes the National Construction Dictionary/Thesaurus as the data source. Unity of purpose, standardization and consistency across the entire industry must be achieved.

Integrated generic information system: This can be a virtual system linking a number of private and public sector systems. For instance, the Construction Criteria Base (CCB), developed by the National Institute of Building Sciences, (NIBS), and now operational for 10,000 or more Federal users and more than a 1000 private sector users, is the current standard for Federal Government Facilities data and information storage, distribution, retrieval and utilization. CCB is a quarterly CD-ROM publication. CCB now contains about 4 gigabytes of information including, guide specifications for engineering, design and construction, engineering and design guidance manuals, non-government product and test standards and specifications, operations and maintenance manuals, computer programs, Geographical Information Systems (GIS), CAE, and Facilities Management standards for automation, thousands of CADD details etc. CCB could become the USA and later World standard platform for facilities information $(\mathrm{C} \& \mathrm{~B})$ storage, distribution, retrieval and utilization. NIBS will be encouraged to expand $\mathrm{CCB}$, make it interactive (possibly via Internet), and update it continuously.

Individual construction and building project communication system: The Department of Defense will design, implement, and continuously improve a process for the life cycle of individual projects that provides for:

- The development of a data base at the inception of a project 
- Without loss of efficiency of data the addition of all related information on: research, planning, engineering and design, construction, operations, and maintenance.

- The owner to have a complete facility management package at completion of construction that incorporates all the above such that mission execution is enhanced and life cycle costs are optimized.

Standards and tools are being developed that will allow software written for disparate hardware and software architectures and engineering domains to work together as agents in a virtual work space. At the heart of this work space are engineering models of the built environment. Several component parts are undergoing active research and development efforts. Prototypes have been demonstrated for all of the below components. These parts include:

- $\quad$ Agent Collaboration Language: Protocols for heterogeneous and networked computer programs to exchange and translate data and knowledge are being developed and tested on two facility design test bed projects. These approaches build on products of the ARPA Knowledge Sharing Effort. The Virtual Workspace Language (VWL) at USACERL supports publish and subscribe queries about objects and their relationships as well as negotiation between agents over object attributes. The Agent Communication Language at Stanford uses a facilitator to allow programs that use different model representations to exchange information. The facilitator provides routing and translation services.

- $\quad$ Modeling and Design Tools: A number of technologies are being developed to allow domain professionals to model design alternatives, provide visualization, and communicate functional requirements and potential solutions to others in a virtual work space. These tools make maximal use of interfaces with modern CAD (e.g., AutoCAD, Micro station), database (e.g., ORACLE, ACCESS, DBASE), and other productivity software to act as unifying software frameworks and provide familiar interfaces to designers. Specific modeling environments involved in this effort include ACE(Army), MDS(DOD), WORK SPACE (DOD), SWIFT (University of Southern California)(USC), and SEED(Carnegie-Mellon University)(CMU). Test bed activities have also focused in integrating these environments with energy analysis, cost estimating, and project management tools.

- Models of Conflict and Negotiation: Protocols for detecting conflicts between disciplines, such as Architects, Engineering, and O\&M personnel are being developed and tested. Computer assistance in detecting and resolving unanticipated conflicts is expected to directly impact both building performance and unnecessary change orders during construction.

The STEP standard is an international standard for automatic exchange of product information. Active, international activities are developing the AEC elements of STEP. The PlantSTEP consortium is preparing a pioneer application to process plants. This work should be generalized to all constructed facilities.

\section{Impact:}

Successful adoption of the products is expected to improve substantially the competitiveness of the U.S. construction industry by producing better designs and reducing inefficiencies caused by current fragmentation. These tools will directly support the formation of virtual corporations that will allow numerous small businesses to work closely together despite geographical and organizational barriers. The Information and Decision Support Systems products will directly contribute to meeting all the National Construction Goals. 


\section{Participating Organizations:}

A combination of public and private sector contributors have been and will continue to be involved in developing these products. Current test bed projects involve DOD(Tri-service), NIST, academia (CMU, Massachusetts Institute of Technology (MIT), Stanford, University of Illinois, U.S.C.), and state support. DOD's Center for Automation of the Facility Life Cycle at Vicksburg, Mississippi will be a major producer of these products. The economic methods and aids for decision making are being developed by NIST in conjunction with ASTM. NIBS will continue to enhance and promote CCB. CSI will work with NIBS and others in the private sector to develop a universal process/system information classification system.

\section{Delivery Mechanism:}

The products will be brought to market through several mechanisms. Two of the modeling environments are being developed through cooperative R\&D agreements (CRADAs). Standards for communication and negotiation must be pursued through standardization efforts such as ASTM, ISO, and CORBA. Tools will be publicly available as research tools and may be commercialized once proven.

\section{Roadmap:}

\begin{tabular}{||l|c|c|c|l||}
\hline \multicolumn{1}{|c|}{ MILESTONE } & $\begin{array}{c}\text { START } \\
\text { FY }\end{array}$ & $\begin{array}{c}\text { END } \\
\text { FY }\end{array}$ & $\begin{array}{c}\text { COST } \\
\$ M\end{array}$ & \multicolumn{1}{|c||}{ PARTICIPANTS } \\
\hline \hline 1. Value Analysis Standard & 1995 & 1998 & 0.5 & NIST and ASTM \\
\hline $\begin{array}{l}\text { 2. Multiple-Attribute Decision } \\
\text { Analysis Standard }\end{array}$ & 1995 & 1998 & 0.5 & NIST and ASTM \\
\hline 3. Supporting software & 1996 & 2000 & 1.0 & NIST and ASTM \\
\hline 4. Draft Classification System & 1997 & 2000 & 2.0 & DOD, CII, CSI, NIBS \\
\hline 5. CCB standardized & 1996 & 2001 & 3.0 & NIBS, NIST, ANSI, DOD \\
\hline 6. Agent collaboration language & 1996 & 2000 & 3.0 & DOD, ARPA, Private Industry \\
\hline $\begin{array}{l}\text { 7. Modeling and Design Tools } \\
\text { 9. Models of Conflict and }\end{array}$ & 1998 & 2001 & 5.0 & $\begin{array}{l}\text { CERL, U.Southern Cal., Carnegie } \\
\text { Melon, NIST, NSF }\end{array}$ \\
\hline $\begin{array}{l}\text { 9. Extend PLANTSTEP to all sectors } \\
\text { of construction }\end{array}$ & 1995 & 2002 & 5.0 & NIST Private Sector \\
\hline $\begin{array}{l}\text { 10. DOD Life-cycle integrated } \\
\text { actuation system }\end{array}$ & 1996 & 2000 & 5.0 & DOD \\
\hline \hline
\end{tabular}




\section{Milestone Description:}

1. The ASTM value analysis standard will focus on buildings and construction, but will be applicable to any kind of capital budgeting decision.

2. The ASTM multi-attribute decision analysis (MADA) standard will be supported with a computer program to assist decision makers.

3. The supporting software will be widely available to help users implement the MADA standard method.

4. A draft coordinated classification system will be developed and reviewed by many potential users.

5. $\quad \mathrm{CCB}$ is expanded and becomes the USA standard platform for facilities information $(\mathrm{C} \& \mathrm{~B})$ storage, distribution, retrieval and utilization management tools.

6. Agent collaboration language beta-tested.

7. Modeling and design tools tested and demonstrated.

8. Models of Conflict and Negotiation. Protocols for detecting conflicts between disciplines, such as Architects, Engineering, and O\&M personnel will be developed and tested. Computer assistance in detecting and resolving unanticipated conflicts is expected to directly impact both building performance and unnecessary change orders during construction.

9. The international standard for automatic exchange of product information will be extended from the current process plant application to all sectors of the construction industry.

10. Process for having the engineering and business data for each phase of a project transferred automatically without loss of data so that the owner or others who need to information will have the full set of information available.

\subsection{HIGH PERFORMANCE MATERIALS AND SYSTEMS}

\section{Objective:}

Speed the development and acceptance into use of high-performance materials and systems while monitoring and integrating facility performance in an automated manner to sense faults and life threatening situations so that the system can reactively take corrective action without human interference.

\section{Problem:}

Materials technology is advancing at a much faster pace then the acceptance and use of these materials in structures. Associated gains must be made in automatically assessing the qualities of these materials in place from construction through their life cycle. Better materials will allow savings to be made in the total quantities that will be used in construction and structural members will be thinner and lighter. The use of less materials requires more refined detailing in design which creates a more balanced design at the same time the conservation built into older systems will be reduced and the total system 
factor of safety will be a narrower margin, possibly creating more risk. The reduced physical factor of safety will be reinstated by using reliable SMART materials and computerized monitoring.

Environmental needs and the availability of advanced sensors and automation demand and permit a new generation of advanced mechanical systems for constructed facilities. The integrated computerbased monitoring control system will be extended to manage all aspects of constructed facilities including maintenance, energy management, air quality, fire safety, security, diagnosis and self testing and automatic remediation of problems, or activation of warning systems for the tenants or users.

Barriers to the use of high performance materials and systems must be overcome. The primary barriers are education of the potential designers/users, overcoming specification and code restrictions, obtaining capital investment so that new products may be developed, and the resolution of possible liability issues.

\section{Products:}

- Develop the necessary enabling technologies and knowledge base for properly using the various material sub-systems. R\&D encompasses data collection, models of performance (including health, safety and environmental quality), durability, measurement techniques and standards supporting the effective use of innovative, high performance materials components and systems for constructed facilities.

- Develop better ways of assessing a building's condition in a reliable, quantitative, less costly manner and non-intrusively. This development of better computerized sensors and communication systems must be accompanied by deployment and field use of the technology.

- Develop the framework and components of a system that can be used to assess the condition and quality of mechanical equipment, electronic equipment, structural system, materials, thermal comfort, indoor conditions, and services supplied to a constructed facility. The system will be used as a tool for quality assessment during construction, and in evaluating the performance of a building or constructed facility after it is built. For existing facilities the system will use a set of portable diagnostic tools that can be used to assess the current condition of a constructed facility and diagnose problems, thereby providing the basis for improved maintenance and reduced operating costs. For new construction the system can have built-in smart sensors.

- Develop open interface standard protocols for an integrated computer-based control system to manage all aspects of constructed facilities including maintenance, energy management, air quality, fire safety, security, diagnosis and self testing and automatic remediation of problems, e.g., BACnet, and ASHRAE/ANSI standard protocol for building automation systems. These standards will permit automatic exchange of information among devices with diverse capabilities and functions made by different manufacturers.

\section{Impact:}

A cooperative, coordinated program between government and the private sector can speed the development and deployment of technologies related to high performance materials, smart materials, sensors, advanced mechanical systems, and integrated communication and computerized systems control. Revolutionary concepts for future buildings will be developed. New structures will require about $1 / 3$ less in the amount of construction materials (concrete, steel, etc.) used and will be at least twice as durable as existing structures. Sensors, smart materials and integrated systems development 
will challenge the capabilities of the defense industry. Automated construction surveillance will reduce job-related accidents and will produce better quality construction. Overall, smart buildings will operate more energy efficiently and with improved quality, safety and security for the occupants. The more quickly that we develop such technology, the greater the lead we will take in world competition.

\section{Participating Organizations:}

The attack of this problem will require coordination of work and barrier removal in 4 major technology areas: high performance materials (including smart materials); sensor system development; computer integrated systems simulation and development; and building systems technology.

High performance materials, components and systems are commercial products produced by large scale manufacturing industry. The product development R\&D will be funded by industry. Government will assist in R\&D for fundamental and generic technologies, which cannot be recouped in the marketplace, and in removal of market barriers.

Industry has developed a plan for implementing a program of technological research, development, and deployment to accelerate the commercialization of High Performance CONstruction MATerials (CONMAT) under the auspices of the Civil Engineering Research Foundation (CERF). A National Construction Materials Coordinating Council (NCMCC) has been formed by the industry representatives to interface with the government in pursuing the proposed program of $\$ 2$ billion investment over 10 years.

NIST will build integrated knowledge systems for high-performance construction materials and systems by expanding its work on HWYCON (HighWaY CONcrete expert system) which is currently being distributed to 3,000 end-users via the TRB/SHRP program. The ultimate goal is to link these multi-medium systems to simulate, monitor, and manage the life-cycle performance of entire constructed facilities. This will require the seamless electronic integration of simulation models, including images and expert systems; property, cost, and performance databases; testing and design standards and codes; and condition and conformity assessment.

About 18 government agencies are working through the subcommittees of the National Science and Technology Council (NSTC) are coordinating activities and relate to industries through partnerships. The three related subcommittees of the NSTC are: Construction and Building of CCIT, Material Technology of CCIT, and the Transportation Infrastructure Renewal Subcommittee of CT R\&D.

New initiatives such as the AT-TIR (Advanced Technology for Transportation Infrastructure Renewal) are being discussed in the Department of Transportation to create regional consortia. At the local level industries/government/educational entities/ and others will be brought together and raised to the same level of knowledge such that they enable themselves to overcome codes, laws, liability, investment and other barriers.

The broad-based deployment of new technologies, measurements, and standards in construction is a critical national need identified by industry, trade and professional organizations, academia, and government. More than $80 \%$ of the million construction firms have fewer than 10 employees and less than one-tenth of one percent employ more than 500 persons, making broad-based diffusion of new technologies to enhance industry competitiveness extremely challenging. A coordinated program to support the needs of these small and medium sized construction firms, modeled after the Manufacturing Extension Partnership, would provide full-service technology extension services, including information, knowledge, and insight into the adoption and use of modern technologies, measurements, and standards 
that improve the life-cycle quality of constructed facilities, initial planning to assess industry needs, potential economic benefits, alternate delivery mechanisms, links to existing programs, and cost-share potential has been initiated at NIST.

The typical civil and mechanical engineering community needs to reach out to enlist the aid of the defense and electronics industries and other disciplines to help solve civilian technology problems with more adaptable defense-developed technologies.

\section{Delivery Mechanisms:}

The products will be delivered through existing government programs and agencies using improved coordination mechanisms. Some changes need to be made in the ways agencies perform their functions in order to allow more partnering (such as CONMAT) and to help empower regional consortia (such as AT-TIR) to overcome barriers to technology deployment. Existing professional organizations such as ASCE, ASHRAE, TRB, APWA, and IEEE and other consensus standards-developing organizations will be used as widely as possible. The "Information Age" has created communication tools that were previously unavailable.

\section{Roadmap:}

\begin{tabular}{|l|c|c|c|l|}
\hline MILESTONE & $\begin{array}{c}\text { START } \\
\text { FY }\end{array}$ & $\begin{array}{c}\text { END } \\
\text { FY }\end{array}$ & $\begin{array}{c}\text { COST } \\
\$ \mathrm{M}\end{array}$ & \multicolumn{1}{|c|}{ PARTICIPANTS } \\
\hline $\begin{array}{l}\text { 1. Organization of Agency } \\
\text { Programs }\end{array}$ & 1996 & 1998 & 1 & $\begin{array}{l}\text { Construction - Oriented } \\
\text { Agencies }\end{array}$ \\
\hline $\begin{array}{l}\text { 2. Support the CONMAT } \\
\text { Program }\end{array}$ & 1996 & 2006 & 2000 & $\begin{array}{l}\text { CERF with Government } \\
\text { Liaisons }\end{array}$ \\
\hline $\begin{array}{l}\text { 3. Establish Regional } \\
\text { Consortia (AT-TIR) }\end{array}$ & 1997 & 2007 & 2000 & APWA and Other \\
\hline $\begin{array}{l}\text { 4. Develop Models and } \\
\text { Simulation/Control }\end{array}$ & 1997 & 2000 & 40 & NIST, NSF, DoE \\
\hline $\begin{array}{l}\text { 5. Develop Sensor } \\
\text { Technologies }\end{array}$ & 1996 & 2006 & 100 & $\begin{array}{l}\text { NSF, ASTM, NIST, } \\
\text { DoE, etc. }\end{array}$ \\
\hline $\begin{array}{l}\text { 6. Integrated Knowledge } \\
\text { Systems for HIPERF } \\
\text { Materials and Systems }\end{array}$ & 1997 & 2007 & 100 & $\begin{array}{l}\text { NIST, NSF, Industry, } \\
\text { Academia }\end{array}$ \\
\hline $\begin{array}{l}\text { 7. Construction Technology } \\
\text { Extension Program }\end{array}$ & 1997 & 2007 & 500 & $\begin{array}{l}\text { NIST, Other Agencies, } \\
\text { Industry, State/Local } \\
\text { Governments }\end{array}$ \\
\hline $\begin{array}{l}\text { 8. Prototype Showcases } \\
\text { And }\end{array}$ & 1998 & 2005 & 500 & $\begin{array}{l}\text { Federal agencies, AIA, } \\
\text { APWA, NAHB and CII }\end{array}$ \\
\hline
\end{tabular}

\section{Milestone Description:}

1. Organization of Agency Programs 
Under the NSTC organization, the C\&B Subcommittee, The Materials Subcommittee, and The Transportation Infrastructure Renewal Subcommittee have each worked with about 18 agencies to do a cross-cut on materials/construction budget cross-cuts in a superficial way. An in-depth review of who is doing what in the technologies is needed and re-assignments/responsibilities re-delegated to develop an organized front that can interface with industry.

\section{Support the CONMAT Program}

Industry has formed a coordinating council that represents the materials/construction industries and have developed an R\&D agenda. Elements common to the government programs and to industry will be negotiated to develop partnering/co-funding with industry. The CONMAT concept will be extended if needed, to supplies of building mechanical systems.

3. Establish Regional Consortia (AT-TIR)

Several consortia of a regional nature presently existing and they have expressed interest in partnering/co-funding to create a pull for getting new infrastructure related technology into place. Most consist of a Federal lab, state and local governments, transportation agencies, and universities. They represent groups of owners who can work with local industries to overcome liability and building code barriers on a regional basis.

4. Develop Models and Simulation/Control

Smart structures technology is an evolving discipline. Think-tank type of analysis and development needs to be done to coordinate the various aspects of substituting active civil structures for deadweight mass. A simple example of this type of structure is the cranes used in construction where moving counter weights reduce the overturning moments such that cranes used today are less massive than those in the past. Advanced control systems are needed for fire safety, transportation, security, environmental and other mechanical systems for constructed facilities.

5. Develop Sensor Technologies

Just as sensors are now used in vehicles to monitor/control antilock brakes, emissions, stability, etc., similar applications are possible for monitoring structural and functional characteristics of constructed facilities. Long term reliability of memory steel gauges, fiber optic sensors, and other technologies must be established.

6. Integrated Knowledge Systems for High Performance Materials and Systems

Ready access is needed to the world's knowledge of materials and system performance. Sensor, computers, communications, and activation units are needed to create a project-specific information system that can monitor itself and its environments, analyze its condition or threat (self-diagnose) and react to repair itself. The system must compensate for the changes that take place with environmental degradation and wear.

\section{Construction Technology Extension Program}

A substantial program is needed to get owners/designers/constructors to use the improved technologies and to train the workforce in their effective use. 


\section{8. $\quad$ Prototype Showcases}

Forward thinking owners from industry and government will test and exhibit advanced technologies.

\subsection{AUTOMATION}

\section{Objective:}

Dramatically expand the use of automation in design, fabrication, construction, operation, maintenance, renovation, demolition and removal of constructed facilities. Develop methods for simulating, analyzing and planning each of the life-cycle phases of a facility.

\section{Problem:}

Construction has been unsuccessful at delivering improved value over time as compared with, for example, the manufacturing and shipping industries. The potential benefits from improvement in performance of the construction process are enormous, given the scale of the industry and its impact on national and global economies. The construction process itself must be redesigned as a system if technology innovation is to be effectively exploited by the U.S. construction industry. Automation is a central enabler to the better use of limited global resources (capital, human and material) and therefore has a key role in achieving development which is environmentally sustainable. Innovation through automation is central to competitiveness of the industries of construction and of the facilities they produce.

Automation addresses the following problems: worker productivity; poor working conditions; injuries to workers; decreasing desirability of building and construction jobs; declining quality of the constructed project; over-run schedules; high project costs; decreasing skill level of workers; hazardous materials or site conditions (both known and unexpected); manual handling of heavy and awkward assemblies; and time consuming inspection, repair and maintenance. Automation embodies a systems engineering approach to hardware, software and interface technologies, as well as to condition assessment and real-time site metrology.

Accurate and flexible simulation tools for the construction process, in all its dimensions, are central to solving the problem of performance of the constructed facility over the entire life cycle. In the design stage, simulations of constructability and maintainability, as well as performance under natural and manmade environments during the facility's use, must be undertaken. Simulation includes performance of construction equipment; environmental factors and impacts; and behavior of human participants. Thus, simulations of construction and maintenance or renovation activities are as essential to design as they are to selection of optimal alternative construction processes.

\section{Products:}

Simulations and simulation tools will be developed for the performance of individual pieces of construction equipment. These simulations and software tools will permit users to determine key characteristics of construction equipment and processes (e.g., the productive output of the equipment and the response, or failure, of the equipment to its environmental factors such as weather and soil conditions). Manufacturers and commercial software companies will develop the "commercial" simulation capabilities, but will make use of common standards for data exchange, thus facilitating inter-operability and flexibility. Federal R\&D will focus on fundamental and enabling research needed 
(e.g., dynamic properties of soil, nonlinear response of mechanical systems, vision/user interface technologies, control algorithms, automated site metrology/telemetry, data exchange standards, and planning/reasoning techniques).

Simulations will be developed of the construction process at various levels of detail. Critical path scheduling is simulated at a high level of abstraction, whereas simulation of mechanical tasks, for example, a back hoe loading of a truck, is at a very detailed level. Eventually, there should be capability to move through a hierarchy of planning detail for the construction process. Commercial organizations are expected to provide the "commercial" versions of these simulations, but construction contractors, equipment manufacturers and academic and Federal researchers will be principals in the development and verification of algorithms, database standards, and proof-of-concept demonstrations through virtual construction test-beds.

Simulation includes simulations of interactions with the environment and people; static and dynamic, linear and non-linear response of materials and systems to forces, displacements and temperatures; behavior of equipment considering its position and attitude, its flexibilities and degrees of freedom, component inertias, environment, control systems and operator interventions; and gaming-type models for effects of operations with time. Simulations of operation, maintenance, renovation, and demolition are within this scope provided that removals and well as placement of materials and components are simulated. Simulation techniques can be incorporated into computer assisted training programs which will increase worker productivity and reduce worker injuries.

Federal R\&D can facilitate development of effective, neutral standards in the form of guide specifications to manufacturers of the physical systems and equipment that will utilize automation, advanced metrology and sensing capabilities and the software/data interface standards that will link all these disparate sub-systems. These standards and guides will act as a framework, evolving under industry consensus and technological innovation, that equipment manufacturers can use to ensure acceptance of new and innovative equipment and systems. Standards will support robust and reliable equipment which will yield attractive production rates and high quality construction.

Three dimensional graphics, including virtual reality technologies, will be a key aspect of the simulation tools so that workers, managers and engineers can understand the reasons for problems in the process of concern and easily identify improvements. Non-graphic analytical and reasoning techniques also will be needed to identify opportunities and needs for improvements and recommend changes in construction processes. Commercial software companies will be involved in developing and marketing construction simulations, with research activities involving research organizations, owners, designers, and contractors.

Human factors and display research will be essential to close the loop and bring the database information back to the construction site worker and foreman, where it can be put to practical use in the form of selected access to registered 3D as well as alphanumeric data, updated in real-time, on the job site. The development of lightweight, affordable helmet-mounted and head-up displays are crucial to this process, as are human-factors design to determine methods of displaying data, while avoiding information overload, eye strain and disorientation typical of such systems today. Voice activation and recognition technologies, high capacity compact, local database chips and storage media, and inter-worker communications will also be crucial technologies to this effort. Federal R\&D can develop the initial proof-of-concept technologies, with the private sector subsequently manufacturing commercial versions of the systems. 
Impact:

The integration of high-performance and smart construction equipment with re-engineered, information-rich construction methodologies, and tools for simulation, analysis and planning of the process itself (throughout the entire life of the facility) will provide major contributions to reaching all National Construction Goals. Private sector R\&D for improved products: hardware, software, interface technologies, condition assessment and site metrology, will be stimulated by federal R\&D focused on critical enabling and generic technologies, and by the removal of non-technical barriers to innovation, such as the lack of relevant, neutral standards. The ultimate impacts will be dramatically enhanced competitiveness of the construction industry and the benefit to society in obtaining better value for its capital expenditures.

\section{Participating Organizations:}

Collaborative activities, between Federal laboratories such as NIST and Sandia, already engaged in this research and who are most likely to play a major role in its implementation and the private sector will be conducted. Partnerships with private industry (particularly engineers, contractors and equipment manufacturers) will be sought involving appropriate private and public sector organizations to produce needed products. Participation of key building and construction industry technology cooperatives in the private sector, such as the Construction Industry Institute, will be essential to obtain acceptance, credibility and meaningful participation of the labor, management and developer communities. Longterm involvement of university programs related to this focus area, e.g., the University of Texas Robotics Program, Carnegie Mellon University Robotics Institute, and Stanford University Robotics Laboratories, are needed to ensure continued development of key, innovative technologies.

\section{Delivery Mechanisms:}

Commercial software producers, equipment suppliers and major engineering construction firms, often in consortia, are expected to be the producers of automation products. These will be delivered through normal marketing practices, including Beta tests as a tool to gain acceptance. At the prototype stage, well documented milestone demonstrations, involving public and private collaboration, are likely to be needed to verify and develop confidence and enthusiasm of potential developers and users.

The planned products and associated standards will provide the infrastructure to accomplish several vital objectives: open automation systems architecture for low-cost market entry, develop retrofit products, develop strategic alliances with equipment manufacturers and users, and promote new ventures to stimulate the market for a new generation of automation products and tools. The ATP can

provide direct support for high risk research. Further, the MEP can provide help to buyers and users of automation equipment and simulation software. Finally, the technology transfer strategy will disseminate information about these systems to students at universities and technical schools in order to stimulate the development of applications and establish acceptance of a new paradigm in the construction and building industries. 
Roadmap:

\begin{tabular}{|c|c|c|c|c|}
\hline MILESTONE & $\begin{array}{l}\text { START } \\
\text { FY }\end{array}$ & $\begin{array}{l}\text { END } \\
\text { FY }\end{array}$ & $\begin{array}{c}\text { COST } \\
\$ M\end{array}$ & PARTICIPANTS \\
\hline 1. Simulation-enabling technologies & 96 & 98 & 100 & $\begin{array}{l}\text { R\&D agencies and } \\
\text { researchers }\end{array}$ \\
\hline 2. Hardware/Software Standards & 96 & 98 & 10 & All concerned \\
\hline 3. Site Metrology & 96 & 00 & 200 & All concerned \\
\hline $\begin{array}{l}4 . \\
\text { Simulation/planning/analysis/software }\end{array}$ & 97 & 02 & 200 & $\begin{array}{l}\text { Construction equipment } \\
\text { manufacturers, software } \\
\text { developers, innovators, } \\
\text { contractors, academe }\end{array}$ \\
\hline 5. Equipment & 96 & 03 & 500 & $\begin{array}{l}\text { Equipment manufacturers } \\
\text { and contractors }\end{array}$ \\
\hline 6. Graphics/Visualization Tools & 96 & 00 & 100 & All concerned \\
\hline 7. Person in the loop feedback systems & 96 & 02 & 50 & All concerned \\
\hline
\end{tabular}

\section{Milestone Descriptions:}

1. Simulation-Enabling Technologies

Fundamental and enabling research needed as the prerequisite to development of software to simulate the performance of individual pieces of construction equipment. Examples include dynamic properties of soil and generic chaotic response of mechanical systems, vision technologies, control algorithms, and reasoning techniques.

\section{Hardware/Software Standards}

Development of standards in the form of guide specifications to manufacturers of the physical systems and equipment that will utilize automation, advanced metrology and sensing capabilities. Similarly, develop standards for data interchange between software tools, to facilitate inter-operability and a flexible, modular approach to improvements. Standards and guides will act as a framework for equipment manufacturers and software developers to ensure acceptance of new and innovative equipment and systems.

\section{Site Metrology}

Development of real-time precision metrology, data telemetry in the construction environment, and data representation standards that will enable commercial software developers to readily use site metrology data. 
4. Simulation/Planning/Analysis Software

Development of computer-based performance simulation of individual pieces of construction equipment and the site construction process. Simulation includes interactions with the environment and people; response of materials and systems; behavior of equipment including operator interventions; and effects of operations with time. Analysis tools will facilitate understanding of the results and assist in determining promising alternatives to test via simulation. Planning tools, working in concert with simulation and analysis, can be used by management to develop efficient strategies for construction and to facilitate rapid development of contingency plans, when needed.

5. Equipment

Development, prototyping and market introduction of new more efficient, productive and safer construction equipment and tools, building upon the functional, fundamental equipment presently available. Advances are needed in better and cheaper sensors; algorithms and equipment for data transmission on the position, attitude, and status of all kinematic elements of a machine; feedback systems to improve operator productivity; and cheap, robust, onboard, real-time positioning systems.

6. Graphics/Visualization Tools

Implementation of three dimensional graphics, virtual reality and related technologies to the display of construction simulations (or real-time data) so that results can be clearly seen and understood, and problems can be easily identified. This milestone also includes non-graphic analytical and reasoning techniques. This work is targeted mainly at management level systems which operate inside controlled environments where more sophisticated computational equipment, not constrained by weight nor size, may be employed.

7. Person-in-the-Loop Feedback systems

Develop lightweight, human-factor-engineered "smart helmets" for construction and maintenance workers and "smart cockpits" for equipment operators, based on helmet-mounted displays, head-up displays, user-portable database storage, and telemetry systems to permit real-time information at the worker and job site foreman level and to permit inter-worker communications and position identification. Develop control systems that permit users to direct the activities of equipment in a safe and efficient manner, either locally or from a remote location (as in the case of radioactive or hazardous material cleanup activities). This activity is intended specifically to connect the on site worker into the information loop.

\section{COST SUMMARY AND PLANS FOR DEPLOYMENT}

\section{$\underline{5.1 \text { COST SUMMARY }}$}

These are initial estimates of both private sector and government $R \& D$ investments required to meet the National Construction Goals. Substantial revisions are expected as planning proceeds with industry sectors in fiscal year 1996. 
$\underline{\text { Summary of cost of producing products }}$

Leadership for Innovation $\quad 12$

Regulatory Reinvention 37

Skilled Construction Workforce 300

Baselines and Measures of Progress 5

Human Factors 201

Information Systems $\quad 30$

High Performance Construction Materials $\quad 5,241$

Automation $\quad 1,160$

$\sim \$ 7,000 \mathrm{M}$

\subsection{PLANS FOR DEPLOYMENT}

Beneficial innovation occurs when improved technologies are used successfully and able to compete in the marketplace. Because of barriers, such as lack of leadership, prescriptive regulations, concerns for liability, and lack of workforce skills, getting technologies used may be as difficult as developing them.

Mechanisms for deployment include private and public sector collaborations in:

- Development of standards and conformity assessment procedures, which is covered in Section 4.2, Regulatory Reinvention.

- $\quad$ Education and training, which is covered in Section 4.3, Skilled Construction Workforce. Manufacturers advertising and marketing activities are an important, private sector method of education for deployment.

- Demonstration projects which provide low risk test beds for innovations. Private/public collaborations have high potential for demonstrations.

Federal agencies are motivated to support demonstration projects to show how a new product or service can advance the agency mission. For some missions, participation in demonstration projects is Administration policy:

Executive Order 12902 of March 8, 1994, requires that when an agency constructs at least five buildings per year, it shall designate at least one building, at the earliest stage of development, to be a showcase highlighting advanced technologies and practices for energy efficiency, water conservation, or use of solar or other renewable energy. The Order also requires that each agency designate one of its major existing buildings to become a showcase to highlight energy or water efficiency and attempt to incorporate solar and other renewable technologies, and indoor air quality improvements. Each agency is required to develop and implement plans and work in cooperation with DOE, and where appropriate, in consultation with GSA and other appropriate agencies to determine the most cost effective strategies to implement these demonstrations.

The following examples of ongoing and planned Federal/private sector collaborations illustrate mechanisms for deployment: 


\section{$\underline{\text { High Performance Construction Materials (CONMAT) }}$}

Industry has developed a plan for implementing a program of technological research, development, and deployment to accelerate the commercialization of High Performance CONstruction MATerials (CONMAT) under the auspices of the Civil Engineering Research Foundation (CERF). A National Construction Materials Coordinating Council (NCMCC) has been formed by the industry representatives to interface with the government in pursuing the proposed program of $\$ 2$ billion investment over 10 years.

\section{$\underline{\text { Exemplary Buildings }}$}

DOE's Exemplary Buildings are highly efficient passive solar residences. With construction costs funded by others, but using DOE design support, these buildings will utilize about half the energy of typical residences and will be showcased as models of efficient design. Construction is complete on four such residences by including locations in Yosemite, CA, Louisville, KY, Winchester, VA, and Grand Canyon, AZ. Two international locations are also currently planned in the near future as part of an International Energy Agency buildings project.

Plant Step Consortium to Build Information Exchange Technology for Process Plants

In collaboration with NIST a group of major U.S. process owners, engineering firms, equipment suppliers, fabricators, and information technology companies have created a consortium aimed at building a neutral information exchange of process plant data based on the international standard known as STEP, Standard for the Exchange of Product model data. The eleven companies involved have set a goal of raising the capability of raising U.S. firms to compete in the world process market by making sure that they and all U.S. firms can share information seamlessly. The U.S. process and construction industries have a vital stake in STEP. Companies with STEP expertise will have a competitive edge in the increasingly tough global market place. The first results of PlantSTEP will be available in 1995 and all results are scheduled for release in 1996.

$\underline{\text { Golden Gate Federal Building, San Francisco, California. }}$

To encourage the rapid adoption of BACnet within the building industry, NIST, GSA, DOE, Lawrence Berkeley Laboratory, and Pacific Gas and Electric and several energy monitoring and control system (EMCS) manufacturers are planning a BACnet Testbed demonstration project in the 450 Golden Gate Building in San Francisco which is PG\&E's second largest energy demand load in the San Francisco area. The Test bed building will focus on demonstrating the viability of BACnet as an open system communication protocol for Energy Monitoring and Control Systems (EMCS), documenting the energy and operating cost savings that can be achieved through intelligent building control using BACnet. The Project will also facilitate the development and implementation of advanced control concepts involving fault detection, diagnostics, and building system optimization. BACnet will be expanded from HVAC application to the control of all building services, including life safety, security, and transportation. The Test bed Demonstration Project should have a significant positive impact on both domestic and international sales of EMCS by U.S. companies. The installation of BACnet based EMCS throughout the nation could result in an energy cost saving to end users of $\$ 23$ billion per year.

Building America

Building America is an industry partnership program that applies systems engineering approaches to accelerate the development and adoption of building process and technical systems innovations for energy 
efficient, environmentally sensitive, affordable and adaptable residences. The program targets lead residential builders, designers, material suppliers, equipment manufacturers, and related infrastructure.

The Building America Initiative, managed by DOE with support from the National Renewable Energy Laboratory, brings together all segments of the housing industry (designers, builders, developers, financial institutions, material suppliers, and equipment manufacturers). The initiative is accelerating homebuilding energy system innovations using a comprehensive systems engineering approach that increases the quality and efficiency of homes while reducing cost and environmental impacts. The teams are evaluating innovative design and construction strategies ranging in scale from individual houses to neighborhood-scale developments. By working together in cross-cutting industry teams, major design, business, and construction system innovations are quickly identified and implemented. Four consortia are in place in 1995.

\section{Home Energy Rating Systems}

The National Energy Conservation and Policy Act requires DOE to issue voluntary guidelines that may be used by State and local governments, utilities, builders, real estate agents, lenders, agencies in mortgage markets, and others to enable and encourage the assignment of energy efficiency ratings to residential buildings. In FY 1994, the Department of Housing and Urban Development and the Department of Energy cooperatively initiated five multi-year pilot projects to promote the purchase of existing energy efficient residential buildings and the installation of cost-effective improvements in existing residential buildings at the time of purchase. In FY 1995, the Department, in cooperation with Freddie Mac, expanded the pilot program by adding a sixth state. These pilot projects are intended to test the implementation of the delivery mechanism for home energy rating systems and energy efficient financing and provide a basis for the report to Congress required by the legislation. To carry out these legislative requirements DOE created the HERS Council. The HERS Council represents a broad array of stakeholders and originally included the majority of Home Energy Rating Systems providers (including some State "chartered" organizations); Energy Rated Homes of America (ERHA--a pioneering organization in rating systems); the National Association of State Energy Officials (NASEO); the Edison Electric Institute; the Good Cents program and a number of electric utility companies (many of which have various forms of rating systems); the American Gas Association; several major financial institutions, including Fannie Mae and the National Mortgage Bankers Association; the National Association of Home builders; and many other organizations.

\section{The Rebuild America Program}

Rebuild America is a multi-year Department of Energy (DOE) program, currently funded at $\$ 8 \mathrm{M} / \mathrm{year}$, that helps community and regional partnerships improve commercial and multifamily building energy efficiency. Partnerships can be led by anyone. Organizations in partnership may include government agencies, economic development organizations, energy service companies, financial institutions, utilities, private businesses, nonprofit organizations, etc. DOE provides partnerships with technical and financial assistance to help them plan and carry out energy efficient retrofits. 
By the year 2000, the Rebuild America program will:

- Create 250 partnerships;

- Obtain partner commitments to retrofit over two billion square feet (3\% of non-residential floor space).

- Promote a comprehensive approach to energy efficient retrofits;

- Promote good O\&M practices to ensure persistence of savings, and;

- Ensure that the partnership activities continue without further DOE funding or technical assistance, and are replicated in other geographical areas.

By working with the private sector partners, by the year 2000, Rebuild America will:

- Save building owners and tenants $\$ 650$ million dollars annually,

- Have leveraged $\$ 3$ billion of private sector investment,

- Have created 26,000 new private sector jobs in the building and construction trades, and

- Reduce annual CO2 emissions by 1.6 Million Metric Tons of Carbon Equivalent (MMTCE).

Energy Star Buildings

Launched in Spring 1995, the ENERGY STAR Buildings program is a voluntary energy-efficiency partnership between U.S. commercial and industrial building owners and EPA. The program implementation focusses on the use of proven technologies to realize the profitable energy efficiency opportunities in existing buildings. The program is a five-stage energy efficiency upgrade strategy that considers system interactions resulting in additional energy savings, while lowering capital expenditures and preventing pollution. There are over 75 participants in the program representing over 25 Million square meters of commercial and industrial building space.

\section{ENERGY STAR Office Equipment}

The ENERGY STAR Office Equipment program promote the use of energy-efficient office equipment through the ENERGY STAR label. Conventional office equipment often wastes a great deal of energy and money. In a typical office, $20 \%$ of equipment is left on 24 hours a day, but is active only a small percent of the time. ENERGY STAR office equipment automatically powers down and enters a low power mode to save energy when it is not in active use. This "sleep" feature can cut a product's annual energy use by up to $65 \%$. More than 700 manufacturers of office equipment products worldwide are participating in the program and thousands of ENERGY STAR products are currently available at the same cost and performance level as conventional products. In 1993, the first year of the program $45 \%$ of the personal computers and $85 \%$ of the printers sold in the United States met ENERGY STAR specifications for energy efficiency. This market penetration continues to grow. In 1995, EPA reached an agreement with the Japanese Ministry of International Trade and Industry (MITI), under which MITI will implement a program for ENERGY STAR office equipment in Japan.

\section{ENERGY STAR Homes}

ENERGY STAR Homes is a voluntary program for new home builders. The program will provide an ENERGY STAR Home label to homes which meet the Home Energy Rating System Five-star criteria. These homes will average a 30\% energy savings over new construction. To date 28 Builders have signed an agreement with EPA to provide ENERGY STAR homes. EPA has also reached agreements with a number of financial institutions to develop special mortgage packages with terms that recognize the market value of energy efficiency for housing. The program should encompass $10 \%$ of new home construction 
by 2000 , producing significant profits for builders and expanded markets for consumers. EPA is striving for $100 \%$ market penetration by 2010 .

\section{Highway Innovative Technology Evaluation Center (HITEC)}

HITEC was established by the FHWA in 1992, under a 4-year Cooperative Agreement with the Civil Engineering Research Foundation (CERF), to facilitate the evaluation, demonstration and deployment of innovative materials, products, services and technologies for transportation infrastructure applications. HITEC is a model partnership for successful and timely technology deployment, which convenes for each product an evaluation panel comprised from private sector, university researchers, state and local highway officials, and highway users. To date about 20 evaluations of innovative infrastructure technologies are in process, many of which involve advanced materials. For instance, TRANSPO Industries, Inc., has asked that HITEC evaluate Bondade, a liquid bonding compound for asphaltic materials to diverse substrates, which can speed up pothole repair and improve patching asphalts. Another innovative product is a Sight and Sound Screen (SSS), a polystyrene foam panel laminated with DUROCK Cement Board and finished with a decorative coating, made by the US Gypsum Co. Highways and commercial construction sites would benefit from a new, easily deployable barrier system to mitigate noise and other undesirable highway environmental impacts. HITEC in collaboration with Washington State DOT is evaluating in-field and lab tests a new gauge for Water/Cement ration in fresh concrete, based on new technology developed by Troxler Electronic laboratories. This ratio is an important performance indicator and guide acceptance tests for all structural development and rehabilitation projects.

\section{High-Performance Concrete Bridge to Save Time and Money}

A bridge made of high-performance concrete (HPC) decks and piers, cast and processed using advanced methods, is being demonstrated on a state highway overpass in Texas. The bridge, a joint effort of FHWA and the State of Texas, also features advanced nondestructive inspection and testing devices, to monitor strain and performance during and after the construction process. The HPC has greater strength (more than 8,000 pounds per square inch ( $\mathrm{psi}$ ), durability, and resistance to weathering than does traditional concrete and therefore requires fewer piers to support longer spans and a lighter superstructure. The Texas bridge features innovative U-shaped beams, made of 13,000-psi concrete. While HPC is more expensive than conventional materials, the added cost is more than offset by savings in construction and life-cycle costs and building time. The Texas demonstration project is part of a major DOT effort to develop advanced construction materials, novel structural design concepts, and innovative tools and techniques that will improve the long-term viability of structures while reducing costs to a competitive level. This new material advances Goal 6, durability and flexibility of constructed facilities.

\section{Composites Enhance Seismic Protection for Bridges and Highways}

An infrastructure renewal technology that employs advanced composite materials holds promise for improving the earthquake tolerance of concrete bridges and highway pillars. This new method, which involves wrapping thin carbon-fiber composite jackets around support columns in place of conventional heavy steel jacketing, is being developed by a consortium led by the University of California at San Diego, with support from the Technology Reinvestment Project and FHWA. Use of the ultra strong composites -300 pounds offers the strength 3,000 pounds of concrete, with greater durability -- for deck repair and bridge column wrapping promises competitive lifetime cost-efficiency and increased speed of repair (10 to 50 times faster) in comparison to steel. This research is part of DOT's efforts to respond to and learn from earthquake experiences, such as the 1989 Loma Prieta quake in California. Of about 2,000 bridges in the epicentral region, many of which were designed or retrofitted for earthquake tolerance, 6 failed and 
4 were severely damaged and had to be replaced. It is estimated that all would have endured the earthquake without damage had they been fitted with new composite renewal technology.

Pipeline Wrap Material Guards Against High-Pressure Fracture

A new composite-reinforced wrapping material, now being tested in the field, appears to prevent running fractures on high-pressure transmission pipelines. Developed by Clock Spring with DOT support, the composite sleeve material is a polyester resin reinforced with fiberglass, installed in coil form and held in place with a methacrylate adhesive. The adhesive bonds to the pipe surface and to the layers of coil composite reinforcement. The Research and Special Programs Administration (RSPA) accepted this new repair method (under a waiver from current regulations) to enable in-service testing by one transmission company in 1993 and by 28 others in 1995 . The new material is one result of a broad R\&D effort aimed at preventing accidents along the more than 1.5 million miles of petroleum and natural gas pipelines in the United States. The RSPA's materials-related R\&D addresses corrosion protection of pipelines and tanks; high-strength structural materials, including steels, composites, and plastics; development of effective nondestructive inspection (NDI) methods; acquisition of stress and corrosion data; and enhancement of modeling tools that predict material failure.

\section{RECENT ACCOMPLISHMENTS TOWARDS THE NATIONAL CONSTRUCTION GOALS}

Within the mission of each Federal agency, construction research, development and deployment programs are being refocussed to impact the National Construction Goals. The following examples, which are organized under the major product groups for achieving the goals, illustrate progress already made or in process towards the goals. Readers involved in design, construction, maintenance, and repair of constructed facilities are encouraged to explore the further application of these innovations. These examples were provided by DOD, DOE, DOT, VA, NIST, NIOSH, NSF, OSHA, USBM, and USDA.

\section{$\underline{\text { 6.1 LEADERSHIP FOR INNOVATION }}$}

\section{Partnership for Building Innovation Concept Explored}

\section{Agencies: DOC, HUD, DOE, Army Corps of Engineers}

Product: Led by a steering team of industry leaders, including: the American Concrete Institute, Charles Pankow Builders, Enterprise Foundation, Insurance Institute for Property Loss Reduction, Marriott Corporation Monument Construction, National Evaluation Services, New Jersey Division of Housing, New Jersey Institute of Technology, United Technologies Research Center, and USG Corporation, the Civil Engineering Research Foundation completed its first steps towards establishing the Partnership for Building Innovation (PBI). PBI focuses on the development of a definitive national strategy for public/private sector partnerships in implementing technology and systems innovation for the buildings sector. The project explores the barriers and problems inherent in the current approaches to introducing building innovation and discerns the needs and perspectives of the industry.

Initial studies of PBI set out to evaluate the existing implementation roadmap and identify any gaps or missing links. The findings indicated that the existing system was fragmented and limited in scope. As a result, a preliminary strategy for a new, enhanced national process for introducing building innovation to the marketplace was developed. The enhanced system has five components: 
1. An enhanced national evaluation process;

2. Incentives to encourage risk sharing partnerships/test beds between technology developers and private and public sector owners for new technology;

3. A warranty/insurance program for evaluated innovative technologies as an alternative to litigation;

4. An accessible research and in-situ performance database;

5. An information source/roadmap which promotes awareness in the owner and innovator communities.

Recommended PBI goals include: developing a comprehensive implementation plan or roadmap for an enhanced system to expedite bringing innovative building technology to the marketplace and building stakeholder consensus to ensure its success. Several case studies, from innovation to market, and insight gained from international technical assessment organizations will be key elements in implementing a national strategy.

Goals Impacted: All

Quantification of Impact: No measured impact at this time

\section{Regional Conferences on Ergonomics, Safety, and Health in Construction}

\section{Agency: NIOSH}

Product: The Center to Protect Workers' Rights (CPWR) convened four Regional Conferences on Ergonomics, Safety, and Health in 1994. These Conferences followed a national conference on the same topic to confirm national findings at the regional level. A conference in Cincinnati found that hearing loss related to work can be caused by exposure to solvents as well as exposure to noise. Also, much of the work on engineering control of noise that has been developed by the U.S. Bureau of Mines is transferable to construction machines such as heavy equipment. A conference in Atlanta found that owners of the facilities that are to be built can significantly impact the safety of a worksite. A presentation by an owner representative addressed the use of contract language to assure $100 \%$ fall protection with dramatic impact upon the construction costs through savings in workers' compensation. A conference in Seattle found that facility owners represented by the Construction Industry Institute has implemented zero-injury programs at their construction sites with significant reductions in construction-related injuries. The owners save on workers' compensation and exposure to liability as a result of these reductions. A conference in Boston found that collective bargaining on the control of injuries that result in workers' compensation claims may be a cost-effective and viable approach to the control of construction-related injuries. The particular case that was discussed was the Pioneer Valley Building Trades in Western Massachusetts-Bechtel Construction Company agreement on workers' compensation. In addition to reduced injuries, secondary issues included improved access to high-quality care, accelerated benefit delivery, reduced costs, and reduced adversarial proceedings.

Goals Impacted: Health and Safety of Construction Workers

Reduced Delivery Time/Cost of Construction

Quantification of Impact: Impact cannot be quantified at this time 


\subsection{REGULATORY REINVENTION}

\section{Focused Inspections in the Construction Industry}

Agency: Occupational Safety and Health Administration

Products: Until recently, construction site inspections were comprehensive, and traditionally covered all hazards, resulting in less time spent on those hazards that caused the majority of fatalities, and more time on less serious "paperwork" requirements. OSHA's own data show that the most frequently cited hazard in construction is hazard communication, yet only four hazards account for $90 \%$ of the fatalities in construction.

OSHA has initiated a new construction enforcement policy that follows the strategy of targeting the worst actors and worst offenses; protecting vulnerable populations; deterring violations with significant penalties, including criminal penalties; and fixing the problem swiftly and efficiently.

Focused inspections in the construction industry are a more efficient use of OSHA's limited resources, since it allows the OSHA inspectors to investigate whether a controlling contractor has an effective safety and health program, and if there is a person on the job site responsible for implementing that program. If the answers are "yes," then OSHA will perform an inspection focusing only on the four major killers of construction workers: falls, electrocutions; being caught in (trenches); and being struck by machines or materials.

OSHA wants to visit as many work sites as possible to identify those where there seems to be little regard for worker safety, especially in the four main areas of employee fatalities. Compliance officers have been instructed to concentrate their efforts on these four hazards and may end the inspection after they have been evaluated.

Although the focus will be on the four most hazardous areas, when other serious hazards such as confined space are observed or reported by employees, a citation shall be proposed. Other-than serious hazards which are immediately abated will not be cited.

If poor working conditions are noticed during the walkaround inspection, the inspector may determine that a comprehensive inspection is appropriate. Compliance Safety and Health Officer's (CSHO) are expected to identify the need, if any, for subsequent inspections if a site is free of the four main hazards. State plan states have been provided with copies of the new policy and have been asked to notify OSHA of their intent to adopt a similar construction inspection protocol.

Goals Impacted: Delivery Time

Health and Safety of the Construction Workforce

Quantification of Impact: This program has only recently been initiated.

\section{$\underline{\text { Negotiated Rulemaking for Better Standards }}$}

Agency: OSHA 
Products: One key element of OSHA's new approach to better rulemaking is to more directly involve those people who will be most personally affected by OSHA's regulations--employers and employees. OSHA does this through a variety of approaches: negotiated rulemaking (NegReg), advisory committees, and ad $\underline{\text { hoc }}$ approaches.

- $\quad$ OSHA has used formal negotiated rulemaking on several occasions.

- $\quad$ OSHA is currently using NegReg to develop a proposed standard on fall protection for steel erection in construction. In the mid-1980s, a NegReg committee developed OSHA's standard on methylenedianiline (MDA).

- $\quad$ OSHA has found that formal NegReg committees work best when dealing with fairly welldefined, narrow issues, where there are a limited number of interested parties, and the issues are only moderately controversial.

- The 1970 Occupational Safety and Health Act itself permits another form of negotiated rulemaking through standards advisory committees.

- $\quad$ Under paragraph 7(b) of the Act, OSHA has convened advisory committees to develop rules on asbestos, carcinogens, heat stress, noise, coke oven emissions, marine terminals, and several other issues.

- $\quad$ Although these advisory committees fell into disuse in the 1980's because of cumbersome requirements in the Act and the frequent submission of conflicting majority/minority reports to OSHA, the National Association of Manufacturers recently encouraged OSHA to take a fresh look at the use of advisory committees.

- Most recently, OSHA has engaged business and labor groups in more informal, ongoing discussions of key regulatory projects.

- OSHA has met with more that 200 stakeholders representing business, labor, state governments, and professional organizations to help define OSHA's priorities for both regulatory and non-regulatory action. Their response to this ongoing dialogue has been enthusiastic.

- $\quad$ OSHA expects to build on these discussions by working with a group of business and labor representatives to outline the key elements of OSHA's proposed Safety and Programs rule; this rule will be one of the basic building blocks for all future workplace safety and health efforts.

- $\quad$ With assistance from the Keystone Center, OSHA will convene a dialog with business and labor to refine a record keeping simplification proposal.

Goal Impacted: Delivery Time

Quantification of Goals: This program has only recently been initiated.

Policy Dialogue on the Paperwork Simplification Rule

Agency: OSHA 
Product: OSHA is taking steps to simplify the regulation for recording occupational injuries and illnesses which currently affects more than one million employers nationwide. The revision would simplify the forms and definitions and provide greater flexibility to employers for maintaining and using the information. In addition, the revision would provide better data on several types of occupational illness and improve information on injuries and illnesses involving lost workdays and restricted work activity.

The revision stems from a joint effort of business, labor, and government. In 1987 the Keystone Center, an independent nonprofit organization that facilitates national policy consensus building dialogues, convened 46 representatives from labor unions, corporations, health professions, government agencies, Congressional staff, and academia for a year-long dialogue to discuss occupational injury and illness record keeping and the use of injury and illness statistics. Many of the proposed changes in the requirements stem from those discussions.

Improving the record keeping system is important. In addition to serving as an important source of information to employers and employees, the system is the only source for consistent national injury and illness statistics. The data are used by the Bureau of Labor Statistics to produce the only injury and illness statistics that are available on a nationwide basis.

Also, the records are of crucial importance to OSHA. For example, OSHA believes the use of site specific data is a prerequisite to improving the way the agency does business. Currently OSHA uses industry data to focus its intervention efforts. As a result OSHA is unable to distinguish between safe and unsafe workplaces. Relatively safe workplaces in high rate industries are treated the same as unsafe workplaces, and unsafe workplaces in relatively low rate industries are often exempt from OSHA scrutiny.

Goals Impacted: Construction Worker Health and Safety

Reduced Delivery Time

Quantification of Impact: There is substantial evidence that in almost every industry a small percentage of employers have high injury and illness rates; the experience for these employers is persistent; and the type of hazards and the resulting injuries and illnesses vary among establishments, even when the establishments are in the same firm and the same industry. OSHA needs establishment specific injury and illness data (injury and illness rates) to divert resources away from safe establishments to those with the worst safety and health hazards.

\section{$\underline{\text { Reduced Dicobann Lead Exposure for Bridge Renovation Workers }}$}

\section{Agency: OSHA}

Products: OSHA became aware of the problem when the Executive Director of New Jersey's Poison Control Center alerted state and Federal agencies that his organization was encountering an increased number of lead poisoning cases among bridge workers. Traditionally, OSHA would have responded by increasing the number of inspections. In this case however, OSHA decided to forge an active partnership between OSHA's Parsippany Area Office and New Jersey's Departments of Health and Transportation with the purpose of working proactively to develop problem solving strategies.

Increased blood-lead levels indicate lead poisoning which causes neurological, kidney and reproductive system damage. Through unprotected exposure to lead, bridge workers also put their families at risk by bringing excess lead into their homes. The three agencies worked together to develop strategies which would reduce the blood-lead levels in bridge construction and painting employees. 
The agency adopted a 4-pronged response that involved the use of a variety of approaches:

1. Use the Contracting Process to Mandate Protection for all Bridge Workers

Since OSHA did not have a standard for lead in construction until recently (June 1993), staff in the Parsippany Office drafted language which the Department of Transportation put in all its contracts requiring employers to keep blood-lead levels below 50 parts per million, implement a comprehensive medical surveillance program and develop a Lead Health and Safety Plan for the work site.

2. Provide up-front Training for all Employers, Employees and State Regulators

The Parsippany Area Office staff, assisted by the State Health Department, sponsored training sessions for employers and employees before they started working on a bridge painting or renovation project. OSHA staff made sure that contractors understood their responsibilities and obligations concerning their workers safety and health. State personnel received the same training so they would know what was expected of their contractors and could identify safety violations themselves.

3. Provide On-Site Consultation to Contractors

OSHA ensured that the bridge contractors had a group of people they could turn to for assistance during the project. Staff from the State Department of Health and OSHA helped the contractors address hazards that put their workers in jeopardy.

4. Take Strong Enforcement Actions against "Bad Actors"

If an employer, after having been informed of their responsibilities and receiving resource opportunities to comply voluntarily, chose to take the "low" road to compliance, OSHA would initiate strong enforcement action. The enforcement action could be initiated based on a referral from the NJDOT or the NJDOH. Employers were informed of this possibility during the training session.

This proactive, "problem-solving" approach to address safety and health issues is part of the OSHAintegrated model for creating an organization that is both responsive to the public concerns and continually finding innovative and effective ways of protecting the American workforce.

Goal Impacted: Health and Safety of Construction Workers

\section{Quantification of Impact:}

- $\quad$ The mean blood-level among bridge workers dropped 25\% from 1991 to 1994.

- $\quad$ The percentage of employees who had blood lead levels higher than 50 parts per million dropped from $24 \%$ in 1991 to $2 \%$ in 1994.

- $\quad$ The percentage of employees with blood-lead levels less than 40 almost doubled. In 1991 less than 5 out of 10 had blood lead levels of less than 40, in 1994, almost 9 out of 10 were below 40 . 


\subsection{SKILLED CONSTRUCTION WORKFORCE}

\section{Teaching Assistant for AutoCAD and MicroStation}

Agency: U.S. Army Construction Engineering Research Laboratories

Products: The Teaching Assistant programs are Computer-Aided Instruction (CAI) for AutoCAD and MicroStation, Computer Aided Drafting and Design (CADD) systems widely used by the Corps of Engineers, other government agencies, and private firms. The CAI consists of tutorials designed to assist engineers and architects in learning the basic fundamentals of CADD. The instruction allows each professional to learn and experiment with CADD in a highly individualized, self-paced way. The Teaching Assistant series is used by the Army, Air Force, Navy and approximately 3500 private sector CADD users.

Goals Impacted: Reduction in Delivery Time

Reduction in Operation and Maintenance

Increase in Productivity

Quantification of Impact: Designers often have difficulty learning to use Computer-Aided Design (CAD) Systems due to their complex nature. Vendor training sessions and instructional courses at training courses at training centers can be extremely costly, considering tuition, travel, labor, and other related expenses. Those who use the teaching assistant programs and finish the lessons have been observed to spend less than half the time that they spend in traditional courses while performing equally well in drafting tasks. This time difference may be attributed to the learner's freedom to use time on areas that fit their knowledge requirements. The benefit cost ratio has been calculated at a value of eight, figuring in labor costs, tuition, and travel.

\section{$\underline{6.4 \text { HUMAN FACTORS }}$}

\section{Low Vibration Hand-held Tools for Safety and Health}

\section{Agency: NIOSH}

Product: More than a million workers in the U.S. are routinely exposed to vibration from hand-held tools. Prolonged use of these tools causes Raynaud's Disease or Vibration-induced White Finger. For a variety of reasons, the hand-held tools did not get the benefit of technological advances. The construction and heavy machinery industry desperately needs low vibration tools to reduce worker injuries and related liabilities.

NIOSH supported a small business grant in 1994 with the Analytic Engineering Company in California to demonstrated the feasibility of a low vibration tool for control and prevention of musculoskeletal disease.

Goal Impacted: Health and Safety of the Construction Workforce

Quantification of Impact: Three innovations were developed for a prototype through mechanical design: (1) a viable oscillator, (2) a novel construction grade composite material and, (3) a mode decoupling joint design. The elements transmitting impact energy were studied to understand the mechanism that transmitted vibration to the body. Change of frequency spectrum and efficient cutting mechanisms alleviated noise and vibration. 


\subsection{INFORMATION SYSTEMS}

\section{$\underline{\text { Micro Paver Pavement Management System }}$}

Agency: U.S. Army Construction Engineering Research Laboratories

Products: Micro PAVER Pavement Management System was developed to optimize the use of pavement repair funds using state of the art engineering techniques. An important factor in optimizing the use of pavement repair funds is the pavement condition, which is determined by using the Pavement Condition Index (PCI). The PCI is an objective and repeatable rating of pavement condition based on observable stress. PCI procedures for roads, parking lots, and airfield pavements have been developed. Micro PAVER subscribers include cities, universities, consultants, airports, and others. The support centers located at the University of Illinois at Urbana-Champaign (UIUC) and with the APWA sell the Micro PAVER program and provide strategic support, i.e. phone consulting and training, to its users. USACERL provides APWA and UIUC with updated versions of the program. The latest version released is V3.2, May 1995. The Pavement Condition Index for airfields has become an American Society for Testing Materials (ASTM) Standard Test Method (ASTM designation: D 5340-93).

Goals Impacted: Reduction in Delivery Time

Reduction in Operation and Maintenance

Increase Productivity

Quantification of Impact: Reduced funding for pavement maintenance and repair (M\&R) requires that existing funds be used more effectively. This technology results in maximized pavement conditions using available funds.

\section{Geographic Resources and Analysis Support System (GRASS) and Associated GIS Technology}

Agency: U.S. Army Construction Engineering Research Laboratories

Products: GRASS is one of the major GIS Systems of Choice for a significant number of Federal agencies. Development of GRASS began in 1985 to support environmental and land management requirements on military installations but has expanded to include other areas such as emergency response, cultural resource management, global analyses, urban and regional planning and has been a major spin-off product to the Nation.

Goals Impacted: Reduction in Delivery Time

Reduction in Operation and Maintenance

Increase in Productivity and Comfort

Quantification of Impact: GRASS is currently in use by 21 major Federal agencies including DoD Installations, the National Park Service, the Soil Conservation Service, the U.S. Geological Service (USGS), EPA, U.S. Fish and Wildlife Service, NOAA, NASA, Bureau of Reclamation, Forest Service and others. An independent study recently performed by the USGS ("Benefits of GIS Use at Four U.S. Army MACOM- Digital Benefits Study," 1993) states that the implementation of GRASS and Associated GIS Technologies is directly saving the Army over $\$ 40$ million per year for 42 Army installations within the scope of the study. The economic model developed by the USGS found that federal agencies saved $\$ 400 \mathrm{M}$ annually through the use of GRASS and GIS technologies. 


\section{Computer-Aided Design}

Agency: DoE

Products: Pacific Northwest Laboratory, the University of Oregon, and Softdesk have created Softdesk Energy, a software tool that integrates simplified energy analysis with computer-aided building design and drafting application software. Softdesk Energy is part of Softdesk's AutoArchitect computer-aided design (CAD) system. Energy analysis capabilities can be accessed from within the CAD software without leaving the CAD drawing environment.

Goals Impacted: Energy Efficiency in Early Design Pollution Prevention

Quantification of Impact: Softdesk Energy is provided free of charge to users of AutoArchitect, which has a user base of over 50,000 building design professionals internationally. Softdesk Energy was introduced in June 1995. To date, over 500 copies have been distributed.

\subsection{HIGH PERFORMANCE CONSTRUCTION MATERIALS AND SYSTEMS}

\section{$\underline{\text { New Design Values for Structural Lumber }}$}

\section{Agency: USDA Forest Service}

Products: The Forest Product Laboratory in Madison, WI, has provided leadership and technical support to a North American effort to evaluate design values for visually graded structural lumber. The Laboratory cooperated with four U.S. grading agencies and the Canadian Wood Council to develop testing and analysis protocols and results from an extensive testing program. The American Society for Testing and Materials (ASTM) adopted two new standards based on this research. In 1991 the design values for all softwood species were revised and a new National Design Specifications issued by the American Forest and Paper Association. Also in 1991, new species independent relationships identified in this research were adopted for assigning compressive strength to mechanically graded lumber. In 1992 and 1993 the American Lumber Standards Committee adopted guidelines for assigning design values for foreign species based on the ASTM standards resulting from this research program.

Goals Impacted: Reduction in Delivery Time

Reduction in Waste and Pollution

Increased Durability and Flexibility

Quantification of Impact: The average size of the logs available from the Nation's forests is decreasing. This research helps extend timber resource by identifying correct design values for lumber of smaller dimensions. Correct design values are essential for efficient buildings and public safety.

\section{Monitoring Stresses at the National Cathedral}

Agency: US Bureau of Mines (USBM)

Product: The US Bureau of Mines (USBM) is helping in the preservation and restoration of the historic National Cathedral in Washington, D. C. The cathedral was envisioned in Pierre L'Enfant's original plans for the city, although it was not begun until 1893. Major stonework was completed almost 100 years later, in 1989, and even today stone carvers continue to work on the building. 
Preserving this national treasure requires monitoring, maintenance, repair, and restoration as the years go by. The Cathedral Foundation, charged with that task, asked for assistance from the USBM to determine the movement and settlement of the building in the next few years to that officials can plan and prioritize future restoration projects. The USBM was contacted because of its expertise in the area of stress and subsidence monitoring.

Under a memorandum of agreement with the Cathedral Foundation, USBM personnel designed and installed and now operate the monitoring system. Data are being collected for a year to incorporate seasonal effects, and the USBM staff will analyze and interpret the data to provide Cathedral officials with a sound basis for repair and restoration decisions.

Goal Impacted: More Durability

Quantification of Impact: This program has only recently started, so its impact has not yet been demonstrated.

\section{National Acid Precipitation Assessment Program (NAPAP) and Monticello Roof Restoration}

\section{Agency: US Bureau of Mines}

Product: From 1982 to 1991, the Bureau cooperated with NPS and USGS in assessing the effects of acid deposition on materials and the Nation's cultural resources. The Department of the Interior was the lead agency for determining materials effects for NAPAP, authorized by Congress under the Acid Precipitation Act of 1980 because of concern for the adverse effects of acid deposition on the environment. USBM established and operated five field sites in the eastern U.S. (Washington, D.C., NC, NY, NJ and OH) specifically for materials research by USBM, NPS, and USGS on the effects of acid deposition. Unlike sites historically used to evaluate environmental effects on materials and managed by organizations such as ASTM, these five sites had full environmental monitoring including air quality, precipitation and particulate chemistry, and meteorology.

USBM provided these data to NPS, USGS and their contractors. USBM (with EPA), NPS, and USGS, quantified acid deposition effects for metals and dimension stone that were part of the final NAPAP economic assessment of acid deposition effects.

Goals Impacted: More Durability and Flexibility

Quantification of Impact: These results provided the basis for the Clean Air Act Amendments of 1990 that set more stringent standards for air pollutants and acid deposition in the United States. An atmospheric corrosion model developed by USBM and EPA was used to assess the effects of acid deposition on restoration of Thomas Jefferson's home at Monticello and guided the architects in providing a roof with the desired 100 year design life.

\section{Corrosion Protection for Reinforcing Steel}

Agency: NIST, FHWA

Products: Performance criteria and test methods for organic coatings to protect reinforcing bars from corrosion for assuring durability and effective structural performance of coated reinforced bars embedded in concrete. Research showed that only four of 48 coatings evaluated performed well in tests for corrosion and structural performance. 


\section{Goals Impacted: Reduced Maintenance More Durability}

Quantification of Impact: A new industry was created to coordinate the new technologies; it was represented by the Fusion-Bonded Coaters Association. Findings indicate coated reinforcing bars increase expected life of a bridge deck to 40 years (from 5-10 without the coating). The cost of coated bars is about $25 \%$ more than uncoated bars and is insignificant in the total materials and labor cost of a bridge deck. Considering the current $\$ 300$ million annual expenditure for bridge deck repairs the extended service life will result in a present-value savings over 40 years of $\$ 745$ million. These savings would be repeated annually for every $\$ 500$ million repair expenditure until all bridges have been upgraded.

\section{Energy Efficient Industrialized Housing}

\section{Agency: DOE}

Products: The energy-efficient "Spirit for Today" house has been one of the products for the DOE Energy Efficient Industrialized Housing Program. This house, in west Orlando, Florida, combines energy and water efficiency with handicapped accessibility, environmentally friendly materials, excellent indoor air quality and exciting design delivered through panelized systems. The design effort and project management was funded by the Energy Efficient Industrialized Housing (EEIH) program of the DOE Office of Building Technology through a cooperative agreement with the University of Central Florida's Florida Solar Energy Center, the University's Department of Industrial Engineering, and the University of Oregon. The house, completed and purchased in January 1995, is designed to be 50 percent more energy efficient than required under Florida code.

Construction was privately financed with considerable donations of materials and support on the part of manufacturers and Better Homes and Gardens magazine. The October 1994 issue of the magazine featured an 11-page article under the title of the "Forever Young House" and also included the design of the "Modified Forever Young" house, a smaller version employing the same energy saving and environmentally friendly characteristics. Building plans for both houses are available from the magazine.

\section{Goals Impacted: Energy Savings}

Handicapped Accessibility

Reduced Maintenance Costs

Quantification of Impact: Many of the energy and environmental technologies developed for these two houses are directly applicable to entry level housing, to be developed under the DOE Energy Efficient Industrialized Housing and Building America programs during the next few years. The deployment of the construction and other environmentally friendly technologies, actually demonstrated in this house, to the building industry, as well as information from the monitored energy data, will speed the implementation of more affordable, comfortable, and energy efficient residences and assist in the competitive stature of the U.S. building industry internationally.

\section{Earthquake Hazard Mitigation/Intelligent Systems for Seismic Protection of Buildings}

\section{Agency: NSF}

Products: Proof of concept, design criteria and innovative hardware for the seismic isolation of buildings through rigorous analytical and experimental modeling. Technique is now an accepted alternate approach

to seismic resistant design in which buildings are uncoupled from damaging ground motions. Applications 
to several buildings in California are now complete. These include structures which require a higher level of performance than possible under conventional design procedures, as well as those older structures that cannot be economically retrofitted by conventional means.

Goals Impacted: Improved Performance of Buildings and Contents During Major Earthquakes Retrofit Methodology for Fragile Historically Important Buildings

Quantification of Impact: Seismic isolation has given rise to a new industry in seismic protection. Consultants and isolation hardware manufactured have been become established over the last five years. In addition to buildings, the technique is being applied to bridges and industrial equipment. Recent damaging earthquakes in Los Angeles (1994) and Kobe (1995) indicate the potential impact that seismic isolation can have in reducing both direct and indirect losses due to earthquakes. For example the \$55 million Teaching Hospital of the University of Southern California (USC) in Los Angeles is seismically isolated on 149 elastomeric isolators. Completed in 1989, the structure survived the Northridge earthquake of 1994 without either structural or non-structural damage. By comparison, the adjacent USC Medical Center (an 8-building complex) sustained an estimated \$389 million loss.

\section{High- Efficiency, High Intensity Sulfur Lamp}

\section{Agency: DOE}

Products: DOE has sponsored the development a high-efficiency sulfur lamp ("S-Lamp") of high intensity that has been successfully demonstrated at two locations in Washington D.C., The Smithsonian Air and Space Museum and the DOE Headquarters Building. Future demonstrations include aircraft hangers and other high bay industrial and commercial applications. The lamp systems uses "light pipes" that are designed to distribute the light from a relatively few high-intensity sources in lieu of many independent sources or fixtures.

\section{Goals Impacted: $\quad$ Reduced Energy Costs}

Reduced Waste and Pollution

Quantification of Impact: Along with dramatic energy savings, which can be 50\% or more, the light/Slamp combination eliminates difficulties associated with changing light bulbs.

\section{$\underline{\text { Innovative Structural Materials }}$}

\section{Agency: HUD}

Product: As a result of HUD's research and cooperative agreements with the American Iron and Steel Institute (AISI) and the National Association of Homebuilders (NAHB), considerable progress has been made in developing prescriptive methods for a steel framed house. Steel framing is now widely used in residential construction resulting in cost savings, speed of construction, more efficient use of materials, and conservation of natural resources.

Goals Impacted: $\quad$ Reduced Delivery Time

$$
\text { Reduced Waste and Pollution }
$$

Quantification of Impact: It is estimated that more than 4000 builders are using steel for residential framing resulting in over 13500 homes built since 1992. 


\section{Green Lights}

Agency: EPA

Product: Green Lights, a flagship voluntary energy efficiency program, has over 2000 participants who have committed over 500 million square meters of commercial building space to profitable energy efficient lighting upgrades. This represents one in fourteen buildings in the United States.

Goals Impacted: $\quad$ Reduced Energy Costs

Reduced Waste and Pollution

Quantification of Impact: Current Green Lights participants are saving over $48 \%$ of the energy used to operate their lighting. Upgrades already completed prevent one billion $\mathrm{kg}$ of $\mathrm{CO}_{2}$ emissions, 1.5 million $\mathrm{kg}$ of $\mathrm{SO}_{2}$ emissions, and 3.6 million $\mathrm{kg}$ of $\mathrm{No}_{\mathrm{x}}$ emissions. Green Lights participants have also increased the demand for energy efficient technologies and expanded the energy efficiency market.

\section{New Concrete Foam May Help Huge Aircraft Stop}

\section{Agency: DOT/FAA}

Products: A new lightweight concrete material, in the form of phenolic foam, shows promise for enabling large aircraft to stop safely over very short distances, without overrunning runways under hazardous takeoff or landing conditions. The new material, now being developed and tested by FAA researchers and ESCO/Datron of Aston, Pennsylvania, may help resolve an emerging airport safety problem. The nation's 7,800 airports with paved runways are aging, and even the current $\$ 2$ billion maintenance program cannot accommodate the projected growth in air traffic. New pavement designs, materials, and technologies are needed to support the introduction of larger, heavier commercial aircraft, such as the recently introduced Boeing 777. Current runways are not long enough for these planes, and land-use constraints preclude many older airports from extending runways to provide the FAA-mandated 1000-foot safety zone between the end of a runway and a highway, body of water, or other potential hazard. Many potential runway materials have been tested by the FAA since 1987.

Goal Impacted: More Durability

Quantification of Impact: The new concrete arrestor material promises short stopping distances with maximum safety, while enabling fire and emergency rescue equipment access to the aircraft.

\section{Self Heating Runway Pavement Enhances Airport Safety}

\section{Agency: DOT/FAA}

Products: A self-heating runway pavement system, currently being demonstrated at Chicago's O'Hare International Airport, promises to increase safety and enable continued operations in snow and other inclement weather. The new technology, developed by Superior Graphite Co. of Chicago and FAA researchers, employs synthetic graphite that conducts electric currents through the pavement, generating heat and preventing icing and accumulation of snow. (Runway pavements generally are made of asphalt or concrete.)

Goal Impacted: Reduced Maintenance 
Quantification of Impacts: The new material is cost-effective over large areas and is expected to enhance air and ground operations safety, keep the airport open and operating during storms, and save the time and cost of snow cleanups by ground crews. The breakthrough was achieved in the FAA's Airport Pavements Research Program, which conducts R\&D in partnership with industry under Cooperative Research Development Agreements and with the new FAA Air Transportation Center of Excellence on Pavement Research at the University of Illinois, Champaign-Urbana.

\section{“Smart" Steel Inspection Technology Improves Bridge Safety}

\section{Agency: DOT/FHWA}

Product: A novel "smart" inspection tool, now undergoing final testing, is expected to enable rapid nondestructive inspection (NDI) of steel bridges, thereby improving both safety and the cost-effectiveness of maintenance programs. The Fatigue Crack Detection System (FCDS) developed by Sierra Matrix of Fremont, California, under contract to FHWA, employs the latest portable computer, voice recording, processing, and display technologies. Traditional ultrasonic testing technology for crack detection is combined with an AC-current magnetic field disturbance transducer, which discovers cracks in steel members. The FCDS computer is worn by the bridge inspector as a backpack and powered by a belt-worn battery. A visor worn in front of one eye provides virtual "heads-up display" of magnetic and ultrasonic data, while the inspector maintains contact with the real environment with the other eye. A single handheld mouse can be used to interact with a virtual keyboard for data entry and inspection operations. The new tools will help the Nation obtain the best possible performance from aging pavements and bridges. The new tool is among many new NDI methods being developed to monitor the structural integrity and predict the failure of structures, and to assist in the setting of priorities for maintenance and to assist in the setting of priorities for maintenance and repair. One-third of U.S. bridges are structurally deficient.

Goals Impacted: More Durability

Less Waste and Pollution

Health and Safety of Construction Workforce

\section{Performance Specification for Blended Hydraulic Cements (ASTM C1157)}

\section{Agency: NIST/ Army Corps of Engineers}

Product: The first performance specification for structural cements was issued by ASTM in 1993. It is for blended hydraulic cements. Blended cements are, essentially, blends of Portland cements with other materials that contribute to the cementing action when used in mixtures with Portland cement. The other materials are usually waste or by-product silicious materials such as granulated blast furnace slag and fly ash from coal burning power plants. The new standard, which was developed through government industry collaboration in the ASTM C01 Committee on Cement, should facilitate innovation by allowing cement manufacturers to produce cements meet the specified performance criteria. The committee is chaired by Geoffrey Frohnsdorff of NIST, and the committee members include an expert from the US Army Corps of Engineers.

\section{Goal Impacted: Less Waste and Pollution}

Quantification of Impact: When the performance specification comes into widespread use, benefits to the nation will include conservation of energy in cement manufacture, and environmental protection by reducing the need for the mining of raw materials and reducing emissions of the greenhouse gas, carbon dioxide, in cement manufacture. 


\section{Frost Protected Shallow Foundation}

\section{Agency: HUD}

Product: In FY 1993 and FY 1994, HUD sponsored research through the NAHB Research Center to develop a new type of foundation system, the "frost protected shallow foundation." Total PD\&R support for this effort was under $\$ 300,000$. This year the results of this research were formally accepted by model code groups.

\section{Goal Impacted: Delivery Time and Cost}

Quantification of Impact: This new technology has had substantial and immediate benefits for HUD, as well as for the housing industry as a whole. In Denver, a 131 town home project is being built by the Denver Housing Authority - North Lincoln Park. Using this new foundation system technology, the architects redesigned the project with resulting savings of $\$ 300,000$, almost 10 percent of the total project cost. The savings in this one project exceeded the total amount that PD\&R invested in the research. Moreover, it is our understanding that the private homebuilding industry is now rapidly adopting this technology with the expectation that millions of dollars in construction costs will be saved over the next few years.

\section{High Performance Ultra-Light Concrete Masonry Unit}

\section{Agency: U.S. Army Construction Engineering Research Laboratories}

Products: This project merges the rapidly developing high-strength concrete technology with lightweight concrete technology to produce an optimum unit for construction of reinforced masonry walls. Traditional vibro-press technology with full automation is retained as the core of masonry production because of the already established success of this technology and to ease adoption of the research results for the majority of U.S. plants. The block mix consists of the standard materials sand and cement, as well as expanded shale, fly ash, silica fume, and some admixtures. The block shape has also been optimized to minimize materials.

Goals Impacted: Reduction in Delivery Time

Reduction in Operation and Maintenance

Increase in Productivity and Comfort

Durability and Flexibility

Quantification of Impact: Due to the heavy weight of currently used concrete masonry units (CMU), a serious challenge faces the masonry industry. Early retirement of younger masons due to back injuries and other disabilities, as well as lack of young people entering the trade, has caused the average age of masons to increase from 45 years in 1978 to 54 years in 1988. Concrete Masonry Unit of comparable quality to existing normal weight concrete masonry unit, but with the weight reduced by as much as $50 \%$ and with the cost of the constructed facility reduced by as much as $23 \%$.

\section{Antifreeze Admixtures for Cold-Weather Concreting}

Agency: U.S. Army Cold Regions Research and Engineering Laboratory

Products: Protection of new concrete from low temperatures currently costs the U.S. construction industry $\$ 800 \mathrm{M}$ per year. Through three cooperative efforts with private industry, special chemical compounds 
were developed that when added to a concrete mix are capable of protecting concrete placed at temperatures as low as $-5^{\circ} \mathrm{C}$ without requiring added heat.

\author{
Goals Impacted: Reduction in Delivery Time \\ Reduction in Operation and Maintenance \\ Increase in Productivity \\ More Durability and Flexibility \\ Energy Savings
}

Quantification of Impact: These concrete admixtures significantly improve the current technology in winter concreting by enabling concrete poured at low temperatures to develop adequate and safe levels of strength while curing without additional protection. The cost of using antifreeze admixtures is projected to be less than half the cost of using conventional heated shelters. Antifreeze admixtures can also effectively add several months to the construction season in the colder areas of the 48 contiguous United States. This technology will directly benefit construction activities and be applicable to expedient airfield $\&$ roadway repair activities.

\title{
6.7 AUTOMATION
}

\section{Mechatronically Assisted Mason's Aide (MAMA)}

Agency: U.S. Army Construction Engineering Research Laboratories

Products: The prototype Mechatronically Assisted Mason's Aide (MAMA) consists of a rail trolley system capable of being attached to standard, mast-type masonry scaffolding. The rails provide power and transverse mobility to a double jointed arm assembly suspended below it, much like a crane. A steel cable with a mechanical gripping device attached to the end provides the lifting power to pick up and place concrete masonry units.

\section{Goals Impacted: Reduction in Delivery Time \\ Reduction in Operation and Maintenance \\ Increase in Productivity and Comfort \\ Fewer Occupant Related Illnesses and Injuries \\ More Durability and Flexibility}

Quantification of Impact: The masonry industry is comprised of a highly specialized group of people who perform a major part of the building construction in the United States. The repetitive, simultaneous bending and lifting to lay blocks has caused a high occurrence of on-the-job back injuries by masonry craftsmen, resulting in a high percentage of work related disabilities and early retirement of skilled workmen. The high incident rate of back injuries in work places across the U.S. has prompted the Occupational Safety and Health Administration to propose new guidelines for manual lifting that lowers allowable limits. This technology increases the productivity of the masonry craftsmen and alleviates the skeletal and muscular strain associated with lifting and handling heavy masonry units.

\section{Falling Beam Soil Saw, Advanced Process for Forming Underground Cutoff Walls}

\section{Agency: U.S. Army Waterways Experiment Station (WES)}

Products: The Waterways Experiment Station and its industry partner (Haliburton NUS Environmental) completed a cooperative research and development agreement on a falling beam soil saw. The SoilSaw ${ }^{\mathrm{TM}}$ 
technology creates high-quality, "formed-in-place" barrier walls insitu soil with a permeability modifying reagent typically, but not limited to a bentonite or cement/bentonite slurry. Cutoff was greater than 40 feet deep in soils which do not have excessive amounts of large rock or debris can be installed at rates of 100 square feet per minute and will be significantly more economical to produce.

\section{Goals Impacted: Reduction in Delivery Time \\ Reduction in Operation and Maintenance \\ Less Waste and Pollution}

Quantification of Impact: The narrow cut and rapid installation achieved with a Soil Saw can reduce cost per square foot of wall for a $12.2 \mathrm{~m}$ (40ft) deep wall by as much as $30 \%$ using conventional slurry mixes and further savings are estimated for an 24.4 to $30.5 \mathrm{~m}$ ( 80 to $100 \mathrm{ft}$ ) deep wall due to time and equipment cost savings. Very little soil is brought tot he surface with his technique. This is a definite advantage when installing a cutoff wall at a site where the soil is contaminated.

\section{Improving Construction Productivity Through Integration of Real-Time Position Measurement with $\underline{\text { CAD/CAE }}$}

Agency: U.S. Army Waterways Experiment Station (WES)

Products: The Waterways Experiment Station and its industry partner (Civil Engineering Research Foundation) completed a cooperative research and development agreement on the integration of a real-time position measurement system with CAD/CAE. A new laser-based positioning system capable of high accuracy, short-range three-dimensional measurements was developed and integrated with computer-aided design and drafting (CADD) technology. By integrating the positioning technology with CADD technology, the capability that results permits craftspeople, foreman, and on-site construction personnel to look at the CADD as-designed data on portable computers and instantly relate the graphic design to the construction environment. In addition, dimensional data on existing facilities can be rapidly collected for creation of accurate as-built drawings. The real-time recovery of as-built information will facilitate on-thespot changes in components not yet installed to deal with the as-built environment. Upon completion of a project, an electronic CADD file of what was actually installed (as-built) is available for the client.

\section{Goals Impacted: Reduction in Delivery Time \\ Reduction in Operation and Maintenance \\ Increase in Productivity and Comfort}

Quantification of Impact: It is estimated that the construction time will be reduced by $5 \%$. Accurate asbuilt drawings will be available upon completion of the project.

\section{Decision Tool: Hydrologic Evaluation of Landfill Performance Model}

Agency: U.S. Army Waterways Experiment Station

Products: Version 3.0 of the Hydrologic Evaluation of Landfill Performance (HELP) model is now available. HELP is a menu-driven software package for the personal computer, complete with default data bases, extensive context sensitive, on-line help and guidance, data checking, and complete documentation. It has been distributed to over 150 federal offices, 500 state and local government offices, 75 universities, and 3000 offices in the private sector. 
Goals Impacted: Reduction in Delivery Time

Reduction in Operation and Maintenance

Quantification of Impact: The HELP model is required by the U.S. EPA in evaluating the closure designs for all hazardous waste management facilities and is also required by most states for closure design for nonhazardous waste sites. Its use has potentially saved more than $\$ 5$ billion in landfill closures, Superfund site capping and new landfill cells at some 8000 sites. The model is also being adapted to perform water balances for wetlands. 


\section{REFERENCES}

[1] Deaths Resulting from Residential Fires -- United States, 1991, Morbidity and Mortality Weekly Reports. Vol. 43, No. 49, December 1994.

[2] Analysis of Worker Protection Programs Linked to State Worker's Compensation Statutes or Encouraged by Insurance Companies, Final Report, Prepared for Office of Program Evaluation, Occupational Safety and Health Administration, Washington, D.C., May 27, 1994.

[3] An Agenda for Change, Report of the National Conference on Ergonomics, Safety and Health in Construction, Center to Protect Workers Rights, Washington, D.C., July 18-22, 1993.

[4] Census of Fatal Occupational Inquiries, Bureau of Labor Statistics, U.S. Department of Labor, 1993.

[5] Survey of Occupational Injuries and Illnesses, Bureau of Labor Statistics, U.S. Department of Labor, February 1995.

[6] Program of the Subcommittee on Construction and Building, NISTIR 5443, National Institute of Standards and Technology, June 1994.

[7] Innovation in the U.S. Construction Industry: An Essential Component for America's Economic Prosperity and Well-Being, Civil Engineering Research Foundation, April 1994.

[8] Priorities for the Fiscal Year 1996 Budget, Office of Management and Budget, Office of Technology Policy, May 1994.

[9] Rationale and Preliminary Plan for Federal Research for Construction and Building, NISTIR 5536, National Institute of Standards and Technology, November 1994.

[10] White Papers Prepared for the White House - Construction Industry Workshop on National Construction Goals, NISTIR 5610, December 1994.

[11] National Construction Goals: A Construction Industry Perspective, Civil Engineering Research Foundation, December 1994

[12] National Construction Sector Goals: Industry Strategies for Implementation, NIST-GCR-95-680, July 1995.

[13] National Homeownership Strategy: Partners in the American Dream, Department of Housing and Urban Development, Office of Policy Development and Research, May 1995. 


\section{LIST OF ACRONYMS}

\begin{tabular}{|c|c|}
\hline ACI & American Concrete Institute \\
\hline AGC & Association of General Contractors \\
\hline AIA & American Institute of Architects \\
\hline APWA & American Public Works Association \\
\hline ASCE & American Society of Civil Engineers \\
\hline ASHRAE & American Society of Heating, Refrigerating and Air-conditioning Engineers \\
\hline ASTM & American Society of Testing and Materials \\
\hline ATTIR & Advanced Technology for Transportation Infrastructure Renewal \\
\hline ATP & Advanced Technology Program \\
\hline BFRL & Building and Fire Research Laboratory \\
\hline CAD & Computer-Aided Design \\
\hline CADD & Computer-Aided Drafting and Design \\
\hline CAE & Computer Assisted Engineering \\
\hline C\&B & Construction and Building \\
\hline $\mathrm{CCB}$ & Construction Criteria Base \\
\hline CCE & Cost of Conserved Energy \\
\hline CCIT & Committee on Civilian Industrial Technology \\
\hline CERF & Civil Engineering Research Foundation \\
\hline CPWA & Center to Protect Workers' Rights \\
\hline EEIH & Energy Efficient Industrialized Housing \\
\hline EPA & Environmental Protection Agency \\
\hline FCDS & Fatigue Crack Detection System \\
\hline FHWA & Federal Highway Administration \\
\hline GIS & Geographical Information Systems \\
\hline GSA & General Services Administration \\
\hline HITEC & Highway Innovative Technology Evaluation Center \\
\hline HPC & High Performance Concrete \\
\hline HUD & Housing and Urban Development \\
\hline HVAC & Heating Ventilating and Air Conditioning \\
\hline IEQ & Indoor Environmental Quality \\
\hline IIPLR & Insurance Institute Property Loss Reduction \\
\hline M\&R & Maintenance and Repairs \\
\hline MEP & Manufacturing Extension Partnership \\
\hline NAHB & National Association of Home Builders \\
\hline NASA & National Aeronautics and Space Administration \\
\hline NCMCC & National Construction Materials Coordinating Council \\
\hline NFIRS & National Fire Incidence Reporting System \\
\hline NIBS & National Institute of Building Sciences \\
\hline NIOSH & National Institute for Occupational Safety and Health \\
\hline NIST & National Institute of Standards and Technology \\
\hline NSF & National Science Foundation \\
\hline NSTC & National Science and Technology Council \\
\hline OMB & Office of Management and Budget \\
\hline OM\&E & Operation, Maintenance, and Energy Costs \\
\hline OSHA & Occupational Safety and Health Administration \\
\hline OSTP & Office of Science and Technology Policy \\
\hline PBI & Partnership for Building Innovation \\
\hline
\end{tabular}


PCI

R\&D

RD\&D

USBM

USGS

VWL
Pavement Condition Index

Research and Development

Research Deployment and Development

U.S. Bureau of Mines

U.S. Geological Survey

Virtual Workspace Language 


\title{
APPENDIX - FEDERAL AGENCY PROGRAM SUMMARIES
}

\section{U.S. DEPARTMENT OF AGRICULTURE}

\author{
Forest Service \\ Forest Products Laboratory
}

\section{Mission:}

The USDA Forest Service's natural resource stewardship responsibilities include ensuring the wise and efficient use of our Nations forests. As part of that responsibility, the Forest Service conducts research to develop technology that helps meet America's growing demand for forest products, conserve our Nation's forests, and improve the environmental sensitivity of forest products manufacturing. Within that framework, a Forest Service research initiative is aimed at increasing the use of recycled wood and paper in housing.

\section{Major Activities Contributing to the National Construction Goals:}

- Develop processing technologies that increase efficiency, minimize environmental impacts, and improve utilization of wood wastes.

- $\quad$ Provide technical basis for performance characteristics of wood products used in housing.

- Identify test procedures and criteria for development of codes and standards for new wood products.

- Determine economic feasibility and impacts of emerging technologies in the wood products

- $\quad$ Facilitate implementation of new technologies with industrial partners.

\section{Impact:}

The primary impact of this program will be to reduce waste and pollution on the job site. Also, the use of new, more competitive wood products and the availability of codes and standards for wood products will simplify design and construction and thereby reduce delivery time.

\section{Contacts:}

Thomas Hamilton, Director, Forest Products Laboratory, One Gifford Pinchot Drive, Madison, WI 53705.

Tel: (608) 231-9200, Fax: (608) 231-9567

Hao Tran, Forest Products and Harvesting Research, USDA Forest Service, 14th \& Independence, Washington, D.C. 20090. Tel: (202) 205-1565, Fax: (202) 205-2497 


\section{DEPARTMENT OF COMMERCE}

\section{National Institute of Standards and Technology}

\section{Mission:}

NIST's Building and Fire Research Laboratory (BFRL) is dedicated to improving the life cycle quality of constructed facilities. Its performance prediction and measurement technologies enhance the competitiveness of U. S. industry and public safety. The laboratory studies structural, mechanical, and environmental engineering, fire science and fire safety engineering, building materials, and computerintegrated construction practices.

\section{Major Activities Contributing to the National Construction Goals:}

- Develops technologies to predict, measure, and test the performance of construction materials, components, systems, and practices.

- $\quad$ Provides the technical basis for integrated automation and robotics in the construction process supporting industry's development of automated constructed facilities, and reducing injuries to the construction workforce.

- $\quad$ Develops new technologies for earthquake and wind hazard reduction.

- Develops the underlying technical support for new safety standards, and generates the engineering methodology to support the practice of fire protection engineering.

- Develops measurement methods to define the performance of advanced building environmental systems.

\section{Impact:}

This research program will provide underlying technology, standards, measurement methods, and practices that will help to advance all National Construction Goals.

\section{Contact:}

Richard N. Wright, Director, Building and Fire Research Laboratory, NIST

Tel: 301-975-5900, Fax: 301-975-4032 E-mail: wright@enh.nist.gov 


\section{DEPARTMENT OF DEFENSE}

\section{Mission:}

\section{Civil Works Research \& Development Program}

DoD administers the Civil Works (CW) Research \& Development (R\&D) program to provide solutions to problems related to the Corps of Engineer's Civil Works Program. The CW R\&D is highly applied research utilizing products and techniques developed by industry and universities and adapting them to civil works needs. Research in six areas: Materials; Coastal Structure Evaluation and Design; Flood Control Structures; Repair, Evaluation, Maintenance and Rehabilitation; Construction Productivity; and Earthquake Engineering of the Civil Works R\&D program contribute to the goals of the Construction and Building R\&D Program.

\section{Military Research \& Development Program}

The primary goal of the DoD civil engineering research program is to support the national security objectives of the Nation by conducting research to enhance the life cycle performance of the infrastructure required to provide an efficient and cost effective power projection platform for the armed forces. The DoD Reliance program eliminated redundant military R\&D. Five Civil Engineering Reliance R\&D focus areas: Conventional Facilities; Airfields and Pavements; Fire Fighting; Ocean and Waterfront Construction and Building R\&D program. The Enhanced DoD Architect/Engineering and Construction (A/E\&C) industry R\&D Partnership Program was initiated in FY95 to provide the A/E\&C industry access to advanced DoD technologies, $\mathrm{R} \& \mathrm{D}$ infrastructure, and installation test beds to help improve $\mathrm{A} / \mathrm{E} \& \mathrm{C}$ industry productivity.

\section{Major Activities Contributing to the National Construction Goals:}

DoD's civil and military missions comprise a synergistic relationship between the research conducted in response to the needs of these two customer bases. The comprehensive research and development program is critical to the National Construction Goals of fifty (50) percent reduction in delivery time and operations and maintenance, fewer occupant related illnesses and injuries, less waste and pollution, more durability and flexibility, and thirty (30) percent increase in productivity and comfort. Activities include: automated design systems to construct and maintain the DoD's 1.4 billion SY of pavements at reduced costs; integrated tools to analyze maintenance alternatives for buildings, utility systems and transportation systems; materials that extend pavement life by 5 years $(25 \%)$, and reduce maintenance costs by $\$ 72$ million (20\%); technologies and operational procedures for efficient; cost effective heat distribution systems; corrosion resistant coatings and cathodic protection devices; cost effective methods for evaluating and upgrading existing facilities vulnerable to seismic events; techniques and technologies for monitoring and controlling air quality in buildings, criteria for recycling construction materials, and materials to obtain significant increases in durability of waterfront structures.

\section{Work with Private Sector:}

\section{Example:}

Construction Productivity Advancement Research Program (CPAR) allowed the Corps of Engineers labs to conduct cost-shared cooperative research on construction relevant technologies that are an industry initiative, but of interest to DoD. Up to $50 \%$ of the development effort can be funded through the Corps' 
CPAR authority. The work is accomplished via a Cooperative Research and Development Agreement (CRADA) that defines the roles and responsibilities of each partner and specifies the rights of the government and the private partner to the technology following development. A long list of CPAR projects have been initiated since the inception of the program in 1990. They include the development of antifreeze admixtures for low temperature concrete, landfill clay liner design criteria, bioremediation techniques for contaminated soils, robotically assisted masonry construction, recycling of plastic waste as construction materials and prestressed clay brick walls. CPAR is generating some very impressive advances. For example, the development of two antifreeze admixtures for concrete with two private sector partners will dramatically extend the construction season in the U.S. and reduce the cost of placing concrete at lower than $5^{\circ} \mathrm{C}$, the current limit. The construction industry currently spends around $\$ 800$ million per year to protect concrete from low temperatures. Another example is the application of Global Positioning System (GPS) software and technology to earth moving equipment in partnership with Caterpillar, Inc. The GPS technology is being interfaced to an on-board computer aided design and drafting system to build real-time as-built files, eventually leading to automated construction processes.

\section{Contact:}

Don Leverenz, Assistant Director for Research and Development, DoD

Tel: 202-761-1415, Fax: 202-761-0907, E-mail: don.leverenz@ inet.hq.usace.army.mil 


\title{
U.S. DEPARTMENT OF ENERGY
}

\author{
Office of Building Technologies and the \\ Federal Energy Management Program
}

\begin{abstract}
Mission:
The building sector, including both residential and commercial buildings currently uses 7560 quadrillion cal of primary energy annually. This is $35 \%$ of total U.S. energy consumption, and includes $65 \%$ of all electricity used in the U.S. Federally owed facilities represents approximately 2 percent of U.S. building stock. The mission of Office of Building Technologies (OBT) is to limit the expected increase in building sector energy consumption by improving energy efficiency and expanding the use of renewable energy in buildings. Recent analysis has shown that the growth in demand for energy services in buildings can be met without increasing the total energy use. Increase emphasis in market-pull activities has been the result of the Energy Policy Act of 1992 and the Climate Change Action Plan of 1993.
\end{abstract}

\section{Major Activities Contributing to the National Construction Goals:}

- $\quad$ OBT conducts a comprehensive research program designed to develop, demonstrate and, if appropriate, commercialize advances in energy performance of major building components including thermal insulation systems, windows, and heating and cooling equipment. In addition, system improvements in how we design, build and operate new building structures are address by major program elements of OBT. Taken together the OBT component and system research are critical to the Nation Construction Goals of 50\% efficiency increase in building operation as well as the $30 \%$ increase in productivity.

- $\quad$ Through it's Federal Energy Management Program (FEMP), DOE leads the Federal government's drive for increased energy efficiency and renewable energy utilization in it's own facilities and vehicle fleets. The C\&B identified strategy of using the Federal facilities as a test bed of new innovation is dependant on FEMP.

- $\quad$ Additionally OBT conducts a program that focusses on the activities of market-pull and market transformation of energy efficient buildings systems. This includes many of the activities recently authorize by Energy Policy Act and the Climate Change Action Plan: for example "Rebuild America" is a program directed at upgrading the energy performance of the existing stock of commercial building. "Design Tools" program focusses on the market delivery of tools that will allow for full consideration of energy options in the design of our future buildings. Improve Design Tools contributes to the $\mathrm{C} \& \mathrm{~B}$ goals of better constructed facilities by reducing delivery time as well as operating and maintenance costs.

\section{Work with Private Sector:}

Examples:

"Build America Program" is a series of private sector consortia developing and demonstrating advances in home construction. DOE provides technical support to the competitively selected consortia. 
With private sector input through the industry consensus process, OBT develops and promotes building energy codes, and equipment standards for residential and commercial buildings.

\section{Impact:}

The program will result in a $30 \%$ improvement in energy efficiency by the year 2003 .

\section{Contact:}

Arthur Rosenfeld, Science Advisor, Energy Efficiency and Renewable Energy, DOE

Tel: 202 586-6593, Fax: 202 586-5954, E-mail: arthur.rosenfeld@ hq.doe.gov 


\title{
DEPARTMENT OF HEALTH AND HUMAN SERVICES
}

\author{
The National Institute for Occupational Safety and Health
}

\section{Mission:}

The National Institute for Occupational Safety and Health (NIOSH) is the federal institute responsible for conducting work-related research and making recommendations to prevent work-related injuries and illnesses. The Institute has a special focus on construction workers, with research addressing a wide range of construction-related hazards such as fatal and nonfatal injuries, falls, electrocutions, ergonomics, dermatitis, lead exposure, noise exposure, and silica exposure. The goal of the construction research program is to develop intervention programs to reduce the unacceptable toll of work-related deaths, injuries, and illnesses in the construction industry. NIOSH is also conducting research related to the health of building occupants including research on indoor environmental quality and violence in the workplace.

The purpose of the Institute's construction research is to: 1) identify the hazards and risks associated with construction working populations, 2) identify effective means of intervening to reduce workplace hazards and risks, 3) communicate this information to the construction industry groups, contractors, labor organizations, workers, and other industry constituents, and 4) serve as a catalyst for worksite implementation of preventive interventions.

\section{Major Activities Contributing to the National Construction Goals:}

- Evaluate carpenters' tasks during erection and dismantling of frame scaffolds to identify risk factors for overexertion injuries and to assess work methods as risk reduction techniques.

- Determine risk factors for falls from elevated work surfaces in the construction industry.

- Provide training as an interventions for contact dermatitis among plasterers and cement masons.

- Evaluate engineering control systems to reduce worker exposure to lead and silica during nonresidential lead-based paint removal.

- Develop a medical surveillance program to prevent lead toxicity in bridge workers.

- Identify key factors responsible for ineffective hearing conservation programs in the construction industry, testing ways to reduce these factors, and demonstrating an efficacious model program.

- Recommend methods to reduce silica exposure levels in construction occupations and settings during which silica exposure is suspected to occur.

- Evaluate substitute materials for silica in abrasive blastings to reduce or eliminate use of silica in abrasive blasting.

- Conduct a study to identify aspects of building design which reduce crime in convenience stores. 
- Conduct indoor air health hazard evaluations at the request of employees, employee representatives, and employers. Over 1500 have been completed, resulting in specific recommendations at those locations.

- Develop protocols for controlled experimental intervention studies related to health effects of indoor environmental quality.

- Provide user-friendly informational hazard alerts to workers and employers with recommendations to reduce fatal injuries from confined spaces, falls, and electrocutions.

- Conduct prevention activities including case-based surveillance and on-site investigations.

\section{Impact:}

This program will have a major impact on the health and safety of the construction workforce, and provide the technology to reduce the illnesses and injuries of building occupants.

\section{Contact:}

Melvin Myers, Special Assistant to the Deputy Director, NIOSH

Tel: 404-639-3345, Fax: 404-639-2196, E-mail: mlm2@ niood1.em.cdc.gov 


\title{
DEPARTMENT OF HOUSING AND URBAN DEVELOPMENT
}

\author{
Policy Development and Research
}

\section{Mission:}

The Office of the Assistant Secretary for Policy Development and Research is responsible to the Secretary of Housing and Urban Development for overall Departmental policy, program evaluation and research. The Division of Affordable Housing and Technology conducts research and analysis on the production and supply of housing and on the physical and technical aspects of community development. The Division addresses all physical, structural, developmental technology, regulatory, and related issues needed to support the Department's commitment to ensure decent, safe, and sanitary housing in a suitable living environment for all Americans.

\section{Major Activities Contributing to the National Construction Goals:}

- $\quad$ Expanding Housing Opportunities for Low- and Moderate-Income Families

Research and policy analysis to expand affordable housing opportunities by reducing the initial and operating cost of housing and to expand the affordability of new and rehabilitated housing supplied by both the private and publicly-assisted market.

- $\quad$ Empowering Communities

Technical, developmental and related regulatory research to assist in the physical redevelopment of communities.

- $\quad$ Opening Housing Markets

Research to develop new legislative and regulatory tools to ensure that new development provides equitable access to jobs and housing for lower-income and minority families.

- $\quad$ Meeting Key Administration Objectives

Research that permits the integration of other major social objectives such as environmental protection and hazard prevention into the programs of the Department and into housing production without sacrificing housing affordability and viable urban redevelopment.

\section{Impact:}

This program addresses affordability of housing, will contribute to fewer occupant related illnesses and injuries, and will help to reduce waste and pollution.

\section{Contact:}

David Engel, Director Affordable Housing Research and Technology Division, HUD

Tel: 202-708-4370, Fax: 202-619-8360 


\section{U.S. DEPARTMENT OF LABOR}

\section{Occupational Safety and Health Administration}

\section{Mission:}

The mission of the Occupational Safety and Health Administration (OSHA) is to save lives, prevent injuries and protect the health of America's workers. To accomplish this, federal and state governments must work in partnership with the more than 100 million working men and women and their six and a half million employers who are covered by the Occupational Safety and Health Act of 1970 (OSHA Act). OSHA and its state partners have approximately 2100 inspectors, plus complaint discrimination investigators, physicians, educators, standards writers, and other technical and support personnel spread over more than 200 offices throughout the country.

Because construction is such a hazardous occupation, the OSHA Office of Construction and Engineering was created in 1990 to improve health and safety in the construction industry. The office works with construction industry management and labor to implement proactive strategies for worker protection that make safety and health part of workplace culture.

\section{Major Activities Contributing to the National Construction Goals:}

- Set standards to reflect construction industry safety performance and the need for worker protection.

- $\quad$ Conduct worksite inspections to enforce standards.

- $\quad$ Provide training to construction safety and health enforcement personnel to improve inspections. Training is also provided to industry personnel through agreements with local educational institutions, including community colleges.

- Investigate accidents to determine industry wide causative factors to be reduced or eliminated.

- Establish cooperative programs with companies to benchmark good safety practices and recognize those contractors who are role models for the industry.

- Coordinate Federal activity to assure a government leadership role in promoting health and safety programs through responsible construction project ownership.

\section{Impact:}

This program is designed to reduce construction workforce illnesses and injuries.

The program promotes the training of a skilled construction workforce, and provides the baseline and performance measures for monitoring progress towards goal 7.

\section{Contact:}

Bruce Swanson, Director of OSHA Office of Construction and Engineering, OSHA

Tel: (202) 219-8644, Fax: (202) 219-6599

\section{DEPARTMENT OF TRANSPORTATION}




\section{Mission:}

The Department of Transportation (DOT) was established "to assure the coordinated, effective administration of the transportation program of the Federal Government," and to develop "national transportation policies and programs conducive to the provision of fast, safe, efficient, and convenient transportation at the lowest cost consistent therewith."

The Federal Highway Administration, Federal Railroad Administration, Federal Aviation Administration, Federal Transit Administration, The Maritime Administration, and United States Coast Guard are the primary model offices involved with the programs related to the Nation's transportation infrastructure.

\section{Major Activities Contributing to the National Construction Goals:}

- Research on High Performance Materials for Renewal Engineering will provide stronger, longerlasting structures and facilities.

- Research on Diagnostics and Analysis will develop nondestructive testing and monitoring technology for futuristic transportation systems.

- Research on Automation for Renewal Engineering will supply robotics and site integration technologies that will reduce manpower requirements.

- Research on Reduction of Intermodel Hazards will help provide emergency response to transportation interruptions caused by earthquakes, floods, wind storms, etc., and restore lifelines.

- Research related to geotechnology, environment and materials conservation as a means to a sustainable evolution.

\section{Impact:}

Goal 1, 50\% Reduction in Delivery Time: The public is well aware of the effects that construction delays have on their travel time. Less well understood is the effects that delayed just-in-time deliveries have on the prices of consumer products. New high performance materials and automated construction technology will help to reduce transportation delays. "Fast-Track" technologies are being used more frequently in highly congested corridors. Most of the materials used are the improved concrete, steel, and other products that are under joint development for other structural uses.

Goal 2, 50\% Reduction in Operation, Maintenance and Energy Costs: The evidence of decaying infrastructure surrounds us and the costs of its maintenance says our limited resources while slower operators wastes energy. Better repairs technologies and materials can improve the life of repairs while new structures/facilities can be built for longer lives. For instance, we now design bridges for longer than 40 year deck lives.

Goal 3, 30\% Increase in Productivity and Comfort: Transportation headquarters and related facilities such as air terminals can greatly benefit from more efficient design and use of space.

Goal 4, 50\% Fewer Occupant Related Illnesses and Injuries: Safety is a major concern of air, rail, water, and highway systems and much R\&D is conducted to make the facilities more user-friendly. 
Goal 5, 50\% Less Waste and Pollution: All modes of transportation are concerned with reducing waste and pollution from construction and operators. All traverse environmentally sensitive wetlands and drainage basins. Additionally, our constructed facilities offer safe disposal sites for wastes from the other human activities, such as mine spoil, waste tire rubber, fly ash and incinerator residue, old shingles, crushed ceramic products (bathroom fixtures), etc. Today much of the old roadways are recycled back into new roads.

Goal 6, 50\% More Durability and Flexibility: High performance materials are being investigated to provide longer lived structures that resist the forces of nature and man. High strengths and lower mass provide more flexibility in design with longer spans thus allowing the possibility of future reconfiguration, or, if desired, complete removal in easier because of less total mass.

Goal 7, 50\% Reduction in Construction Work Illnesses and Injuries: Safety of workers is of the highest priority in transportation. Over 1000 highway workers are killed each year and more elaborate technology is being adopted each year to protect them. Similarly, workers falling at bridges, airport terminal, etc. sites are a constant concern. Environmentally, the use of lead paints, volatiles, sand blasting, explosives, asbestos, etc. are being severely restricted and workers forced to use protective technologies, which are being continuously evolved.

\section{Summary:}

All of the National Goals of the NSTC Subcommittee on Construction and Building are equally applicable to the construction and operation activities of the various Transportation modes (air, rail, sea, highway). Transportation related activities account for the use of more than $15 \%$ of the cement used in the USA and involve over $\$ 100$ billion a year National expenditure.

\section{Contact:}

Thomas J. Pasko, Director, Office of Advanced Research, FHWA

Tel: 703-285-2035 Fax: 703-285-2379 


\section{DEPARTMENT OF VETERANS AFFAIRS \\ Facilities Management Office}

\section{Mission:}

The Department of Veteran's Affairs (VA) is dedicated to constructing quality facilities for serving veterans in medical centers, outpatient clinics, nursing homes, domicliaries, regional office buildings, and cemeteries. VA's Facilities Management (FM) Office implements planning, design, construction, and real estate programs in support of the department's missions, with a strong commitment to customer service. FM also promotes maximizing VA-owned assets through creative development initiatives.

\section{Major Activities Contributing to the National Construction Goals:}

- Updating, consolidating, and automating Design and Construction Standards

- Developing criteria for operating in and responding to natural disasters

- Creating functional and physical Design Guides to improve quality, control cost, and increase user satisfaction

- Managing traditional and alternate methods of design and construction, emphasizing the use of Design Programs to minimize the need for change during the design and construction process

- $\quad$ Reviewing project designs for function, efficiency, flexibility, and regulatory approvals

- Creating and maintaining a Cost Data Base for budgeting

\section{Impact:}

This work will demonstrate design improvements that will: reduce operation, maintenance, and energy costs; increase productivity and comfort; and increase durability and flexibility.

\section{Contact:}

Lloyd H. Siegel, Director, Facilities Quality Office

Tel: 202-565-4663, Fax: 202-565-5454; E-mail: siegel@dvacm.gov or siegel@101cm00a.med.dvacm.gov 


\title{
US DEPARTMENT OF INTERIOR
}

\author{
U. S. Geological Survey
}

\section{Mission:}

The U.S. Geological Survey conducts research, transfers technology to end users and fosters the adoption and implementation of public policies and professional practices to reduce losses from earthquakes, volcanic eruptions, landslides, and hydrologic hazards in the United States and abroad.

\section{Major Activities Contributing to the National Construction Goals:}

- Conduct basic research on geologic (earthquakes, volcanoes, and landslides) and hydrologic hazards

- Perform hazard and risk assessments on national, international, regional, urban, and local scales

- $\quad$ Develop monitoring networks and geographic information systems

- Transfer technology needed to enhance professional skills and expand technical capacity for mitigation, preparedness, emergency response, and recovery

- $\quad$ Organize and conduct post-disaster investigations

\section{Impact:}

This program will provide tools to reduce delivery time, and reduce the number of occupant related illnesses and injuries.

\section{Contacts:}

Walter Hays, Office of Earthquakes, Volcanoes, and Engineering, USGS

Tel: 703-648-6712, Fax: 703-648-6717

Charles (Bill) Boning, Office of Surface Water, USGS

Tel: 703-648-5305, Fax: 703-648-5295 


\section{U.S. ENVIRONMENTAL PROTECTION AGENCY}

\section{Mission:}

The mission of the U.S. Environmental Protection Agency (EPA) is to preserve and improve the quality of the environment, protect human health, and safeguard the productivity of natural resources on which all human activity depends. To achieve these goals, the Agency is committed to reduced risks to humans, the environmental, and natural resources using the best available science and innovative technologies.

While all aspects of EPA's activities can be linked to construction and building (C\&B), major activities contributing to $\mathrm{C} \& \mathrm{~B}$ goals include:

\section{Major Activities Contributing to the National Construction Goals}

- Provide leadership in the identification, characterization, and mitigation of indoor air pollutants. Develop technologies for the prevention of indoor air pollution.

- $\quad$ Promote energy conservation, efficient energy use through voluntary actions such as the energy star buildings, green lights and energy star computer programs.

- Promote sustainable development through the Green Buildings Initiative, the Environmental Technology Initiative, and Community based, in place environmental management.

- $\quad$ Promote the safe and sustainable reuse of idled and underused industrial and commercial facilities through the Agency's "Brownfields Initiative".

- $\quad$ Promote efficiency and streamline environmental regulation through the Agency's Common Sense Initiative.

- $\quad$ Provide leadership in the nation's environmental science, research, training and assessment.

\section{Impact:}

The program will reduce waste and pollution. The regulatory reform initiatives will help to reduce delivery time of constructed facilities through improvement in the approvals process. The indoor air pollution program will increase the productivity and comfort of occupants, and reduce occupant illnesses and injuries.

\section{Contact:}

Jean M. Lupinacci, Air Pollution Prevention Division, EPA

Tel: 202-233-9137, Fax: 202-233-9579. 


\title{
GENERAL SERVICES ADMINISTRATION
}

\author{
Public Buildings Service
}

\section{Mission:}

The General Services Administration (GSA) is the Federal business manager which responsibilities including space acquisition and management, retail and wholesale supply sales, fleet management, travel and transportation management, telecommunications and information management.

The Public Buildings Service (PBS) serves as the Federal government's chief buildings' planner, developer, owner, and real property asset manager. PBS managers over 8,000 buildings providing in excess of 267 million square feet.

\section{Major Activities Contributing to the National Construction Goals:}

- The design and construction program provides a means for demonstrating and deploying innovative technology. The program is estimated to be $\$ 8$ billion, and more than $\$ 2$ billion has been budgeted annually for new projects.

- The PBS' Design Excellence Program has invigorated the design community to actively pursue GSA projects. GSA's new program stresses creativity, including the exploration of innovative use of technology. Emphasis is placed on the unique aspects of the particular project, design philosophy, possible approaches in carrying out the project, and project management.

- GSA participates with local utility companies' demand side management rebate programs. GSA now participates in energy rebate programs, retains the savings, and reuses the funding resources for additional program requirements.

\section{Impact:}

The program will have a positive impact on all the National Construction Goals. Since 1973 energy consumption in PBS buildings has been reduced by more than $40 \%$ and $8 \%$ from 1985 levels. Current energy usage is more than $40 \%$ below the Federal average.

\section{Contact:}

Wade Belcher, Public Building Service, GSA

Tel: 202-501-1646, Fax: 202-501-3393 


\section{NATIONAL SCIENCE FOUNDATION}

\section{Mission:}

The National Science Foundation (NSF) is created to promote and advance scientific and engineering progress in the United States. NSF funds research and education in most fields of science and engineering, through grants, contracts and cooperative agreements to colleges, universities, and other institutions. Civil infrastructure systems research (which includes the Construction and Building Program) is one of the Foundation-wide initiatives.

\section{Major Activities Contributing to the National Construction Goals:}

- DETERIORATION SCIENCE examines how materials and structures break down and wear out, improving our understanding of deterioration and design, and how to build, and maintain structures that are more durable, safer, and more environmentally sound.

- $\quad$ ASSESSMENT TECHNOLOGIES determines durability, safety, and environmental conditions of structures and facilities. Research can lead to nondestructive evaluation techniques, improved sensor technologies, and self-correcting materials.

- RENEWAL ENGINEERING extends and enhance the life of civil infrastructure systems and components that would otherwise continue to deteriorate.

- INSTITUTIONAL EFFECTIVENESS AND PRODUCTIVITY recognizes the importance of those factors affecting the decision processes underlying the provision and management of civil infrastructure on the economic and social productivity of society, leading to better decisions that maximize the impact of civil infrastructure investments on the productivity and on the economic and social well-being of the public.

\section{Impact:}

Theses programs are directed mainly at increasing the durability and flexibility of constructed facilities, but will also reduce operation and maintenence costs, and occupant related illness and injuries.

\section{Contact:}

Ken P. Chong, Civil and Mechanical Systems Division, NSF

Tel: 703-306-1361, Fax: 703-306-0291; Email: kchong@nsf.gov 